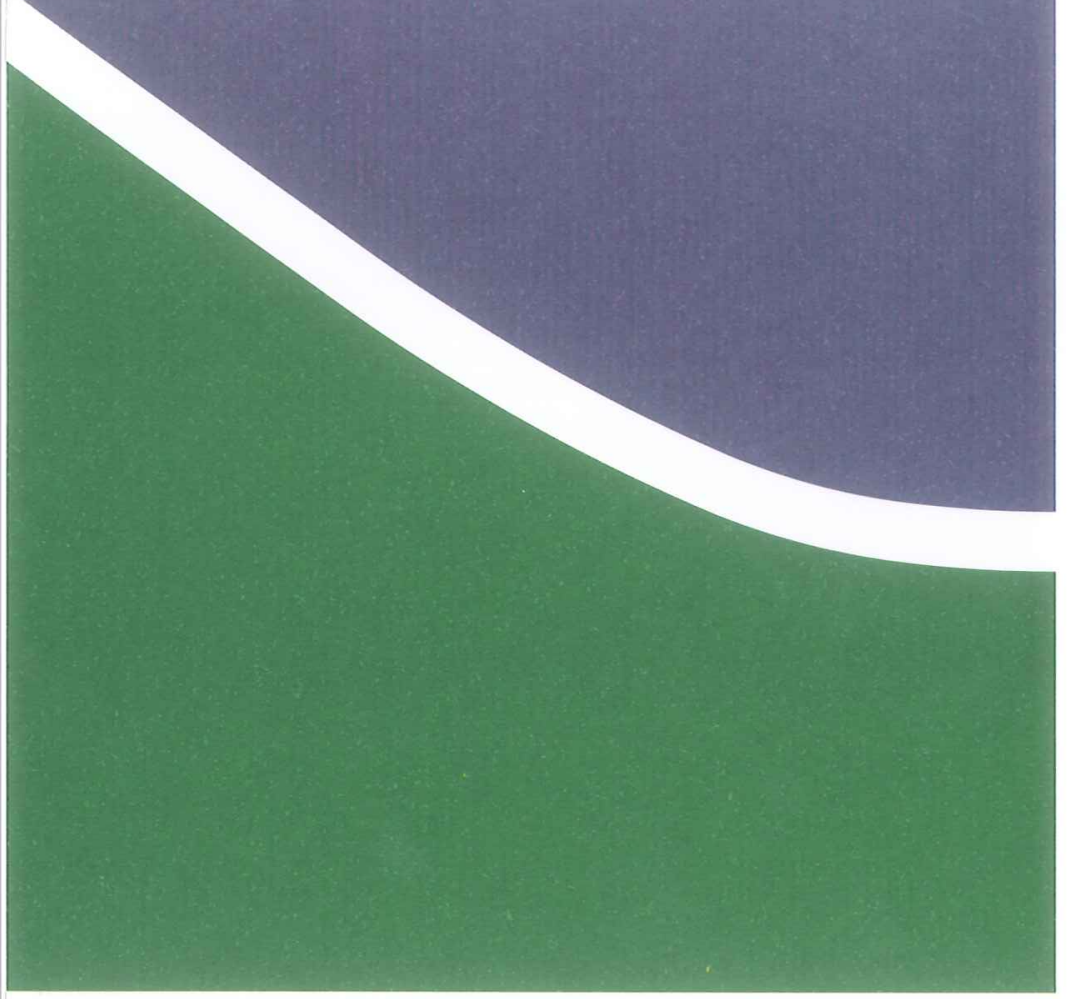

APLICAÇÃO DO PROBLEMA INVERSO PARA POROELASTIICIDADE DINÂMIICA USANDO MÉTODO DOS ELEMENTOS DE CONTORNO $\mathbb{E}$ ALGORITMO GIENÉTIICO

NIIÉCIO IDA COSTA ANUNCIACÇ̃̃ JUNIOR

DISSERTAÇÃO DE MIESTRADO EMIINTEGIRIDADE

DE MATEIRIAIS DA IENGIENHARIA 
UNIVERSIDADE DE BRASÍLIA

FACULDADE GAMA / FACULDADE DE TECNOLOGIA
PROGRAMA DE PÓS-GRADUAÇÃO EM INTEGRIDADE
DE MATERIAIS DA ENGENHARIA.

\section{APLICAÇÃO DO PROBLEMA INVERSO PARA POROELASTICIDADE DINÂMICA USANDO MÉTODO DOS ELEMENTOS DE CONTORNO E ALGORITMO GENÉTICO}

NIÉCIO DA COSTA ANUNCIAÇÃO JUNIOR

ORIENTADORA: Prof Dra. Carla Tatiana Mota Anflor

DISSERTAÇÃO DE MESTRADO EM INTEGRIDADE DE MATERIAIS DA ENGENHARIA

PUBLICAÇÃO: FGA.DM-/2016

BRASÍLIA/DF: AGOSTO - 2016 
UNIVERSIDADE DE BRASÍLIA

FACULDADE GAMA / FACULDADE DE TECNOLOGIA PROGRAMA DE PÓS-GRADUAÇÃO EM INTEGRIDADE DE MATERIAIS DA ENGENHARIA.

NIÉCIO COSTA ANUNCIAÇÃO JUNIOR

APLICAÇÃO DO PROBLEMA INVERSO PARA POROELASTICIDADE DINÂMICA USANDO MÉTODO DOS ELEMENTOS DE CONTORNO E ALGORITMO GENÉTICO

DISSERTAÇÃO DE MESTRADO SUBMETIDA AO PROGRAMA DE PÓSGRADUAÇÃO EM INTEGRIDADE DE MATERIAIS DA ENGENHARIA DA FACULDADE GAMA E FACULDADE DE TECNOLOGIA DA UNIVERSIDADE DE BRASÍLIA, COMO PARTE DOS REQUISITOS NECESSÁRIOS PARA A OBTENÇÃO DO GRAU DE MESTRE EM INTEGRIDADE DE MATERIAIS DA ENGENHARIA. 


\section{UNIVERSIDADE DE BRASÍLIA \\ FACULDADE GAMA / FACULDADE DE TECNOLOGIA \\ PROGRAMA DE PÓS-GRADUAÇÃO EM INTEGRIDADE DE MATERIAIS DA ENGENHAR\|A.}

\section{APLICAÇÃO DO PROBLEMA INVERSO PARA POROELASTICIDADE DINÂMICA USANDO O MÉTODO DOS ELEMENTOS DE CONTORNO E ALGORÍTMO GENÉTICO}

\section{NIÉCIO DA COSTA ANUNCIAÇÃO JUNIOR}

DISSERTAÇÃO DE MESTRADO SUBMETIDA AO PROGRAMA DE PÓS-GRADUAÇÃO EM INTEGRIDADE DE MATERIAIS DA ENGENHARIA DA FACULDADE GAMA E FACULDADE DE TECNOLOGIA DA UNIVERSIDADE DE BRASÍLIA, COMO PARTE DOS REQUISITOS NECESSÁRIOS PARA A OBTENÇÃO DO GRAU DE MESTRE EM INTEGRIDADE DE MATERIAIS DA ENGENHARIA.

APROVADA POR:

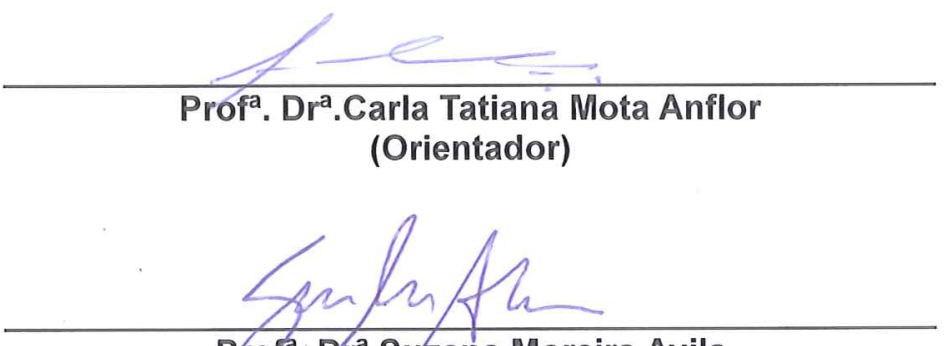

Pcrofa. Dra.Suzana Moreira Avila

(Examinador Interno)

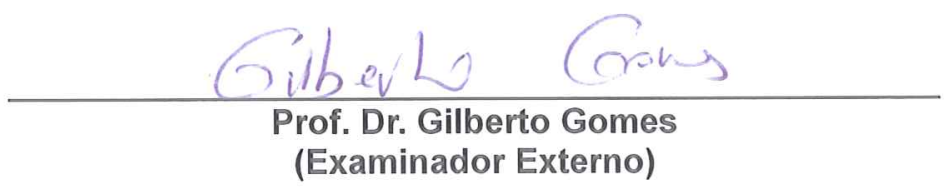

BRASÍLIA, 26 DE AGOSTO DE 2016. 


\section{FICHA CATALOGRÁFICA}

NIÉCIO DA COSTA ANUNCIAÇÃO JUNIOR

APLICAÇÃO DO PROBLEMA INVERSO PARA POROELASTICIDADE DINÂMICA USANDO MÉTODO DOS ELEMENTOS DE CONTORNO E ALGORITMO GENÉTICO. [Distrito Federal] 2016.

$\mathrm{N}^{\circ}$ 122p. 210 × $297 \mathrm{~mm}$ (FGA/FT/UnB, Mestre, Integridade de Materiais da Engenharia, 2016).

Dissertação de Mestrado - Universidade de Brasília. Faculdade UnB Gama. Programa de Pós-Graduação em Integridade de Materiais da Engenharia. Grupo de Mecânica Experimental e Computacional - GMEC.

1. MÉTODO DOS ELEMENTOS DE CONTORNO

3.OTIMIZAÇÃO

2.POROELASTICIDADE

4. ALGORÍTMO GENÉTICO

I. FGA/FT/UnB

II. Título (série)

\section{REFERÊNCIA BIBLIOGRÁFICA}

ANUNCIACAO JUNIOR, N. C. (2016). APLICAÇÃO DO PROBLEMA INVERSO PARA POROELASTICIDADE DINÂMICA USANDO MÉTODO DOS ELEMENTOS DE CONTORNO E ALGORITMO GENÉTICO. Dissertação de Mestrado em Integridade de Materiais da Engenharia, Publicação No 40a/2016, Faculdade UnB Gama/ FT/ Universidade de Brasília, DF, n 122p.

\section{CESSÃO DE DIREITOS}

AUTOR: NIÉCIO DA COSTA ANUNCIAÇÃO JUNIOR.

TÍTULO: APLICAÇÃO DO PROBLEMA INVERSO PARA POROELASTICIDADE DINÂMICA USANDO MÉTODO DOS ELEMENTOS DE CONTORNO E ALGORITMO GENÉTICO

GRAU: Mestre

ANO: 2016

É concedida à Universidade de Brasília permissão para reproduzir cópias desta dissertação de mestrado e para emprestar ou vender tais cópias somente para propósitos acadêmicos e científicos. O autor reserva outros direitos de publicação e nenhuma parte desta dissertação de mestrado pode ser reproduzida sem a autorização por escrito do autor.

NIÉCIO DA COSTA ANUNCIAÇÃO JUNIOR

RUA ALTAMIRA, QUADRA 01, CASA 05, BAIRRO CPA I

Cuiabá, MT - Brasil.

engnjunior@gmail.com 
Dedico este trabalho a meus pais, Maria Inês e Niécio Costa, pelo incentivo e apoio incondicional. 


\section{AGRADECIMENTOS}

A minha família que sempre me apoiou em todas as minhas decisões, que sempre me deram força e aconselharam. Aos meus pais Niécio e Maria Inês, obrigado por me ensinarem os valores de ser um bom homem, obrigado pela honestidade $e$ simplicidade que sempre me passaram. Aos meus irmãos Nilton obrigado pelas palavras e orações. As irmãs Nádia pela força e conselhos, a Inglyd pelas incríveis palavras que tens me falado e a Neydiane por ser meu lado mais forte, por me ajudar a pensar e exclarecer todas as minhas angústias e dificuldades.

Aos meus amigos (irmãos) Malu, Luma, Benedito por mesmo de longe me ouvirem a chorar, brincar, sorrir, por brigarem comigo e mostrar o verdadeiro sentido da amizade. As pessoas que me apoiaram na difícil (melhor) decisão da minha vida em vir para Brasília: Frankie, Tiago, Juliana e todas as pessoas que me querem bem.

Aos professores da graduação que acreditaram em mim e apoiaram incondicionalmente para este grande passo em minha vida.

A minha orientadora, Prof ${ }^{a}$ Carla e seu esposo Prof. Jhon por me abraçarem, me inserirem ao mundo acadêmico, por me ensinar desde o básico, pelos conselhos em tempos de angústias e pelos puxões de orelhas, sem dúvida se não fosse por vocês eu não teria feito metade do que fiz e não saberia o que é ser um bom engenheiro.

A todos os integrantes e ex-integrantes do GMEC, Rolan, Matheus, Miele, Tiago e em especial a Tatiane por ser uma pessoa muito querida comigo. Registo um segundo agradecimento ao Matheus, por me auxiliar em alguns momentos na elaboração do trabalho.

Ao Prof. Édson pelo auxílio e "desenrolar" da parte computacional (softwares) no período em que a pesquisa "não andava". Sua ajuda foi fundamental para a desenvolvimento do trabalho. A toda a comunidade da FGA que direto ou indiretamente me auxiliaram.

A CAPES e a DDS da UnB pela bolsa e auxílio a mim atribuído, pois sem estes auxílios eu não poderia fazer o que mais gosto. Estudar.

A todos aqueles que de alguma forma contribuíram para a execução deste trabalho. Seja por um boa sorte, por oração, por conselho, ou até mesmo por questionamentos. Sei que toda a aposta a mim concedido não foi em vão. Fica aqui registrado meu muito obrigado! 
"Cada sonho que você deixa para trás, é um futuro que deixa de existir".

Steve Jobs 


\section{RESUMO}

Este trabalho tem o objetivo de usar o Método dos Elementos de Contorno (MEC) e um Algoritmo Genético (AG) para resolver um problema de poroelasticidade dinâmica, considerando a engenharia inversa. O problema inverso é formulado como um procedimento de otimização no qual um Algoritmo Genético determina o melhor conjunto de constantes do material. O procedimento de caracterização proposto apresenta uma metodologia para determinar as propriedades mecânicas das rochas através do processo de otimização de ajuste de curva, uma vez que a curva $x$ amplitude de frequência é conhecidao. As equações governantes para o problema apresentado são introduzidas considerando as variáveis de tensão-deformação na formulação estabelecida por Biot para o problema de porosidade dinâmica. A metodologia mostrou boa precisão para determinar as propriedades mecânicas da rocha.

Palavras-chave: Método dos Elementos de Contorno, Poroelasticidade, Otimização, Algoritmo Genético. 


\begin{abstract}
This research aims to use the Boundary Element Method (BEM) and a genetic algorithm (GA) to solve a problem of dynamics poroelasticity considering inverse engineering. The inverse problem is formulated as an optimization procedure in which an genetic algorithm determines the best set of material constants. The procedure of characterization proposed, presente a method to determine the mechanical properties of the stone through the optimization process of curve fitting in a once that curve $x$ amplitude of frequency is known. The governing equations for the problem presented are introduced considering the tension of variable- deformation in formulation established by Biot to the problem of dynamic porosity. The methodology showed good precision to determine the mechanical properties of the stone.
\end{abstract}

Keywords: Boundary Element Method, Poroelasticity, Otimization, Genetic Algorithm. 


\section{LISTA DE FIGURAS}

Figura 2.1 - Fases do solo; (a) no estado natural; (b) separadas em volumes;.........12

Figura 2.2 - Compressão solo ................................................................ 13

Figura 2.3 - Modelo esquemático de solo .................................................16

Figura 2.4 - Modelo mecânico utilizado por Terzaghi .........................................17

Figura 2.5 - Fluxograma simplificado do fenômeno do adensamento .......................19

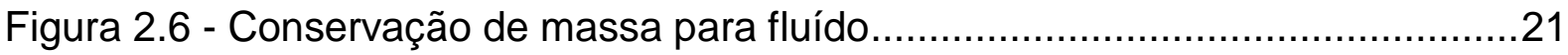

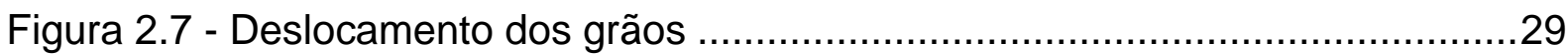

Figura 2.8 - Equilíbrio dos elementos .....................................................

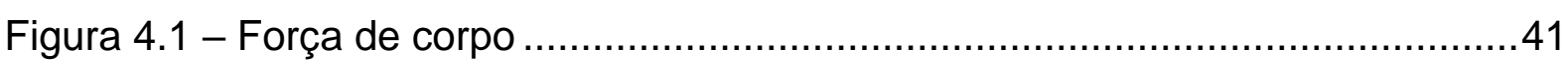

Figura 5.1 - Processo natural de otimização por uma colônia de formigas ...............47

Figura 5.2 - Analogia entre os AGs e a teoria da genética ................................50

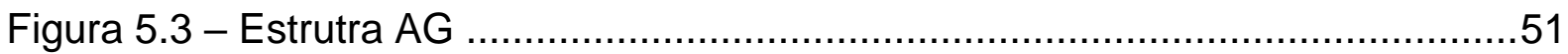

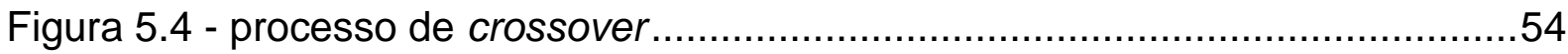

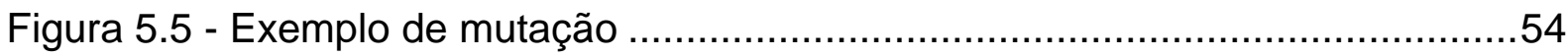

Figura 5.6 - Representação da classificação de indivíduos ................................60

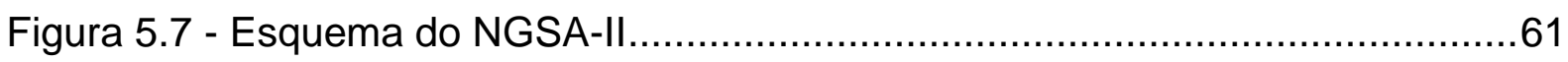

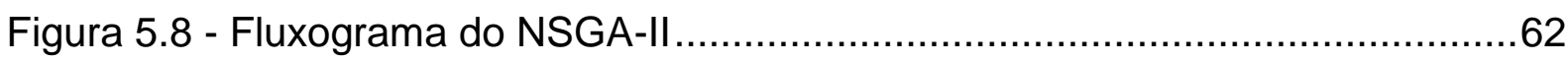

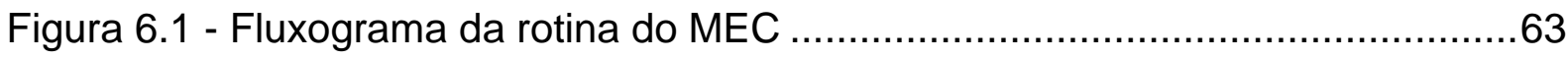

Figura 6.2 - Programação de otimização .........................................................66

Figura 6.3 - Estrutura de programação ....................................................67

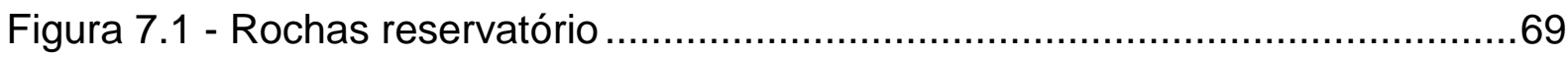

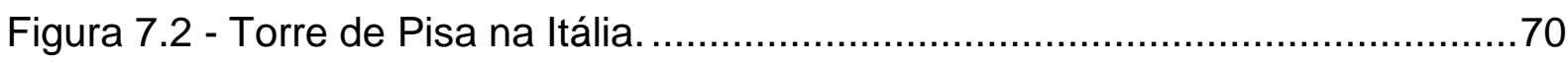

Figura 7.3 - Coluna de solo saturado sobre carregamento dinâmico .......................71

Figura 7.4 - Deslocamento no topo da coluna (tensão de excitação) .......................74

Figura 8.1 - Vetor com 327 frequências .................................................. 77

Figura 8.2 - Coordenadas Paralelas.................................................................. 78

Figura 8.3 - Coordenadas paralelas aleatórias.............................................. 80

Figura 8.4 - Função de Pareto do processo de otimização ...................................81

Figura 8.5 - Variáveis com maior influência na solução ótima................................82

Figura 8.6 - Distribuição do Coeficiente de Permeabilidade ................................83

Figura 8.7 - Distribuição do coeficiente de Poisson............................................. 83 


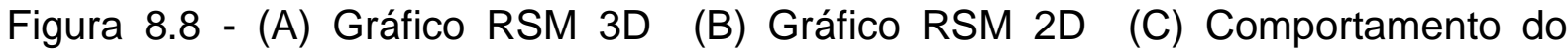

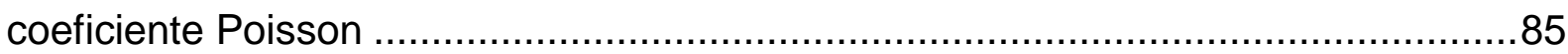

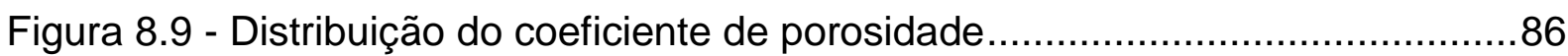

Figura 8.10 - (A) Gráfico RSM 3D (B) Gráfico RSM 2D (C) Comportamento do

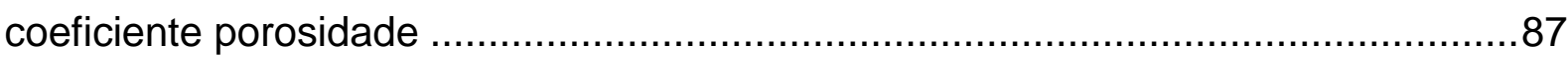

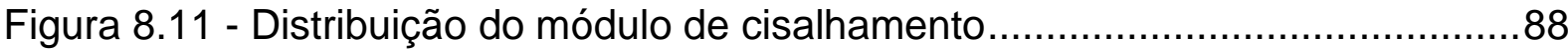

Figura 8.12 - (A) Gráfico RSM 3D (B) Gráfico RSM 2D (C) Comportamento do módulo

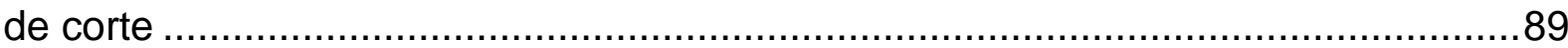

Figura 8.13 - Distribuição do coeficiente de skempton ..............................................90

Figura 8.14 - $\begin{array}{llll}\text { (A) Gráfico RSM 3D } & \text { (B) Gráfico RSM 2D } & \text { (C) Comportamento do }\end{array}$

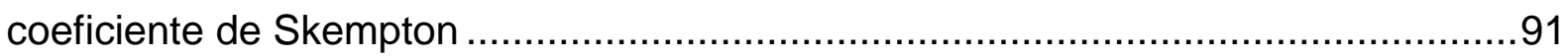

Figura 8.15 - Distribuição do coeficiente de Poisson drenado ……………….......92

Figura 8.16 - (A) Gráfico RSM 3D $\quad$ (B) Gráfico RSM 2D $\quad$ (C) Comportamento do

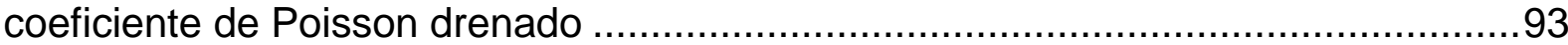

Figura 8.17 - Sobreposição das curvas analítica versus a otimizada ......................94 


\section{LISTA DE TABELAS}

Tabela 1 - Constantes poroelásticas para vários materiais .......................................37

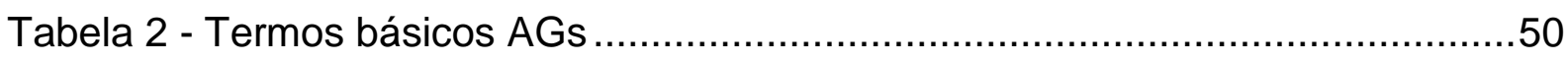

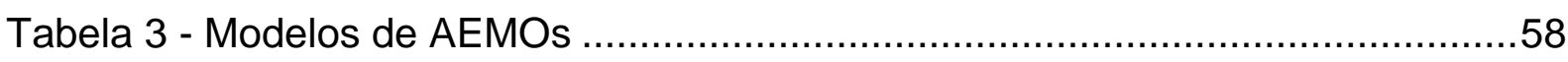

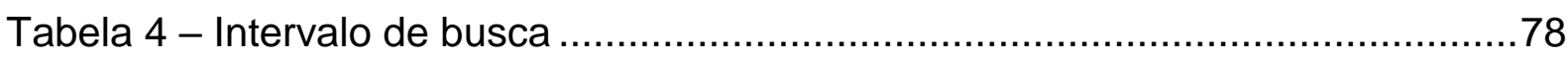

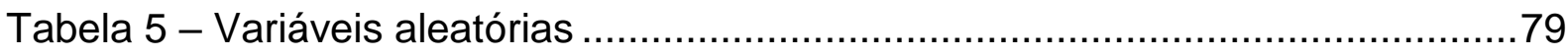

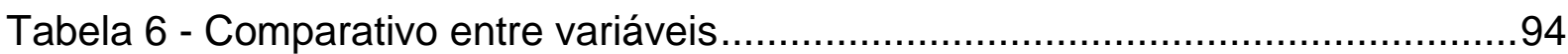




\section{LISTA DE ABREVIATURAS}

\begin{tabular}{ll}
$\sigma_{i j}$ & Tensão total (Tensão efetiva de Biot) \\
$\sigma$ & Pressão efetiva \\
$p$ & Poro pressão, Pressão neutra \\
$e_{i j}$ & Tensão sólido \\
$u_{i j}$ & Deslocamento sólido \\
$\zeta$ & Variação fluído \\
$G$ & Módulo de corte \\
$v$ & Poisson \\
$v_{u}$ & Poisson drenado \\
$B$ & Coeficiente de Skempton \\
$R$ & Coeficiente constitutivo poroelástico de Biot \\
$q_{i}$ & Lei de Darcy \\
$k$ & Coeficiente de permeabilidade, Permeabilidade intrínseca \\
$\mu$ & Viscosidade fluído \\
$\rho$ & Densidade \\
$V$ & Volume \\
$S$ & Trajetória fluxo, Coeficiente de armazenamento \\
$K_{s}$ & Permeabilidade \\
$\gamma$ & Peso específico \\
$\phi$ & Potencial fluxo \\
$\tau_{i j}$ & Viscosidade \\
$\gamma_{i}$ & Carga \\
$\gamma_{12}$ & Tensão no sólido \\
\hline & Dorça de corpo sólido \\
\hline &
\end{tabular}




$\begin{array}{ll}\gamma_{22} & \text { Densidade do adicional } \\ u_{i} & \text { Deslocamento sólido } \\ U_{i} & \text { Deslocamento fluído } \\ b & \text { Coeficiente de dissipação } \\ \tau & \text { Tensão no fluído } \\ X_{i}^{\prime} & \text { Força de corpo fluído } \\ \phi & \text { Porosidade } \\ \lambda & \text { Permeabilidade intrínseca } \\ e & \text { Dilatação do sólido } \\ e_{i j} & \text { Deformação do sólido } \\ \varepsilon & \text { Dilatação fluído }\end{array}$

$\Delta \quad$ Operador Laplace

$\omega \quad$ Carga

i $\omega b \quad$ Excitação harmônica

$\Omega \quad$ Domínio

$\Gamma \quad$ Contorno

$t_{i}=\tau_{i j} \quad$ Tensão no sólido

$U_{n}=U_{i} \quad$ Deslocamento fluido

$n \quad$ Normal do contorno

c Fator de forma utilizado no MEC

$\Delta \sigma \quad$ Tensão total

$\Delta p \quad$ Pressão poro

$C_{f} \quad$ Compressibilidade de pressão no poro

$\phi V \quad$ Volume total poro

$(1-\phi) V \quad$ Volume das partículas
$\Delta V_{s}$
Volume do sólido
$C_{s}$
Compressibilidade do sólido 


\begin{tabular}{ll}
$\Delta V$ & Volume total poroso \\
$\Delta V_{f}$ & Pressão no fluído \\
$C_{m}$ & Compressibilidade do meio poroso \\
$\delta_{i j}$ & Delta de Kronecker \\
$\alpha$ & Tensão efetiva de Biot (Coeficiente de Biot) \\
$\varepsilon$ & Volume de deformação \\
$v$ & Velocidade média do fluido \\
$w$ & Velocidade média do sólido \\
$g$ & vetor de gravidade \\
$\mathrm{k}$ & Condutividade hidráulica \\
$\rho_{0}$ & Massa específica \\
$\phi_{0}$ & Porosidade no instante \\
$k_{f}$ & Módulo de Bulk \\
$f_{x}$ & Componente de força de corpo \\
$f_{y}$ & Componente de força de corpo \\
$f_{z}$ & Componente de força de corpo \\
$\lambda$ & Coi de \\
\hline & Corcy \\
\hline &
\end{tabular}




\section{SUMÁRIO}

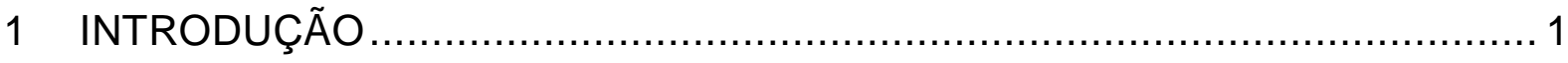

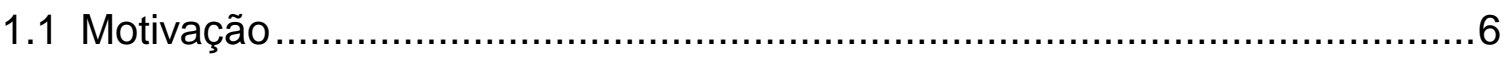

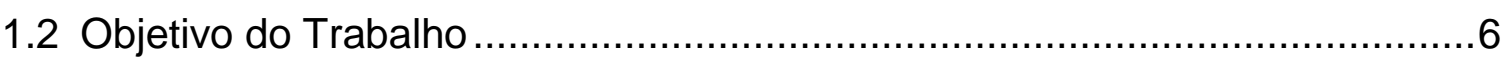

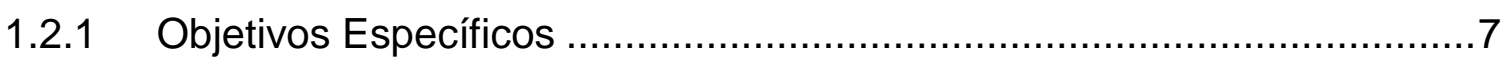

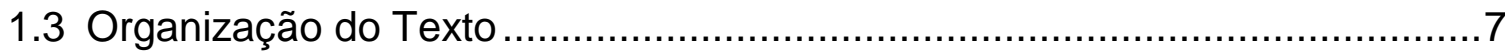

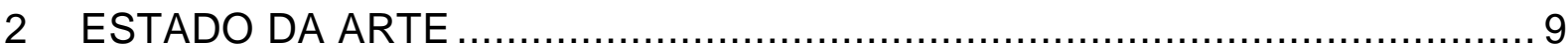

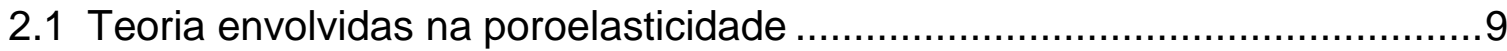

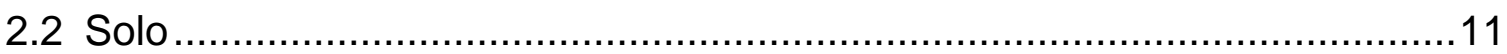

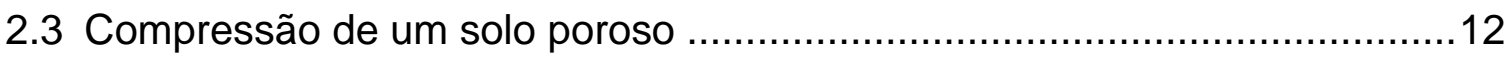

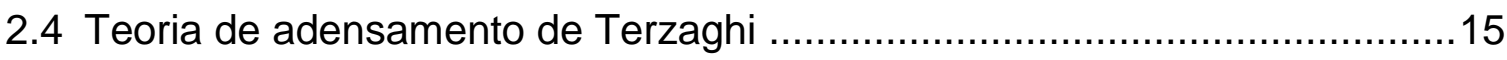

2.5 Teoria de adensamento de Biot .......................................................

2.6 Poroelasticidade de Biot acoplada à teoria de adensamento de Terzaghi ...19

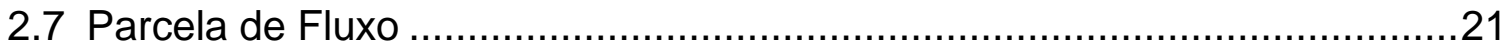

2.7.1 Equação de conservação de massa....................................................

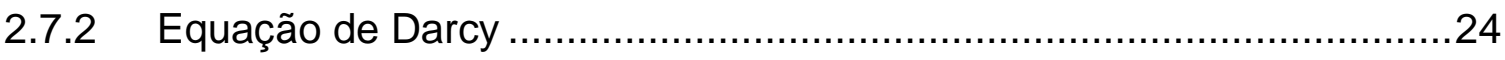

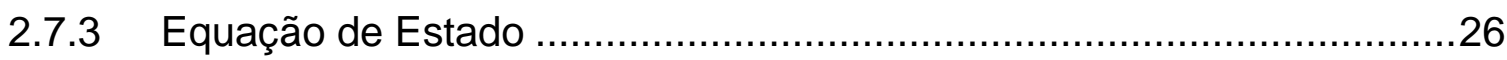

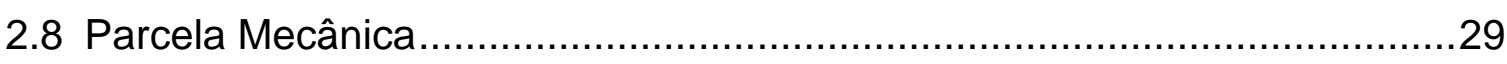

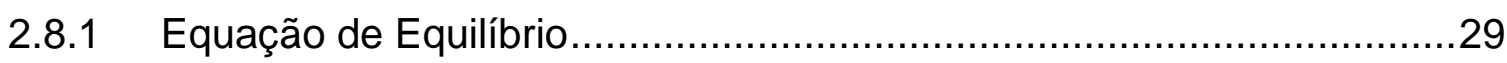

2.8.2 Relação deformação-Deslocamento...................................................

3 CONSTANTES DE COMPORTAMENTO POROELÁSTICO ..........................33

3.1 Módulo de elasticidade Linear $(E)$.....................................................33

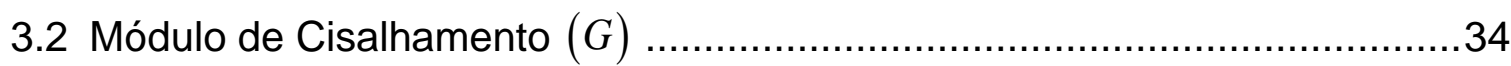

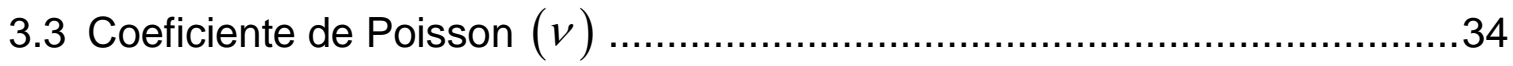

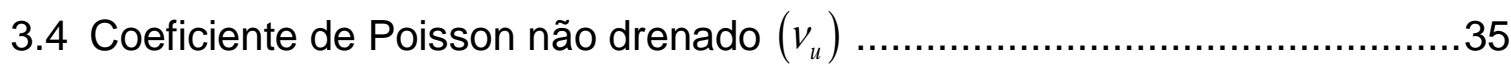

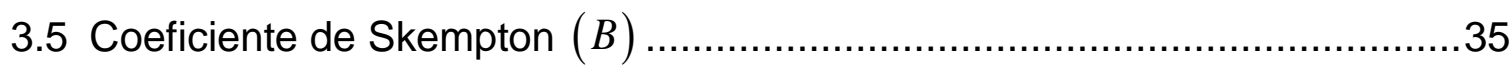

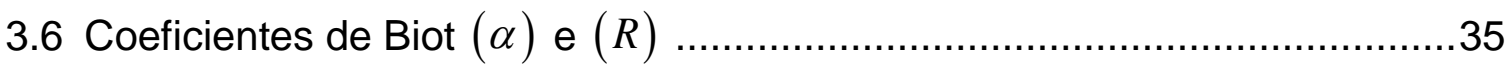

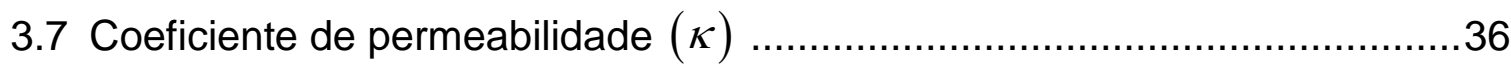

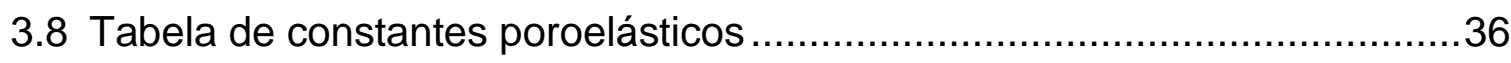

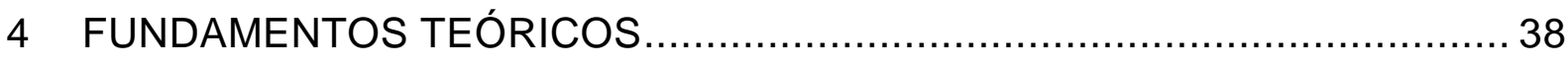

4.1 Equações básicas para poroelasticidade dinâmica.....................................38 


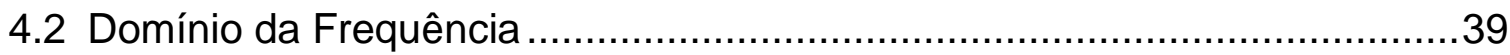

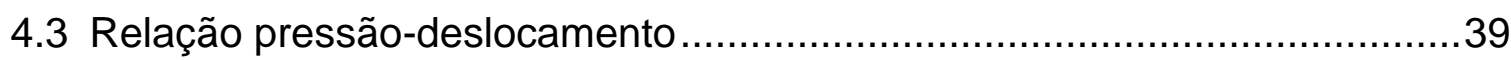

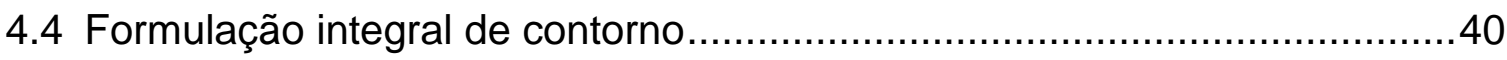

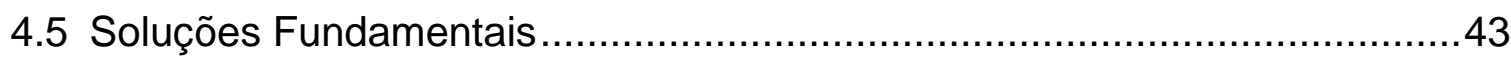

4.6 Elementos de Contorno (Elementos Constantes) …..................................44

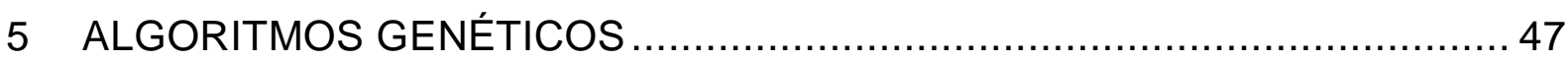

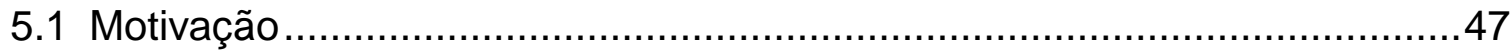

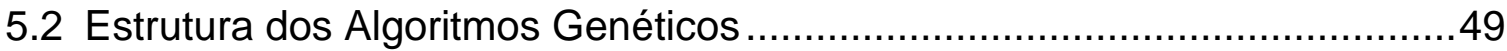

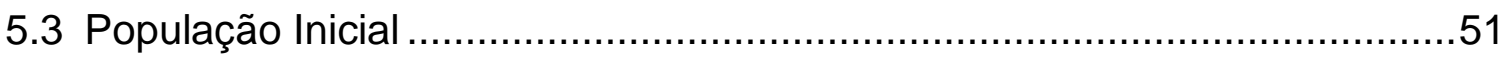

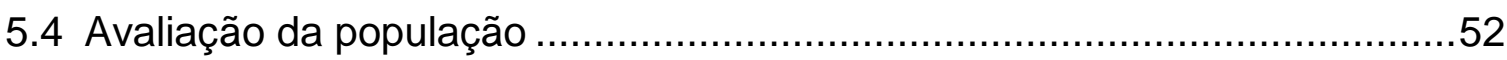

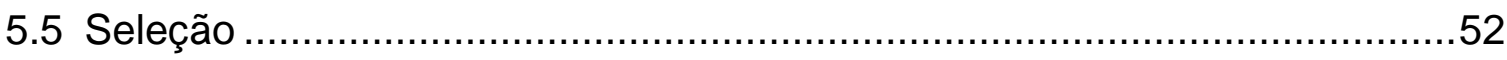

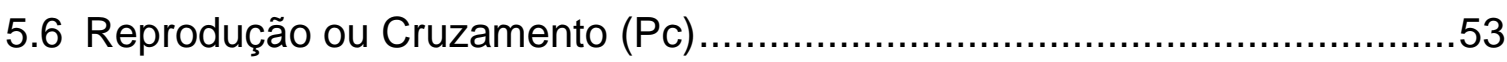

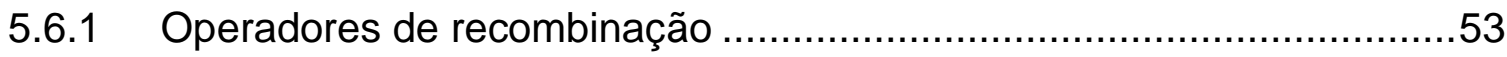

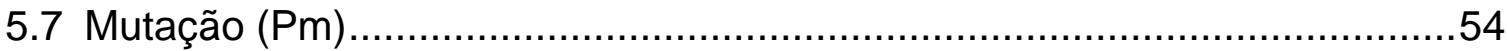

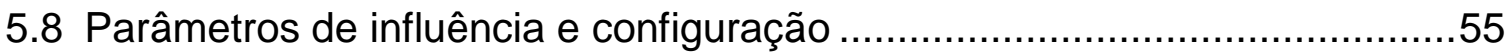

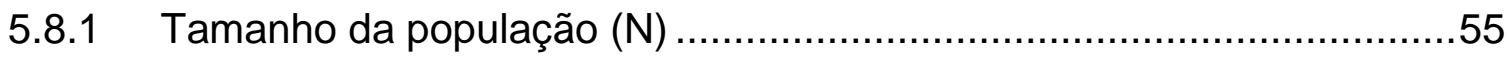

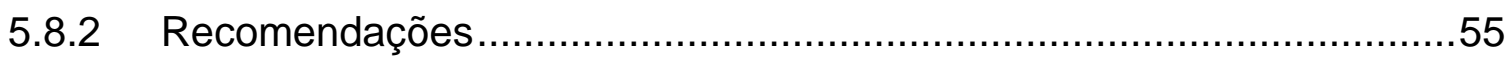

5.9 Algoritmos Evolucionários para Otimização Multi-Objetivo (AEOM) ............56

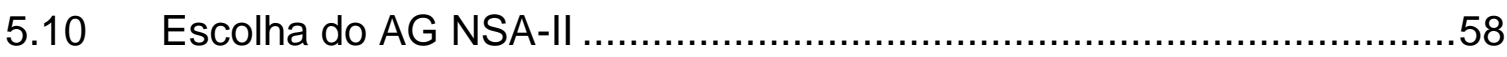

5.10.1 NSGA (Non-Dominated Sorting Genetic Algorithm) ….......................59

5.10.2 NSGA-II (Elitist Non-Dominated Sorting Genetic Algorithm) ..................60

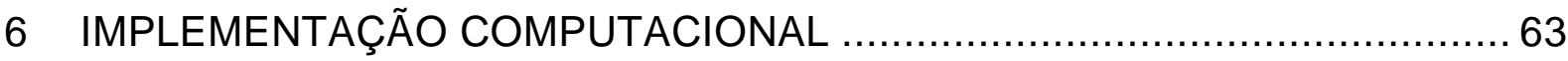

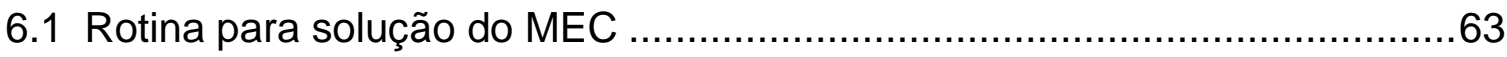

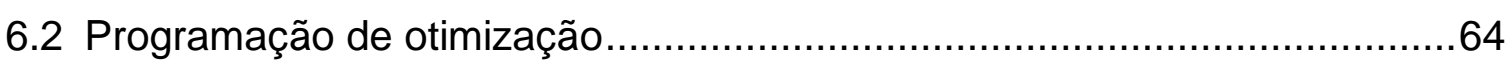

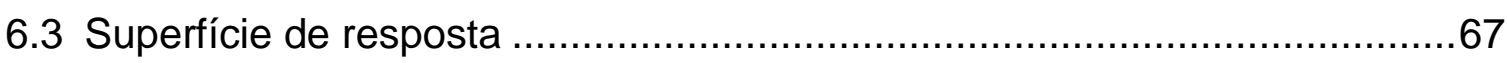

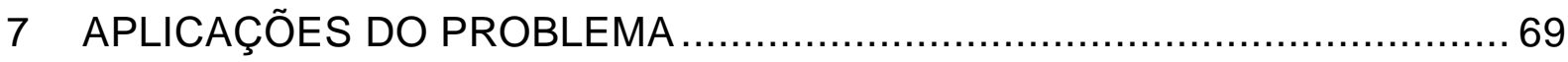

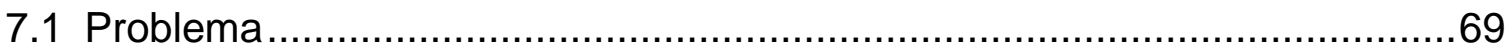

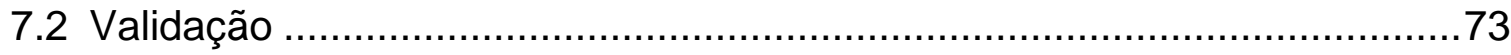

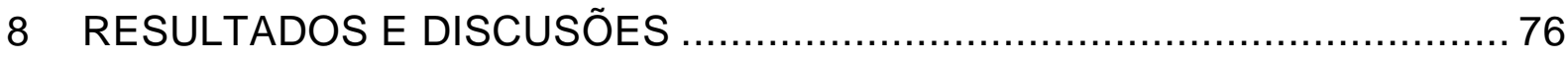

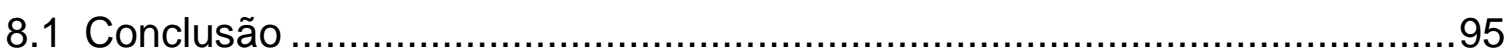

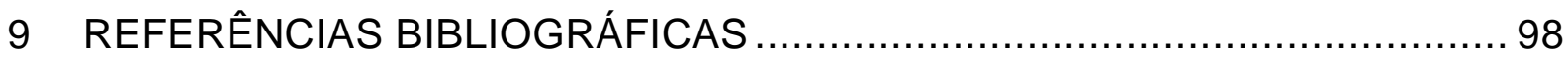




\section{INTRODUÇÃO}

O processo de desenvolvimento da sociedade tem se difundido com novas descobertas, e com a evolução da ciência, pertinentes ao avanço do conhecimento. Com base na capacidade de observação, experimentação e análise, o ser humano vem desenvolvendo teorias e modelos cada vez mais complexos e eficientes para resolver diversos tipos de fenômenos e comportamentos. Este tema tem sido muito recorrente na engenharia, onde exige do engenheiro uma alta capacidade de análise e síntese de projetos.

A alta complexidade dos problemas e a disponibilidade cada vez mais crescente de recursos computacionais abrem espaços para utilização de análises mais abrangentes. E através destes recursos se sugere abordar o problema deste trabalho, no âmbito de problemas relacionados à Geotecnia.

A análise de problemas Geotecnicos está relacionada a conceitos da Mecânica dos Solos e teve como início estudos apresentados por Terzaghi na Teoria da Elasticidade e na Teoria de Análise Limite (Plasticidade). Posteriormente Biot apresentou a Teoria de Adensamento que é a base para estudos relacionados à poroelasticidade do solo. Os problemas geotecnicos são decorrentes da interferência do homem ou até mesmo da natureza. Dentre os problemas podem ser citados os relacionados a adensamento de camadas moles do solo, submetidas a carregamento na superfície, provocando rachaduras ou até mesmo levando construções a ruir.

Nas escavações em meios porosos saturados como a de um túnel, por exemplo, o contorno da abertura passa a representar uma fronteira drenante (poropressão nula), criando uma diferença de potencial que tenderá a dissipar nas imediações da cavidade. Como consequência promovendo transferência de cargas adicionais ao esqueleto sólido (parte sólida do solo), resultando em deformações do meio ao longo do tempo. Também é encontrado no bombeamento (retirada) de fluido (petróleo ou água) por meios porosos saturados, através da dissipação da pressão por imediações e transferência de carga ao esqueleto sólido, resultante de deformações ou no processo e sucção do fluído.

Estes problemas podem ser representados através de formulações matemáticas, sendo assim passíveis de modelagem e manipulação através de métodos numéricos. Nesta dissertação apresenta-se uma modelagem numérica de propagação de ondas, no contexto da Teoria de Poroelasticidade de Biot acoplada a 
teoria de adensamento de Terzaghi, explorando a aplicação dos Métodos dos Elementos de Contorno (MEC) para problemas de adensamento de meios poroelásticos. O problema abordado consiste no adensamento bidimensional em estado plano de deformações, no qual foi tratado através de subdivisão de análise em intervalos de frequências de excitações ao longo do tempo.

Ainda aplicada a classe de problemas inversos, onde a busca para detectar qual tipo de material (características do solo) é encontrado a partir das respostas de exitação dinâmica, através de processo de otimização via Algoritmos Genéticos, já que este processo tem o intuito de aproximar o modelo numérico aos dados experimentais (solução analítica), de modo a torna-la mais preciso no intuito de aumentar a precisão entre as soluções.

O fenômeno de adensamento do solo, em que consiste na queda de volume, por conta da baixa taxa de água ou ar (espaços vazios) na parte interna do solo, foi estudado por diversos cientistas, porém Terzaghi (1925) foi o propulsor e mais importante cientista a abordar o tema, sendo chamado de "pai da mecânica dos solos". A propagação de ondas e adensamento do solo é objeto de estudo há muito tempo. Os cientistas Terzaghi (1936) e Gassmann (1951) forneceram resultados de propagação de ondas em meios porosos em baixa frequência $(0-100 \mathrm{~Hz})$, considerando a fase sólida e fluida como única.

Já Biot (1956a) refere-se ao estudo de adensamento do solo de Terzaghi como sendo um caso particular ao seu. E há alguns anos depois ao analisar a propagação de ondas em meio poroelastico, Biot pôde desenvolver a teoria de adensamento dinâmico do solo. Ele dividiu este estudo em duas partes (Biot 1956b e 1956c). Um estudo tratou a propagação de ondas elásticas em um meio poroso saturado para baixas frequências, e o outro para altas frequências, consecutivamente.

Através dos estudos apresentados por Biot foram observados dois tipos diferentes de propagação de ondas, as primárias e secundárias. São as primárias: as ondas de compressão ou longitudinais e as secundárias as de cisalhamento, distorção ou rotacional. A existência de onda lenta foi sujeita a especulações durante vários anos, até obter registro em laboratório sob condições experimentais controladas (Plona, 1980).

Para descrição do meio poroso precisa-se de duas escalas, a primeira é a escala macroscópica, correspondente ás dimensões do volume representativo, para o caso das ondas (sísmica), e ao comprimento da onda que se propaga; a segunda 
escala corresponde ás dimensões dos poros e é a escala microscópica. No caso da dupla porosidade têm-se três escalas: a macroscópica, a microscópica e a escala dos tamanhos das aberturas das fraturas, esta é uma escala intermediária entre as duas anteriores, denominada de mesoscópica (Zambrano, 2009).

Wilson e Afantis (1982) desenvolveram a teoria de consolidação para a dupla porosidade e pesquisaram a propagação em rochas porosas fraturadas, eles assumem o modelo da dupla porosidade, com o meio saturado por um único fluido, mostrando a existência de uma terceira onda compressional. Esta onda é altamente atenuada, tem velocidade muito baixa e apresenta-se principalmente no fluido das fraturas.

Já para um meio saturado com dois fluídos os cientistas Tuncay e Corapcioglu (1996a e 1996b) mostraram a existência de quatro ondas compressionais: as duas primeiras são as ondas compressionais da teoria de Biot (poroelasticidade simples), a terceira é associada com as fraturas (similar a de Wilson e Afantis), a quarta onda é associada com a diferença de pressão entre as fases de fluido nos blocos de rocha porosa. As duas ondas adicionais da dupla porosidade são altamente atenuadas em toda a faixa de frequência.

Berryman e Wang (1995) generalizaram a abordagem de Biot (1956a), definindo funções de energia e dissipação e obtendo equações de movimento resolvendo as equações de Euler-Lagrange. Esta análise macroscópica é da mesma abordagem de Biot para porosidade simples. Os resultados deste trabalho de Berryman e Wang demostraram uma segunda onda lenta, em que ela é atenuada em toda a faixa de frequência do mesmo modo em Wilson e Afantis (1984).

No final da década de 60, com o aperfeiçoamento dos computadores e a evolução dos métodos numéricos, fizeram com que as soluções fechadas ficassem ultrapassadas. Uma vez que as soluções numéricas ofereciam não apenas uma grande flexibilidade de modelagem, como também agilidade na resolução do problema,

As modelagens de sistemas físicos representam os mais diversos problemas existentes nos vários ramos da ciência e tecnologia, de maneira especial na engenharia, em que tem avançado muito nos últimos anos. Graças a excepcional evolução tecnológica, as máquinas estão mais sofisticadas, potentes, velozes e com capacidade de memória crescente, contribuindo para o processo de modelagem. 
Segundo Ferro (2002) a engenharia é uma beneficiária e usuária direta destas ferramentas computacionais. Problemas onde havia a impossibilidade, indisponibilidade ou inviabilidade econômica ou de tempo de serem resolvidos há poucos anos atrás, hoje já podem ser solucionados com o uso dos potentes computadores que existem no mercado, e esta tendência deve continuar.

Os métodos computacionais utilizados podem ser aplicados para todas as áreas da engenharia, destacando-se a das estruturas, geotecnia, recursos hídricos, transportes e outras. Alguns dos métodos numéricos utilizados são os Métodos dos Elementos Finitos (MEF), Métodos dos Elementos de Contorno (MEC), Diferenças Finitas (DF), Volumes Finitos (VF) e outros. A utilização da metologia computacional, ou a combinação deles dependem de diversos fatores, tais como: o tipo de problema, equação(ões) governante(s) e o domínio a ser estudado.

Para Brebbia (1978) o MEC pode ser mais atrativo para problemas de engenharia, pois necessita de discretização apenas do contorno do domínio. Esta característica diminui consideravelmente o custo computacional para solucionar a equação integral governante dos problemas.

Segundo Cheng \& Ligget (1984) "O limite atualmente desenvolvido pelo Método dos Elementos de Contorno (MEC) para poroelasticidade pode ser visto como uma alternativa eficiente e precisa, ao ser comparada aos Métodos dos Elementos Finitos (MEF) e aos Métodos de Diferenças Finitas (MDF).

Para problemas de consolidação linear, a aplicação do MEC pode ser uma alternativa eficiente, devido o custo computacional ser menor, comparada a outros métodos computacionais".

Algumas das aplicações numéricas utilizando o MEC foram apresentadas por Cleary (1977) que desenvolveu soluções fundamentais para um sólido poroelastico saturado. Já uma formulação integral para poroelasticidade, onde as integrais no tempo eram eliminadas através da transformada de Laplace foi apresentada por Predeleanu (1981).

No ano seguinte Kuroki \& Onishi (1982) apresentaram formulação do contorno para problemas lineares e de consolidação. Uma análise parecida foi apresentada também por Cheng \& Ligget (1984) com integrais lineares e aplicações de consolidações. Já na década de 90 Chiou \& Chi (1994) fizeram aplicações para camadas elásticas porosas do solo, quatro anos depois Cheng \& Detournay (1998) demostraram aplicação de equação integral singular e soluções fundamentais de 
poroelasticidade. Nas ultimas décadas diversos autores têm explorado a utilização do MEC para o tratamento de diferentes problemas geotectônicos.

Diversos tipos de carregamentos, estáticos ou dinâmicos, e o processo de deterioração estrutural podem causar diferentes tipos de danos a uma estrutura. Este dano pode ser caracterizado por mudança, de tal forma que pode levar a estrutura como a de uma construção sobre um determinado tipo de solo a ruir.

Este conhecimento da mudança nas propriedades do material é de suma importância, pois corresponde ao dano que certo material pode sofrer. Uma avaliação apropriada do dano em uma estrutura pode ser últil para inferir sobre a vida útil de uma estrutura.

Esta avaliação pode ser realizada por meio de uma comparação entre dados medidos e simulação numérica. Para a solução numérica um código é necessário no qual um modelo do problema é simulado por um algoritmo que solucione um problema inverso. Para os problemas medidos diretamente é necessário obter informações sobre a distribuição do problema como técnicas laboratoriais por exemplo.

Para este trabalho, o problema inverso foi aplicado de maneira que, através de informações relativas às soluções diretas do problema, com algumas informações parciais (excitação dinâmica), aplicando um algoritmo de busca, pôde observar todos os tipos de comportamentos do material, até que fosse encontrado o melhor e o pior comportamento, bem como as suas propriedades mecânicas. Esta técnica foi aplicada para descobrir e caracterizar de acordo com os procedimentos de engenharia inversa que tipo de material responde, e como responde a determinada excitação dinâmica.

A formulação é inicialmente apresentada por Dominguez (1993) e soluciona o problema em domínio dinâmico harmônico poroelástico, analisando os coeficientes de Biot nos termos de deslocamentos sólidos e tensão no fluído. A linguagem utilizada por Dominguez (1993) foi a do FORTRAN 77. Esta linguagem apresentava-se com poucos recursos de programação.

Devido o avanço tecnológico, surgiram então outros recursos, aprimorando os já existentes. O código então apresentado por Dominguez (1993) na linguagem 77 , foi reescrito na Linguagem FORTRAN 90, devido este apresentar melhores condições de programação como: mecanismos para manipulação de arranjos, alocação dinâmica de dados, subprogramas recursivos, controle de exceção e estabelecimento de módulos (Da Cunha, 2005). 
Além de possibilitar a integração entre as rotinas do processo de otimização, ou seja, a integração entre as rotinas de formulação integral do contorno, cálculo dos deslocamentos verticais, do processo de otimização e na análise das curvas das soluções.

O processo de otimização foi aplicado no modo multiobjetivo, com integração de processos e processamento permitindo o acoplamento de diferentes recursos computacionais.

\subsection{Motivação}

O estudo da porosidade é de importância primordial na prospecção de petróleo, gás, água subterrânea, e no reconhecimento de "barreiras de permeabilidade", que podem controlar a precipitação de minérios de baixa temperatura. $O$ estudo de fluidos contidos nos poros é escopo da hidrogeologia e engenharia de petróleo. Os valores mais frequentes de porosidade são da ordem de $5 \%$ a $25 \%$ e, se forem encontradas porosidades entre $25 \%$ e $35 \%$, por exemplo, são ditas excelentes tanto para reservatórios de água quanto de hidrocarbonetos.

Qualquer tipo de escavação seja para abertura de túneis ou poços levam a um descarregamento de tensões pré-existentes. Nestas explorações as variações de pressões que preenchem os poros interagem com os campos de tensões contribuindo de modo significativo no comportamento mecânico da estrutura. Os problemas relacionados com a engenharia geotécnica estão relacionados com adensamentos de camadas de solos submetidos a carregamentos na superfície, ou por abalos sísmicos, onde estes sofrem uma acomodação e consequentemente uma desestabilização da estrutura, levando-a a ruir.

\subsection{Objetivo do Trabalho}

Estudar a interação dinâmica solo-fluído-estrutura, no domínio de frequência, baseada na teoria da poroelasticidade de Terzaghi acoplada à teoria de adensamento de BIOT (1956a e 1956b), através de processo de otimização via Algoritmo Genético, para adensamento bidimensional em estado plano de deformações, com análise de intervalos e frequência. 


\subsubsection{Objetivos Específicos}

Este trabalho tem o objetivo de usar o Método dos Elementos de Contorno (MEC) e um Algoritmo Genético (AG) para resolver um problema de poroelasticidade dinâmica, considerando a engenharia inversa. O problema inverso é formulado como um procedimento de otimização no qual um Algoritmo Genético determina o melhor conjunto de constantes do material. O procedimento de caracterização proposto apresenta uma metodologia para determinar as propriedades mecânicas das rochas através do processo de otimização de ajuste de curva, uma vez que a curva $x$ amplitude de frequência é conhecido. As equações governantes para o problema apresentado são introduzidas considerando as variáveis de tensão-deformação na formulação estabelecida por Biot para o problema de porosidade dinâmica. A metodologia mostrou boa precisão para determinar as propriedades mecânicas da rocha.

\subsection{Organização do Texto}

A dissertação está dividida em dez capítulos da seguinte forma:

$\checkmark$ Capítulo 1: Neste capítulo é apresentada a introdução com suas considerações iniciais, conceitos e generalidades, algumas definições dos procedimentos adotados, organização do texto e os objetivos do trabalho.

$\checkmark$ Capítulo 2: Apresentada uma revisão bibliográfica, algumas aplicações com conceitos de aplicações do MEC, como também para problemas relacionados a poroelasticidade. E feita a introdução das equações básicas do regime poroelastico para as parcelas de fluído e sólido.

$\checkmark$ Capítulo 3: Demostrado as constantes do sistema, de modo que a análise e aplicação dos conceitos ficassem mais claras.

$\checkmark$ Capítulo 4: São apresentados os tópicos referentes aos conceitos para formulação do MEC aplicados a problemas poroelásticos, solução fundamental e tratamento das integrais de domínios.

$\checkmark$ Capítulo 5: A programação matemática foi demonstrada neste capítulo, com 
as terminologias e classificações do processo de otimização multiobjetivo adotado para solucionar o problema.

$\checkmark$ Capítulo 6: São apresentados os parâmetros do Algoritmo Genético, bem como a justificativa do operador escolhido, e também a maneira com que são tratados os tópicos referentes à otimização, para o entendimento de conceitos e comportamento de problemas desta natureza.

$\checkmark$ Capítulo 7: A rotina de programação e os procedimentos adotados foram apresentados neste capítulo. Bem como a descrição das ferramentas utilizadas na implementação numérica e a proposta do procedimento MEC+AG para otimização das variáveis de projeto.

$\checkmark$ Capítulo 8: Demonstrada a aplicação do problema e a validação da proposta apresentada nesta dissertação.

$\checkmark$ Capítulo 9: Discutido o problema, conclusão e a proposta de continuidade.

$\checkmark$ Capítulo 10: São apresentadas as referências bibliográficas utilizadas neste trabalho. 


\section{ESTADO DA ARTE}

\subsection{Teoria envolvidas na poroelasticidade}

A teoria clássica de adensamento do solo sob condições de fluxo unidimensional foi inicialmente conceituada por Terzaghi (1923), assumindo que o excesso de poropressão gerado no instante do carregamento, contribui para o progresso do adensamento.

Rendulic (1936) propôs uma abordagem mais abrangente, em que a variação no tempo dos componentes volumétricos interno das tensões totais equivale a do tensor de tensões totais aplicados, resultando em uma teoria pseudo-tridimensional. Também definindo que as deformações são determinadas a partir de uma relação com a dissipação do excesso de poro-pressão.

A teoria de adensamento focada no comportamento poroelástico composto de duas fases interdependentes foi apresentada por Biot (1935), em que observou a distribuição da pressão devido a uma carga concentrada sobre um corpo elástico, investigando o efeito dessa distribuição de pressão em relação à profundidade.

Alguns anos depois Biot (1941) acrescentou em seu estudo de 1935 a compressibilidade do fluído em meios isotrópicos, e em Biot (1955) para anisotrópico. No ano seguinte o pesquisador associou anisotropia com viscoelasticidade em Biot (1956), em Biot (1957) analisou os coeficientes elásticos a serem considerados na poroelasticidade, e em Biot (1973) verificou o comportamento das propriedades físicas que influenciavam o transporte de quantidade de movimento de um fluido não linear e semi-linear.

Para Cavalcanti (2002) a teoria concebida por Biot (1956), os campos de tensões totais e efetivas, bem como o de poro-pressão, são interdependentes, acoplando assim a magnitude dos deslocamentos à sua evolução no tempo em função da dissipação do excesso de poropressão pelo carregamento.

As teorias apresentadas por Terzaghi e Biot sobre a importância do acoplamento entre as fases do fenômeno geraram inúmeras discussões técnicas ao longo de algumas décadas. Dentre as quais podem ser citadas as seguintes contribuições: Mandel (1953) apresentou uma solução completa para um caso de um extrato plano e de uma força concentrada sobre a superfície do solo, através das definições de estudos de Terzaghi (1925), onde puderam ser analisados problemas relacionados com a pressão do solo argiloso estudado. 
Cryer (1963) comparou as teorias de consolidação tridimensional de Biot e Terzaghi, no qual discute e confronta problemas em uma esfera de solo sujeito a uma pressão hidrostática saturada com fluido. As soluções obtidas por Cryer foram encontradas com variações consideráveis de pressão na parcela do fluido no centro da esfera.

Uma investigação um pouco mais profunda da teoria de consolidação foi feita por Schiffman et al. (1969), onde a análise foi feita por três tipos de consolidações sobre um plano, e se observou os campos de tensões do solo. Mandel (1953) e Cryer (1963) observaram e analisaram em termos de motivação física a influência dos poros em condições de falha.

De Jong (1957) pesquisou as aplicações das funções de tensões à problemas de consolidação, o estudo foi mostrado através da utilização de uma esfera rígida incorporada em uma massa de solo, e carregado uniformemente sobre uma área circular da sua superfície, considerando tanto uma fronteira impermeável como permeável. Onde os números de funções de tensões necessária e suficiente para a solução de problemas de consolidação, para o caso estudado foram três: uma para a compressão, uma para rotação e uma função que satisfaça a equação $\nabla^{2} F=0$.

Aplicações numéricas e analíticas de poroelasticidade acoplada foram estudadas por Cleary (1977), onde desenvolviam-se soluções fundamentais para um sólido poroelastico saturado por fluído, através do teorema de reciprocidade. Seguido de Predeleanu (1981) em que apresentou uma formulação integral, onde as integrais no tempo eram eliminadas através de transformadas de Laplace.

Kuroki \& Onishi (1982) apresentaram uma consolidação formulada pela teoria geral de Biot, e seus resultados mostraram boa concordância com soluções observadas pelo Método dos Elementos Finitos, nos campos de deslocamentos.

A aplicação do MEC para poroelasticidade iniciaram-se a partir da década de 80, podendo destacar alguns autores como Banerjee e Butterfield (1981), que abordaram a poroelasticidade como um problema quase estático, desacoplado das equações da difusão e da eletrostática, dentro de um intervalo de tempo, com integrais de domínio e solução fundamental dependente do tempo. Uma aplicação semelhante foi apresentada por Aramaki \& Yasuhara (1981) onde foi aplicado o MEC para solução de problemas de simetria radial, com a teoria de consolidação linear de Biot (1941) em modelagens, nas condições laboratoriais e por fim comparados numericamente. 
Foi proposto por Cheng \& Ligget (1984) para fenômenos físicos regidos pelo modelo de poroelasticidade de Biot, uma relação recíproca, semelhante ao teorema de reciprocidade de Betti, construído a partir da transformada de Laplace, possibilitando a formulação integral de domínio no contorno para problemas poroelasticos, com aplicações para consolidação do solo.

Rudnicki (1989) analisou soluções para pontos de força e carga de linha aplicada repentinamente em corpos elásticos lineares, sólidos e porosos. Rudnicki infiltrou um fluído, e fez análises através de difusão homogênea, obtendo as tensões, deslocamento e pressão nos poros. Tudo isso graças as injeções instantâneas e contínuas de massa de fluido.

Para a integração no domínio através do uso das funções de Green, Cheng \& Predeleanu (1987) propuseram um estudo com equações integrais de contorno transiente, linear e isotrópico, através da técnica de transformação original de Biot. Esta técnica separa uma parte dos campos de deslocamentos dos campos não drenados satisfazendo a equação de Navier. Já Nishimura \& Kobayashi (1989) trabalharam em problemas de consolidação no domínio do tempo, onde a representação solução potencial foi usada não somente para obter a solução numérica, mas também para investigar o desenvolvimento da solução. As informações obtidas através destes desenvolvimentos foram utilizadas para implementar o MEC ao problema.

$\mathrm{Na}$ década de 90, Dargush e Banerjee (1991) apresentaram um desenvolvimento do domínio do tempo, para uma assimetria quase estática, também aplicando na consolidação do solo. Contudo o volume da discretização é requerido tornando a abordagem ideal para problemas geotécnicos, envolvendo extensão infinita. Cavalcanti \& Telles (2003) demostraram uma consolidação da teoria de Biot usando os conceitos de Elementos de Contorno para soluções fundamentais independentes no tempo, para um meio poroso saturado.

Park \& Banerjee (2006) desenvolveram uma formulação simples para Elementos de Contorno poroelástico via integrais particulares.

\subsection{Solo}

Os solos são corpos naturais, que ocupam porções na superfície terrestre, suportam a vegetação e as edificações do homem e apresentam propriedades 
resultantes da atuação integrada do clima e dos organismos, atuando sobre o material de origem, condicionado pelo relevo, durante um período de tempo (CAPUTO, 1981). Tem sua origem na decomposição das rochas que formavam inicialmente a crosta terrestre. Esta decomposição ocorre devido agentes físicos e químicos chamados agentes de intemperismo. Os principais agentes da transformação da matriz rocha em solo são: as variações de temperatura, a água ao congelar e degelar, vento ao fazer variar a umidade do solo e a presença de fauna e da flora. Além do intemperismo, existem os agentes erosivos que são capazes de transportar o material desagregado. Desta maneira existem dois tipos de solos, os transportados e os não transportados. Os solos transportados, sofrem o intemperismo e são depositados em forma de sedimentos em distâncias variadas. Já os não transportados, decompõem-se e permanecem no mesmo local, guardando de certa forma, a estrutura da rocha matriz da qual foi originado. Solos residuais são os solos não transportados.

Segundo Pinto (2006) os solos são constituídos por um conjunto de partículas sólidas com água (ou outro líquido) e ar nos espaços intermediários, conforme pode ser observado na Figura 2.1. Suas partículas, de maneira geral encontram-se livres para deslocar entre si. Em alguns casos, uma pequena cimentação pode ocorrer entre elas, mas num grau extremamente mais baixo do que nos cristais de uma rocha ou de um metal, ou nos agregados de um concreto.

(a)

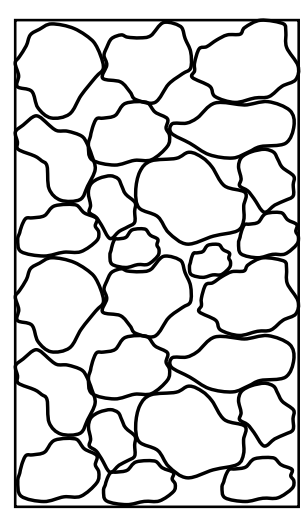

(b)

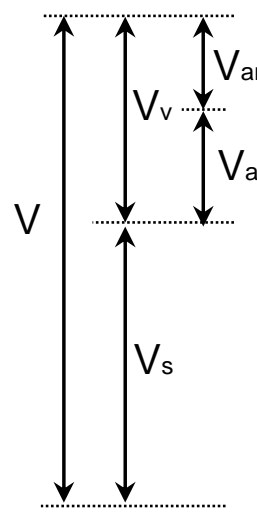

(c)

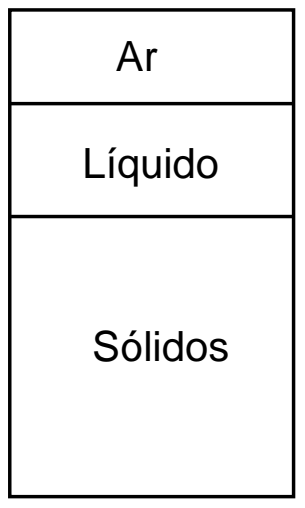

(d)

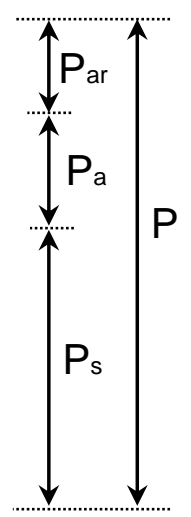

Figura 2.1 - Fases do solo; (a) no estado natural; (b) separadas em volumes;

(c) em função do volume dos sólidos; (d) separadas em pressão.

\subsection{Compressão de um solo poroso}

Considera-se um elemento de solo poroso com porosidade $\phi$ sob um fluído, onde a porosidade é definida como um volume de poro por unidade de volume total 
do solo, conforme Figura 2.2. O elemento é carregado por uma tensão total $\Delta \sigma$, sob condição de solo saturado, ou seja, não existe uma variação de volume de fluído no interior do solo.

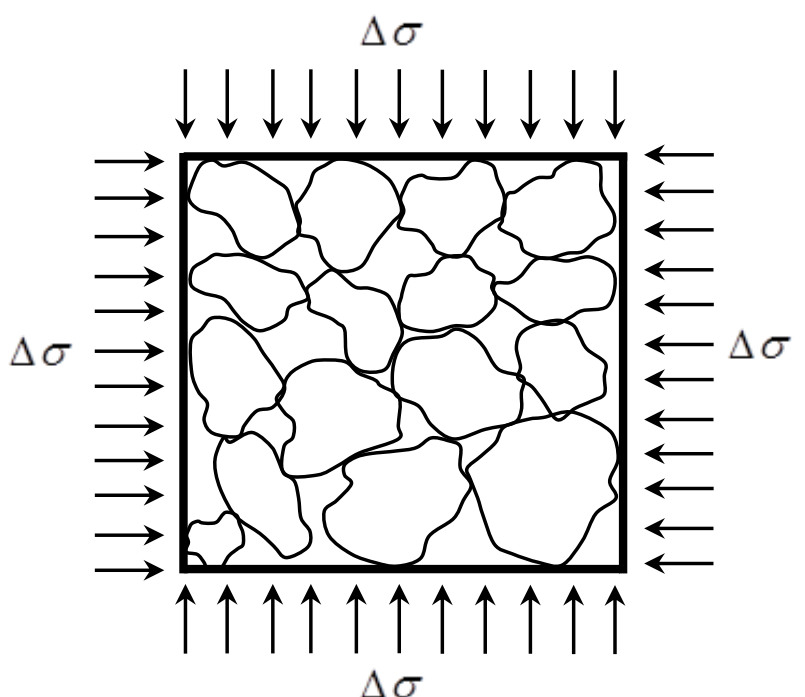

Figura 2.2 Compressão solo

A pressão de poro resultante (pressão no fluido poro) é conhecida por $\Delta p$. Para determinar a relação entre $\Delta p$ e $\Delta \sigma$ um carregamento é considerado, sendo este aplicado em dois estágios. O primeiro com um aumento de pressão no fluído e nas partículas do sólido $\Delta p$, o segundo com um carregamento somente na parte sólida, representado por $\Delta \sigma-\Delta p$. As compatibilidades destes dois estágios exigem que a mudança de volume total seja a soma do volume de fluídos com partículas sólidas.

Na primeira fase em que ambas as tensões no fluído e partículas aumentam pela pressão no poro $\Delta p$, a alteração do volume é representada pela Eq.(2.1).

$$
\Delta V_{f}=-\phi C_{f} \Delta p V
$$

Onde $C_{f}$ é a compressibilidade de pressão no poro (pode incluir compressão de pequenas quantidades de bolhas de gás no fluído), $V$ como o volume total de elementos a serem considerados e $\phi$ como o volume original dos poros. A alteração de volume das partículas é reconhecida por $(1-\phi) \mathrm{V}$.

Já a alteração de volume do sólido é conhecida pela Eq.(2.2). 


$$
\Delta V_{s}=-(1-\phi) C_{s} \Delta p V
$$

Em que $C_{S}$ é a compressibilidade do material sólido. Supondo que as partículas sólidas e fluídicas tenham as mesmas capacidades de compactação, e que a compressão uniforme das partículas resulta em uma alteração do volume dos poros, portanto o volume total do meio poroso pode ser representado pela equação (2.3).

$$
\Delta V=-C_{s} \Delta p V
$$

Na segunda etapa a pressão do fluído permanece inalterada, para que não ocorra nenhuma alteração do volume de fluído, onde pode ser visto na Eq. (2.4).

$$
\Delta V_{f}=0
$$

O acréscimo de tensão $\Delta \sigma-\Delta p$ na parte sólida e a pressão constante nos poros eleva uma tensão nas partículas sólidas $(\Delta \sigma-\Delta p) /(1-\phi)$. Resultando em uma mudança de volume das partículas como na Eq. (2.5).

$$
\Delta V_{s}=-C_{s}(\Delta \sigma-\Delta p) V
$$

A mudança de volume do meio poroso nesta etapa envolve as deformações devidos os rolamentos e deslizamentos (adensamento) entre os contatos das partículas. Assumindo que este também faz parte de um processo linear, a fase de carregamento de volume é visto na Eq. (2.6).

$$
\Delta V=-C_{m}(\Delta \sigma-\Delta p) V
$$

Onde $C_{m}$ é a compressibilidade do meio poroso. Este é considerado maior do que as compressibilidades dos dois componentes: Fluído e das partículas sólidas, porque o principal mecanismo da consolidação do sólido, não é tanto a compressão do fluído ou das partículas sólidas, mas sim uma deformação devido o rearranjo das partículas, incluindo os deslizamentos e rolamentos (adensamentos) das partículas, uns sobre as outras.

Para ambos os carregamentos na parte sólida, do fluído e poro pressão, as variações de volume são divididas em três. A primeira para fluído, representada pela Eq. (2.7). 


$$
\Delta V_{f}=-\phi C_{f} \Delta p V
$$

A segunda para a parte sólida, como visto na Eq. (2.8).

$$
\Delta V_{s}=-(1-\phi) C_{s} \Delta p V-C_{s}(\Delta \sigma-\Delta p) V
$$

A última representada pela Eq. (2.9) referente ao meio poroso.

$$
\Delta V=-C_{s} \Delta p V-C_{m}(\Delta \sigma-\Delta p) V
$$

Com isso, não há escoamento nas cargas combinadas, portanto por hipótese, a variação total de volume deve ser igual à soma das alterações de volume e fluído das partículas $\Delta V=\Delta V_{f}+\Delta V_{s}$. Este pode ser obtido através das Eq. (2.7) e Eq. (2.8) resultando na Eq. (2.10).

$$
\frac{\Delta p}{\Delta \sigma}=B=\frac{1}{1+\phi\left(C_{f}-C_{s}\right) /\left(C_{m}-C_{s}\right)}=\frac{C_{m}-C_{s}}{\left(C_{m}-C_{s}\right)+\phi\left(C_{f}-C_{s}\right)}
$$

Esta equação é fruto de derivação obtida por Bishop (1973) e equações semelhantes foram anteriormente estudadas por Gassmann (1951) e Geertsma (1957). O razão $\Delta p / \Delta \sigma$ sobre um carregamento isotrópico é conhecido pela parcela mecânica representada por $B$, este, é o Coeficiente de Skempton. Este Coeficiente foi estudado por Skempton através, de derivação de alguns valores típicos dos coeficientes de poro-pressão determinados experimentalmente. Estes coeficientes foram denominados por $A$ e $B$, e a eles foram dadas algumas aplicações práticas, onde este estudo pode ser visto em Skempton (1954).

Os coeficientes $A$ e $B$ tem relação direta com poro pressão em um aumento de tensão, e pode facilmente ser determinado experimentalmente através da realização de testes triaxiais não drenado de um solo, conforme feito por Bishop \& Henkel (1962).

\subsection{Teoria de adensamento de Terzaghi}

O tcheco Karls Terzaghi (1883-1963) estabeleceu o princípio de pressão efetiva do solo, a partir de observações e de sua própria intuição. Ele verificou experimentalmente o comportamento de solos saturados, bem como a compressibilidade, e analisou se a resistência ao cisalhamento do solo está relacionada com a pressão média entre os grãos. Este estudo ficou conhecido com o 
seu próprio nome, e também como o estudo da pressão efetiva do solo, publicado em Viena em 1925.

Na Figura 2.3 é possível identificar as fases do solo, em sua parte sólida (esqueleto) e os vazios que podem ser preenchidos por água, ar, gases, óleo etc. Considerando estes vazios preenchidos por água e que o solo está saturado, a pressão atuante sobre o solo é dividida em duas parcelas: pressão neutra e pressão efetiva.

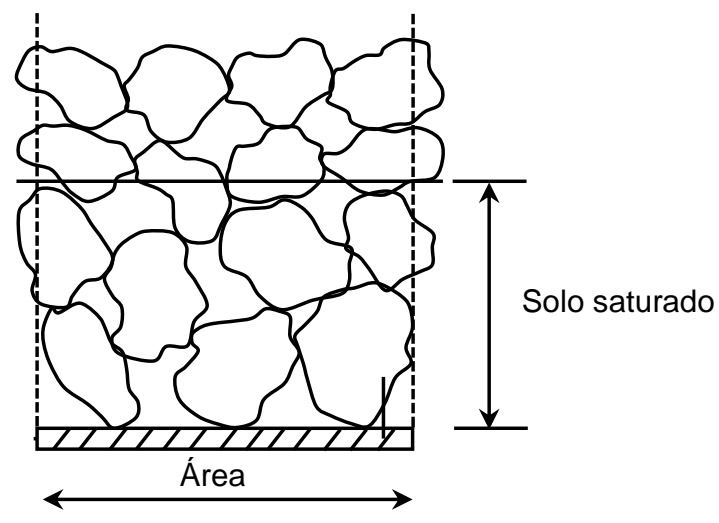

Figura 2.3 Modelo esquemático de solo

Dentre as parcelas tem-se a pressão neutra, onde nada mais é do que, a pressão que atua na água intersticial do solo, seja ela gravitacional, capilar ou excesso de poro-pressão. E a pressão efetiva do solo, em que é responsável por atuar no corpo sólido. Logo a pressão total é igual à soma destas duas parcelas, conforme a Eq. (2.11).

$$
\sigma_{t}=\sigma+p
$$

Onde, $\sigma_{t}$ é a pressão total, $\sigma$ é a pressão efetiva e $p$ é a pressão neutra atuantes no solo. Na mecânica dos solos utilizam a expressão neutra, total ou efetiva com o mesmo significado de tensões. Diferindo da nomenclatura usada na teoria da elasticidade, em que as equações de equilíbrio são prescritas sob forma de tensões.

O fenômeno estudado por Terzaghi começou a ser estudado em 1914 onde analisou o adensamento do solo composto por argilas, mas foi com o estudo de 1925 que o consagrou como o "pai da mecânica dos solos". Ele idealizou um modelo físico composto por um corpo formado de água, molas e um êmbolo com furos, conforme observado na Figura 2.4. Foi através destes processos que Terzaghi constituiu a teoria de adensamento. 
(a)

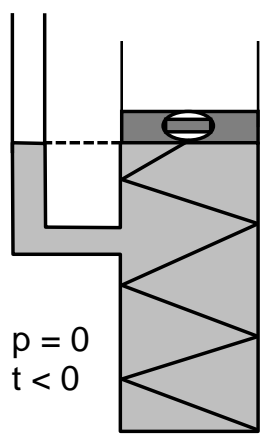

(b)

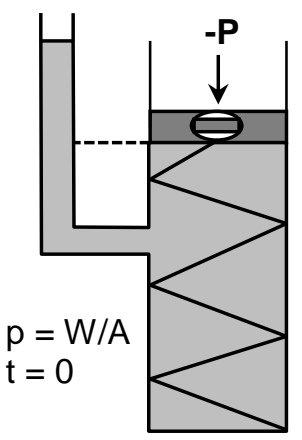

(c)

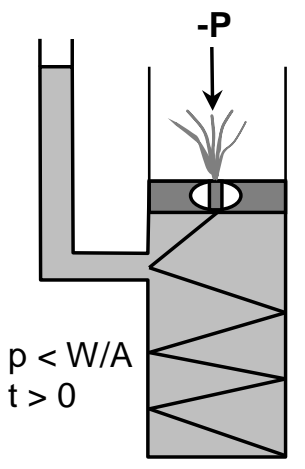

(d)

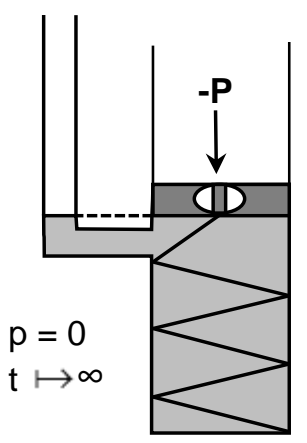

Figura 2.4 Modelo mecânico utilizado por Terzaghi

O cilindro representa uma parcela do solo analisada, e este é preenchido com água, correspondendo ao fluído localizado nos poros. A mola representa o esqueleto sólido, ou seja, os grãos. O fenômeno físico que ocorre segundo Terzaghi (1925) é o seguinte.

a) Equilíbrio estático, ou seja, não existe carregamento sobre o solo e o carregamento adicional $P$ de sobrepressão é nula.

b) Após aplicação de carga adicional, ocorre um rearranjo de grãos e da água em espaços vazios, porém não ocorre ainda o escoamento. Neste momento a fase fluída recebe todo o carregamento de $P$.

c) Inicia o escoamento da água para fora do êmbolo. A pressão no fluído diminui, enquanto que aumenta pressão sobre o esqueleto sólido.

d) Uma parte do líquido escoou até o solo adquirir equilíbrio estático. A pressão na água é nula e toda pressão é transmitida para os grãos.

\subsection{Teoria de adensamento de Biot}

A teoria de adensamento estudada pelo engenheiro belga Maurice A. Biot em 1941 foi o marco inicial, sendo a base para os estudos de poroelasticidade. O autor introduz as constantes poroelásticas, se tornando um dos principais cientistas da área. A chamada Teoria de Biot ou Teoria de Biot-Gassmann ocupa-se da relação entre as propriedades físicas e de fluidos com parâmetros sísmicos. Esta teoria descreve o comportamento acoplado entre os fluidos e sólidos em meios porosos, sendo primeiramente descrita por Biot e teve início com uma série de artigos publicados a partir de 1941. Sua primeira analogia de comportamento de distribuição de problemas 
de temperatura termoelástica, e distribuição de pressão para meios porosos saturados foram trabalhados por Geertsma (1957).

Partindo destes estudos alguns autores analisaram a mesma teoria, e propuseram algumas alterações, principalmente em relação às constantes poroelásticas. Estas mudanças visaram apenas facilitar a obtenção das constantes experimentalmente, não mudando à formação físico-matemática de Biot.

Geertsma (1966) foi um dos primeiros a estudar a teoria de Biot e a citar o termo poroelasticidade. Seus estudos consistiram nas áreas de elasticidade e viscoelasticidade de meios porosos. Durante suas análises ele observou uma similaridade nas teorias de poroelasticidade e de termoelasticidade.

Mais recentemente, a teoria de Biot foi analisada para se considerar os casos onde o comprimento da onda que se propaga no meio poro-elástico é da mesma ordem de grandeza dos tamanhos dos grãos, ou onde a hipótese de um meio estaticamente isotrópico não é devidamente atendida, resultando na teoria chamada de Biot Squirt-Flow (BISQ), segundo Ferro (2002).

Nesta dissertação são observados os aspectos fundamentais da Teoria de Biot, tendo como ponto de partida os conceitos de consolidação de Terzaghi, e da poroelasticidade, caracterizada por Biot através da expansão do adensamento de solo. Esta extensão pode ser vista em Biot (1941), onde foi incorporado o comportamento do esqueleto sólido ao processo, estendendo sua formulação para problemas relacionados a esforços e pressões nas fases sólidas e fluídicas do corpo, e os deslocamentos dos dois componentes. Os meios porosos comportam-se como duas fases distintas: uma sólida e deformável composta por partículas do solo, e outra fluida que permeia os vazios entre os grãos.

Os comportamentos dos elementos que compreendem os meios poroelásticos, podem ser descritos segundo Biot da seguinte maneira:

a) Parcela fluida: $O$ excesso de poro-pressão decorrente de transferência de parte ou da totalidade da carga ao fluido, provocando a expulsão de parte de parcela líquida, resultando em dissipação ou excesso de poro-pressão.

b) Parcela sólida: É a parcela na qual sofrem as deformações do meio, devido parte do carregamento correspondente ao excesso de poro-pressão dissipado na expulsão do fluido, ser transferido ao esqueleto (parte sólida). Este denominado como tensão efetiva. 
Portanto o fluxo decorre do excesso de poro-pressão referente a carga em que é submetido, e a deformação resultante da transferência do excesso de poropressão ao esqueleto sólido. A Figura 2.5 apresenta um esquema do fenômeno.

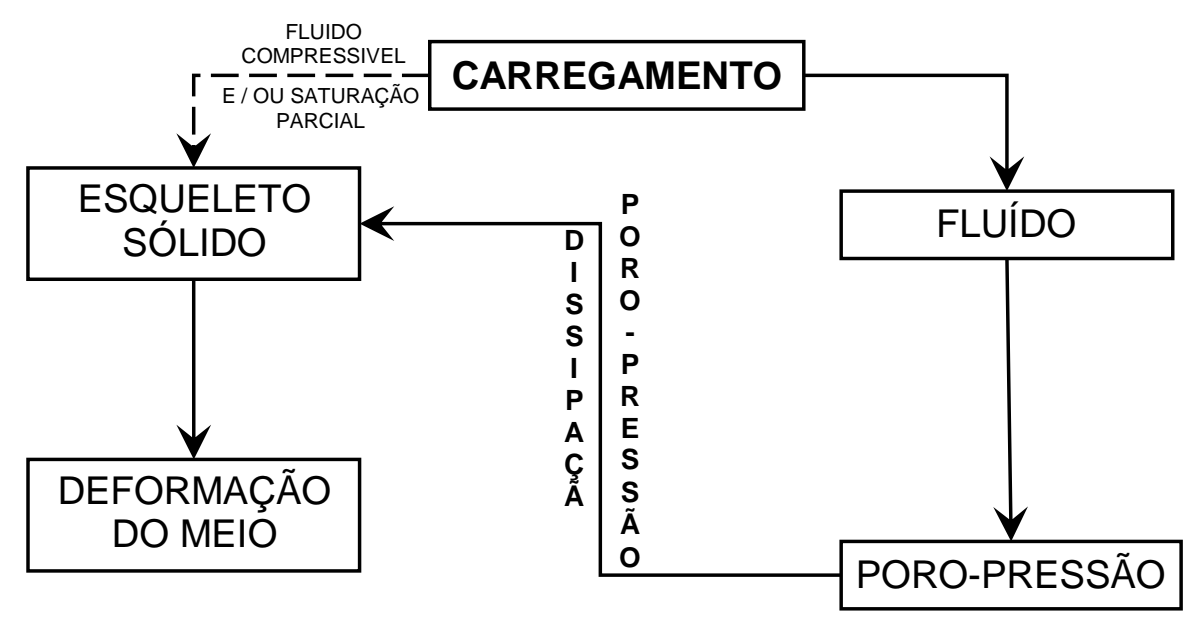

Figura 2.5 Fluxograma simplificado do fenômeno do adensamento

\subsection{Poroelasticidade de Biot acoplada à teoria de adensamento de Terzaghi}

As estruturas internas dos corpos porosos são comparáveis a um sólido homogêneo, embora em sua formação encontram-se grãos que não se encaixam totalmente, deixando espaços vazios. Os espaços podem estar totalmente cheios ou não por algum fluido como água, gás e óleo.

Estes grãos (consolidados e cimentados) são chamados de matriz, e os espaços vazios chamados de poros. Um meio poroso tem volume definido no qual pode dividir-se em dois: o volume da matriz e o volume correspondente aos poros. $A$ porosidade se define pela relação entre o volume dos poros e o volume total. Podendo ser classificada de duas maneiras: conectadas e não conectadas

$\mathrm{Na}$ teoria de poroelasticidade o meio poroso é considerado elástico linear, e consideram-se os poros totalmente ocupados por um fluído. As observações feitas para este tópico foram às mesmas considerações nos estudos de Biot (1941).

A tensão efetiva introduzida por Terzaghi $(1923,1925)$ é definida como a parte em que regula a deformação do solo ou da rocha. Esta tensão pode ser decomposta em termos, com a soma da tensão eficaz e pressão nos poros, somando-se ao coeficiente estabelecido por Biot. A tensão efetiva pode ser visto na na Eq. (2.12).

$$
\sigma_{i j}=\sigma_{i j}^{\prime}+\alpha p \delta_{i j}
$$


Onde $\sigma_{i j}$ são os componentes da tensão total, $\sigma_{i j}^{\prime}$ são os componentes da tensão efetiva, $p$ é a poro-pressão (pressão do fluido nos poros), $\delta_{i j}$ é o delta de Kronecker e $\boldsymbol{\alpha}$ é o coeficiente de Biot. Para meio isotrópico a tensão é escrita de acordo com Eq. (2.13).

$$
\sigma=\sigma^{\prime}+\alpha p
$$

Considerando que o material seja poroso isotrópico e elástico linear a relação entre o volume de deformação $\varepsilon$ e a tensão efetiva isotrópica é descrita conforme a Eq. (2.14).

$$
\varepsilon=\frac{\Delta V}{V}=-C_{m} \Delta \sigma^{\prime}=-C_{m} \Delta \sigma+C_{m} \alpha \Delta p
$$

em que $C_{m}$ indica a compressibilidade do material poroso, o inverso do seu módulo de compressão é conhecido por $C_{m}=1 / K$. A Eq. (2.14) deve estar de acordo com Eq. (2.9) apenas se $\alpha$ corresponder com Eq. (2.15).

$$
\alpha=1-C_{s} / C_{m}
$$

Esta expressão para o coeficiente de Biot geralmente é válida também para a mecânica das rochas Biot \& Willis (1956); Geertsma (1957). Coussy (2004) aplica o coeficiente para outros tipos de materiais porosos. Para solos moles o valor de $\alpha$ é próximo de 1 . Se o coeficiente for considerado com valor 1 , a tensão efetiva pode ser reduzida de acordo com Eq. (2.16).

$$
\alpha=1: \sigma_{i j}=\sigma_{i j}^{\prime}+p \delta_{i j}
$$

As equações governantes do problema poroelástico têm duas parcelas: uma parcela de fluxo e outra parcela mecânica. A parcela de fluxo é obtida combinando as equações de conservação de massa, lei de Darcy e equação de estado (análise de tensões). Para a parcela mecânica são combinadas equações de equilíbrio em termos de tensão efetivas e pressão de poros (considerando o principio da tensão efetiva de Terzaghi) e relação deslocamento-deformação, obtendo a equação de equilíbrio em termos de deslocamentos e pressão de poros. 


\subsection{Parcela de Fluxo}

\subsubsection{Equação de conservação de massa}

Para resolver problemas de fluxo em meios porosos, é preciso satisfazer o princípio físico fundamental da conservação de massa. A equação de continuidade descreve a variação de massa dentro do meio poroso devido a esse fluxo. Adotando um volume de controle de dimensões infinitesimais $\Delta x, \Delta y$ e $\Delta z$, é feito o balanço de massa nas faces do elemento para a direção $y$, utilizando o conceito de velocidade de Darcy. O caso mais geral é aquele em que ocorre a movimentação do fluído nas três direções $x, y$ e $z$. O fluído penetra no meio poroso através de uma face perpendicular a cada uma das direções e sai pela face oposta. A Figura 2.6 ilustra a movimentação do fluído na direção $y$.

Um dos princípios da teoria de consolidação considera que a massa dos dois componentes (água e partículas sólidas) deve ser conservada. A velocidade média do fluído é conhecido por $v$ e a velocidade média dos sólidos conhecido por $w$. As densidades são representadas por $\rho_{f}$ e $\rho_{s}$ respectivamente e a porosidade por $\phi$.

As equações de conservação de massa para sólidos e fluidos podem ser estabelecidas, considerando o fluxo entrando e saindo de um elemento, fixado no espaço.

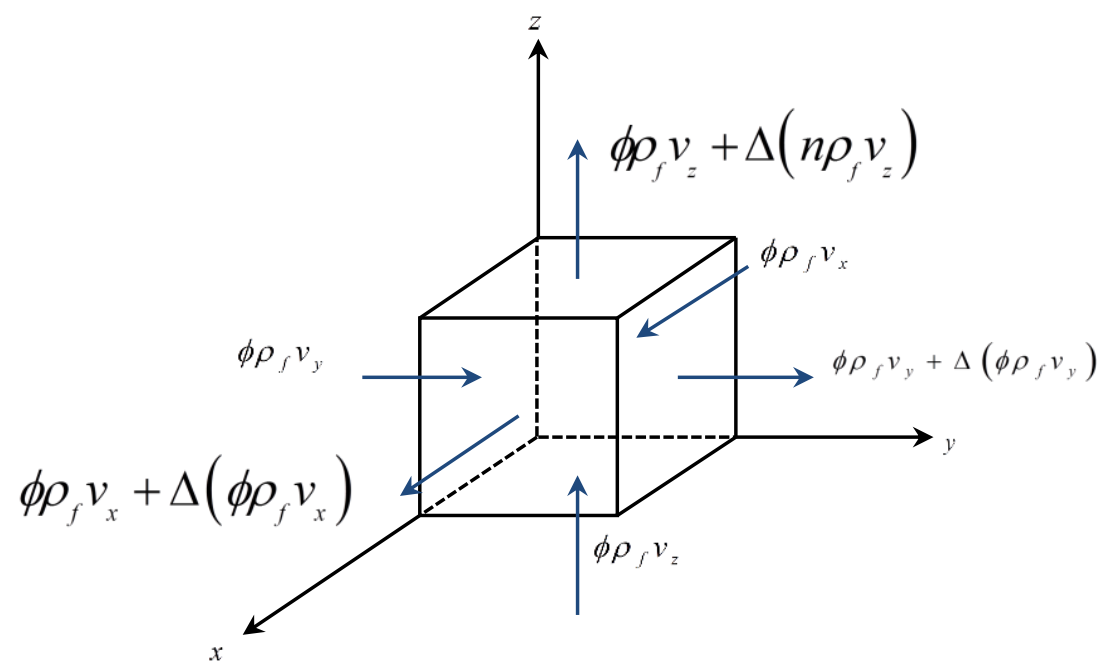

Figura 2.6 Conservação de massa para fluído

A massa do fluído para um volume $v$ é representado por $\phi \rho_{f} V$. O incremento da massa por unidade de tempo é determinado pelo fluxo de liquido ao longo da 
superfície do elemento. O fluxo flui através do lado esquerdo para o direito do elemento conduzindo uma parte do liquido para o exterior, esta formulação de variação de volume pode ser visto de acordo com Eq. (2.17).

$$
\Delta\left(\phi \rho_{f} v_{y}\right) \Delta x \Delta z=\frac{\Delta\left(\phi \rho_{f} v_{y}\right)}{\Delta y} V
$$

onde $V$ representa o volume dos elementos $V=\Delta x \Delta y \Delta z$. Este leva a seguinte equação de balanço, conforme Eq. (2.18).

$$
\frac{\partial\left(\phi \rho_{f}\right)}{\partial t}+\frac{\partial\left(\phi \rho_{f} v_{x}\right)}{\partial x}+\frac{\partial\left(\phi \rho_{f} v_{y}\right)}{\partial y}+\frac{\partial\left(\phi \rho_{f} v_{z}\right)}{\partial z}=0
$$

Usando notação vetorial esta equação pode ser escrita conforme Eq. (2.19).

$$
\frac{\partial\left(\phi \rho_{f}\right)}{\partial t}+\nabla \cdot\left(\phi \rho_{f} v\right)=0
$$

A compressibilidade do fluído pode ser expressa assumindo as equações constitutivas do fluído e pode ser visto pela Eq. (2.20).

$$
\frac{d \rho_{f}}{d p}=\rho_{f} C_{f}
$$

A Eq. (2.20) está de acordo com a definição de compressibilidade do fluído $\left(C_{f}\right)$ conforme apresentada pela Eq. (2.7). Para água pura a compressibilidade do fluído utilizada é $C_{f} \approx 0.5 \times 10^{-9} \mathrm{~m}^{2} / \mathrm{kN}$. Para um fluído que contém pequenas quantidades de um gás (qualquer tipo), a compressibilidade pode ser consideravelmente maior, e para isto deve ser considerado Eq. (2.19). Para expressar o produto da velocidade do fluído onde o gradiente de pressão é ignorado, assumindo que ambos são em pequenas quantidades, de modo que o produto é de segunda ordem, este pode ser visto na Eq. (2.21).

$$
\frac{\partial \phi}{\partial t}+\phi C_{f} \frac{\partial p}{\partial t}+\nabla \cdot(\phi v)=0
$$

O balanço das equações para a parte sólida do material é conhecido de acordo com a Eq. (2.22).

$$
\frac{\partial\left[(1-\phi) \rho_{s}\right]}{\partial t}+\nabla \cdot\left[(1-\phi) \rho_{s} w\right]=0
$$


Agora assumindo as densidades das partículas sólidas como uma função isotrópica, tensão total $\sigma$ e pressão de fluido $p$ temos a Eq. (2.23).

$$
\frac{\partial \rho_{s}}{\partial t}=\frac{\rho_{s} C_{s}}{1-\phi}\left(\frac{\partial \sigma}{\partial t}-\phi \frac{\partial p}{\partial t}\right)
$$

Esta equação está de acordo com a Eq. (2.8), onde o parâmetro $C_{s}$ é a compressibilidade das partículas sólidas. A Eq. (2.22) agora pode ser reduzida conforme a Eq. (2.24).

$$
-\frac{\partial \phi}{\partial t}+C_{s}\left(\frac{\partial \sigma}{\partial t}-\phi \frac{\partial p}{\partial t}\right)+\nabla \cdot[(1-\phi) w]=0
$$

O produto da velocidade e o gradiente de tensão ou pressão é ignorado. A derivada temporal da porosidade $\phi$ pode ser facilmente eliminada a partir das Eq. (2.24) e (2.21), conforme pode ser reescrita na Eq. (2.25).

$$
\nabla \cdot w+\nabla \cdot[\phi(v-w)]+\phi\left(C_{f}-C_{s}\right) \frac{\partial p}{\partial t}+C_{s} \frac{\partial \sigma}{\partial t}=0
$$

A fração de porosidade $\phi(v-w)$ é multiplicada pela velocidade relativa do fluído em relação aos sólidos. É basicamente isto que se pretende encontrar, o fluxo de um fluído através de um meio poroso, conhecida como a Lei de Darcy, que aqui será conhecida pela letra $q$ representada pela Eq. (2.26).

$$
q=\phi(v-w)
$$

Se o vetor de deslocamento dos sólidos é indicado por $u$ o termo $\nabla \cdot w$ pode ser escrito como $\partial \varepsilon / \partial t$, onde $\varepsilon$ é o volume da deformação, e a expressão (2.27) pode representar este termo.

$$
\varepsilon=\nabla \cdot u
$$

E equação (2.25) agora pode ser reescrita, ficando de acordo com a Eq. (2.28).

$$
\frac{\partial \varepsilon}{\partial t}+\phi\left(C_{f}-C_{s}\right) \frac{\partial p}{\partial t}+C_{s} \frac{\partial \sigma}{\partial t}=-\nabla \cdot q
$$

Uma vez que a tensão total pode ser expressa por $\sigma=\sigma^{\prime}+\alpha p$, e a tensão efetiva relativa ao volume de deformação expressa por $\sigma^{\prime}=-\varepsilon / C_{m}$, a Eq. (2.28) pode ser reescrita conforme a Eq. (2.29) em termos de equações de armazenamento. 


$$
\alpha \frac{\partial \varepsilon}{\partial t}+S \frac{\partial p}{\partial t}=-\nabla \cdot q
$$

Onde $S$ é conhecido como o coeficiente de armazenamento, representado pela Eq. (2.30).

$$
S=\phi C_{f}+(\alpha-\phi) C_{s}
$$

Esta é uma importante equação da teoria da consolidação, e admite uma interpretação heurística, ou seja, é uma abordagem para a resolução de problemas, conforme pode ser visto em (Verruijt, 2016). A compressão do solo consiste na compressão do fluído dos poros e suas partículas, expelindo certa quantidade de liquido a partir de um elemento de fluxo. A Equação (2.30) mostra na verdade a conservação da massa de fluído e sólidos, sobre as compressibilidades. Verruijt (2016) ainda completa "Ao derivar a Eq. (2.29), nota-se que ela não é completamente exata, porém todos os pressupostos são realistas. Assim as partículas sólidas e o líquido são linearmente compressíveis".

A Eq. (2.29) conhecida como equação de armazenamento pode, portanto, ser considerada como uma aproximação precisa da realidade física do problema. A forma unidimensional desta equação é considerada como de fluxo vertical único e representado pela Eq. (2.31).

$$
\alpha \frac{\partial \varepsilon}{\partial t}+S \frac{\partial p}{\partial t}=-\frac{\partial q}{\partial z}
$$

Nos trabalhos apresentados originalmente por Biot e em algumas outras pesquisas como as de Detournay e Cheng (1993) a Equação (2.29) foi reescrita de acordo com a Eq. (2.32).

$$
\frac{\partial \xi}{\partial t}=-\nabla \cdot q
$$

Onde $\partial \xi / \partial t$ representa a mudança no conteúdo do fluído (que entra ou que saí), representado pela quantidade $\nabla \cdot q$. A relação $\partial \xi / \partial t=\alpha \partial \varepsilon / \partial t+S \partial p / \partial t$ gerou a Eq. (2.29) foram estabelecidas com bases nas equações de conservação.

\subsubsection{Equação de Darcy}

Nesta etapa procura-se associar a equação da continuidade com uma lei que rege o transporte de fluido no meio poroso. Esta lei relaciona-se com a velocidade 
aparente do fluído, com os gradientes de pressão, ou mais genericamente com os gradientes de potencial, através da Eq. (2.33).

$$
q=-\frac{k}{\mu}\left(\nabla p-\rho_{f} g\right)
$$

Onde $k$ é a permeabilidade do material poroso, e tem relação com o tamanho dos poros, $\mu$ é a viscosidade do fluído e $g$ o vetor de gravidade. Como uma primeira aproximação, pode-se considerar que a permeabilidade $k$ é proporcional ao quadrado do tamanho da partícula. Se o sistema de coordenadas está disposto de tal maneira que o eixo $Z$, está apontado na direção vertical para cima, conforme a Figura 2.6, os componentes de gravidade são $g_{x}=0, g_{y}=0$ e $g_{z}=-g$, portanto a Lei de Darcy pode ser escrita conforme a Eq. (2.34).

$$
q_{x}=-\frac{k}{\mu} \frac{\partial p}{\partial x}, q_{y}=-\frac{k}{\mu} \frac{\partial p}{\partial y} \text { e } q_{z}=-\frac{k}{\mu}\left(\frac{\partial p}{\partial x}+\rho_{f} g\right)
$$

O produto $\rho_{f} g$ pode ser escrito como $\gamma_{f}$ conhecido como peso volumétrico do fluído. Na mecânica dos solos o uso do Coeficiente de Darcy é muitas vezes expressar os termos de condutividade hidráulica, também denominada por $\mathrm{k}$ em vez de permeabilidade $k$. Esta condutividade (por vezes designado como coeficiente de permeabilidade) é definida pela expressão (2.35).

$$
\mathrm{k}=\frac{k \rho_{f} g}{\mu}
$$

Portando a Lei de Darcy também pode ser reescrita conforme Eq. (2.36).

$$
q_{x}=-\frac{\mathrm{k}}{\gamma_{f}} \frac{\partial p}{\partial x}, q_{y}=-\frac{\mathrm{k}}{\gamma_{f}} \frac{\partial p}{\partial y} \text { e } q_{z}=-\frac{\mathrm{k}}{\gamma_{f}}\left(\frac{\partial p}{\partial z}+\gamma_{f}\right)
$$

A partir destas equações tem-se Eq. (2.37).

$$
\nabla \cdot q=\frac{\partial q_{x}}{\partial x}+\frac{\partial q_{y}}{\partial y}+\frac{\partial q_{z}}{\partial z}=-\nabla \cdot\left(\frac{\mathrm{k}}{\gamma_{f}} \nabla p\right)
$$

Substituindo Eq. (2.37) na Eq. (2.29) que serve para validar a Lei de Darcy, já que ambas as equações descrevem as mesmas situações, a Eq. (2.38) então pode ser considerada com mais precisão. 


$$
\alpha \frac{\partial \varepsilon}{\partial t}+S \frac{\partial p}{\partial t}=\nabla \cdot\left(\frac{\mathrm{k}}{\gamma_{f}} \nabla p\right)
$$

Para o caso unidimensional de fluxo vertical, a Eq. (2.38) reduz para Eq. (2.39).

$$
\alpha \frac{\partial \varepsilon}{\partial t}+S \frac{\partial p}{\partial t}=\frac{\partial}{\partial z}\left(\frac{\mathrm{k}}{\gamma_{f}} \frac{\partial p}{\partial z}\right)
$$

No caso de material homogêneo a condutividade hidráulica $\mathbf{k}$, o peso volumétrico do fluído $\gamma_{f}$ pode ser considerado como constante. Portanto a Eq. (2.38) agora é reduzida para Eq. (2.40).

$$
\alpha \frac{\partial \varepsilon}{\partial t}+S \frac{\partial p}{\partial t}=\frac{\mathrm{k}}{\gamma_{f}} \nabla^{2} p
$$

Onde o operador $\nabla^{2}$ é definido conforme a Eq. (2.41).

$$
\nabla^{2}=\frac{\partial^{2}}{\partial x^{2}}+\frac{\partial^{2}}{\partial y^{2}}+\frac{\partial^{2}}{\partial z^{2}}
$$

\subsubsection{Equação de Estado}

A análise de tensões é realizada no cálculo de porosidade e variação de massa específica do fluído devido variação de pressão. Neste caso considera-se a tensão de tração como sendo positiva. A análise de tensão é inserida através da variação da porosidade no tempo. O aumento da massa de fluído pode ser escrito de acordo com a Eq. (2.42).

$$
\frac{\partial m}{\partial t}=\frac{\partial \phi}{\partial t} \rho_{0}+\frac{\partial \rho}{\partial t} \phi_{0}
$$

Onde, $\rho_{0}$ é a massa específica do fluído e $\phi_{0}$ a porosidade em um instante de referência. O termo $(\partial \phi / \partial t) \rho_{0}$ corresponde à variação da massa de fluído, associada ao aumento do volume poroso, e $(\partial \rho / \partial t) \phi_{0}$ corresponde à expansão do fluído. A variação do volume poroso $\left(\Delta \phi=\phi-\phi_{0}\right)$ pode ser decomposta em duas partes. A primeira corresponde a variação volumétrica do esqueleto conforme a Eq. (2.43). 


$$
\left(\frac{\Delta V}{V}\right)=\Delta \varepsilon_{V}=m^{T} \Delta \varepsilon
$$

A segunda parte é uma variação do volume dos grãos, onde o comportamento elástico para os grãos durante o cálculo da variação volumétrica sem carregamento precisou ser também decomposto para que se pudesse ter um melhor entendimento:

a) Parte 1 corresponde ao incremento de tensão efetiva de Terzaghi conforme Eq. (2.44).

$$
\left(\Delta \sigma_{I}=\Delta \sigma+m \Delta p\right)
$$

b) Parte 2 corresponde ao incremento $\Delta p$ de pressão confinante e da pressão de poros.

Para a parte 1, tem se a Eq. (2.45).

$$
\left(\frac{\Delta V_{s}}{V}\right)_{1}=\frac{1}{3 k_{s}} m^{T}(\Delta \sigma+m \Delta p)
$$

Sabe-se que a tensão efetiva é igual a Eq. (2.46).

$$
\sigma=\sigma^{\prime}-\left(m-\frac{D_{T} m}{3 k_{s}}\right) p
$$

É aplicada relação constitutiva para considerar tensão efetiva e deformação da parte sólida (esqueleto) independente da pressão dos poros $p_{0}$, representada conforme Eq. (2.47).

$$
\sigma^{\prime}=D\left(\varepsilon-\varepsilon_{0}\right)+\sigma_{0}^{\prime}
$$

Substituindo a Eq. (2.46) na Eq. (2.45), obtém-se Eq. (2.48).

$$
\left(\frac{\Delta V_{s}}{V}\right)=\frac{1}{3 k_{s}} m^{T} \Delta \sigma^{\prime}+\frac{1}{9 k_{s}{ }^{2}} m^{T} D_{T} m \Delta p
$$

Substituindo Eq. (2.47) na Eq. (2.48), tem-se Eq. (2.49).

$$
\left(\frac{\Delta V_{s}}{V}\right)=\frac{1}{3 k_{s}} m^{T} D_{T} \Delta \varepsilon+\frac{1}{9 k_{s}^{2}} m^{T} D_{T} m \Delta p
$$

Para a parte 2, correspondendo à pressão e poro-pressão tem-se Eq. (2.50).

$$
\left(\frac{\Delta V_{s}}{V}\right)_{2}=-\frac{\left(1-\phi_{0}\right)}{k_{s}} \Delta p
$$


Acrescentando as partes 1 e 2 obtém-se a variação volumétrica dos grãos, apresentada na Eq. (2.51).

$$
\left(\frac{\Delta V_{s}}{V}\right)=\left(\frac{\Delta V_{s}}{V}\right)_{1}+\left(\frac{\Delta V_{s}}{V}\right)_{2}
$$

Ou seja

$$
\left(\frac{\Delta V_{s}}{V}\right)=\frac{1}{3 k_{s}} m^{T} D_{T} \Delta \varepsilon+\frac{1}{9 k_{s}^{2}} m^{T} D_{T} m \Delta p-\frac{\left(1-\phi_{0}\right)}{k_{s}} \Delta p
$$

A variação do volume poroso é obtida com base na variação do volume do esqueleto subtraída da expansão dos grãos, conforme a Eq. (2.53).

$$
\Delta \phi=\left(\frac{\Delta V}{V}\right)-\left(\frac{\Delta V_{s}}{V}\right)
$$

Onde, a variação do volume pode ser representada pelas Eq. (2.54) e Eq. (2.55).

$$
\begin{aligned}
& \Delta \phi=\left[m^{T}-\frac{1}{3 k_{s}} m^{T} D_{T}\right] \Delta \varepsilon+\left[\frac{\left(1-\phi_{0}\right)}{k_{s}}-\frac{1}{9 k_{s}^{2}} m^{T} D_{T} m\right] \Delta p \\
& \frac{\Delta \phi}{\partial t}=\left[m^{T}-\frac{1}{3 k_{s}} m^{T} D_{T}\right] \frac{\partial \varepsilon}{\partial t}+\left[\frac{\left(1-\phi_{0}\right)}{k_{s}}-\frac{1}{9 k_{s}^{2}} m^{T} D_{T} m\right] \frac{\partial p}{\partial t}
\end{aligned}
$$

A expressão volumétrica do fluído $(\partial p / \partial t)_{\phi_{0}}$ pode ser calculada pela Eq. (2.56).

$$
\frac{\partial \rho}{\partial t} \phi_{0}=\rho_{0} \frac{\phi_{0}}{k_{f}} \frac{\partial p}{\partial t}
$$

Onde, $k_{f}$ é o módulo de bulk do fluído. Substituindo a Eq. (2.42) pelas Eq. (2.55) e Eq. (2.56) temos Eq. (2.57).

$$
\frac{\partial m}{\partial t}=\rho_{0}\left[m^{T}-\frac{1}{3 k_{s}} m^{T} D_{T}\right] \frac{\partial \varepsilon}{\partial t}+\rho_{0}\left[\frac{\left(1-\phi_{0}\right)}{k_{s}}+\frac{\phi_{0}}{k_{f}}-\frac{1}{9 k_{s}^{2}} m^{T} D_{T} m\right] \frac{\partial p}{\partial t}
$$


E por último basta considerar a análise das tensões, substituindo a Eq. (2.57) na equação da continuidade Eq. (2.36), e assim obtendo a equação de fluxo, correspondente a Eq. (2.58).

$$
\begin{aligned}
& {\left[m^{T}-\frac{1}{3 k_{s}} m^{T} D_{T}\right] \frac{\partial \varepsilon}{\partial t}+\left[\frac{\left(1-\phi_{0}\right)}{k_{s}}+\frac{\phi_{0}}{k_{f}}-\frac{1}{9 k_{s}^{2}} m^{T} D_{T} m\right] \frac{\partial p}{\partial t}} \\
& -\nabla^{T}\left(\frac{1}{\mu} k \nabla(p+\rho g h)\right)=0
\end{aligned}
$$

\subsection{Parcela Mecânica}

Os solos são constituídos por partículas, e suas forças são transmitidas de partícula a partícula e suportadas pelos fluídos nos espaços vazios. A transmissão de esforços entre partículas ocorrem através das chamadas partículas granulares, onde a transmissão é através do contato direto grão a grão, ou por partículas de argila, por exemplo para solos moles, em que a transmissão se dá por áreas muito reduzidas. Ao longo de um plano horizontal no solo tem-se esforços decompostos em componentes normais e tangenciais. Na Figura 2.7 pode-se observar o efeito de variações de tensão (deformação e resistência ao cisalhamento) a que são submetidas às partículas, devido variação de tensão efetiva do solo. A tensão efetiva é associada ao deslocamento relativo das partículas do solo.

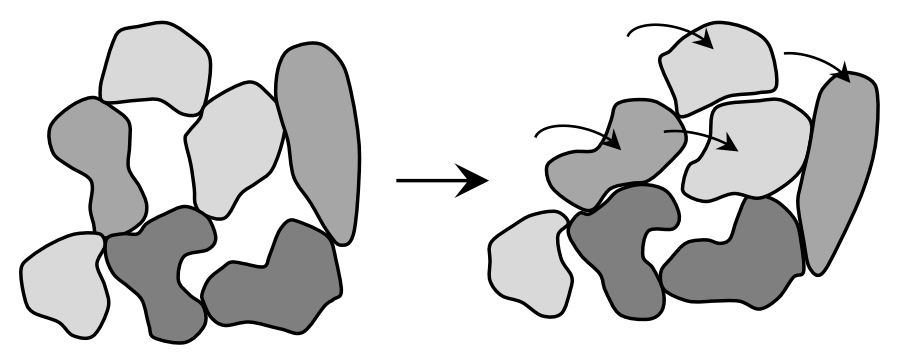

Figura 2.7 Deslocamento dos grãos

\subsubsection{Equação de Equilíbrio}

As equações de equilíbrio podem ser estabelecidas considerando as tensões agindo nas faces dos elementos de volume do cubo conforme mostra a Figura 2.8. Somente as componentes da direção $y$ são indicadas. Suas tensões correspondem com as características de deformabilidade e resistência ao cisalhamento. As equações de equilíbrio nas três coordenadas podem ser vistos na Eq. (2.59). 


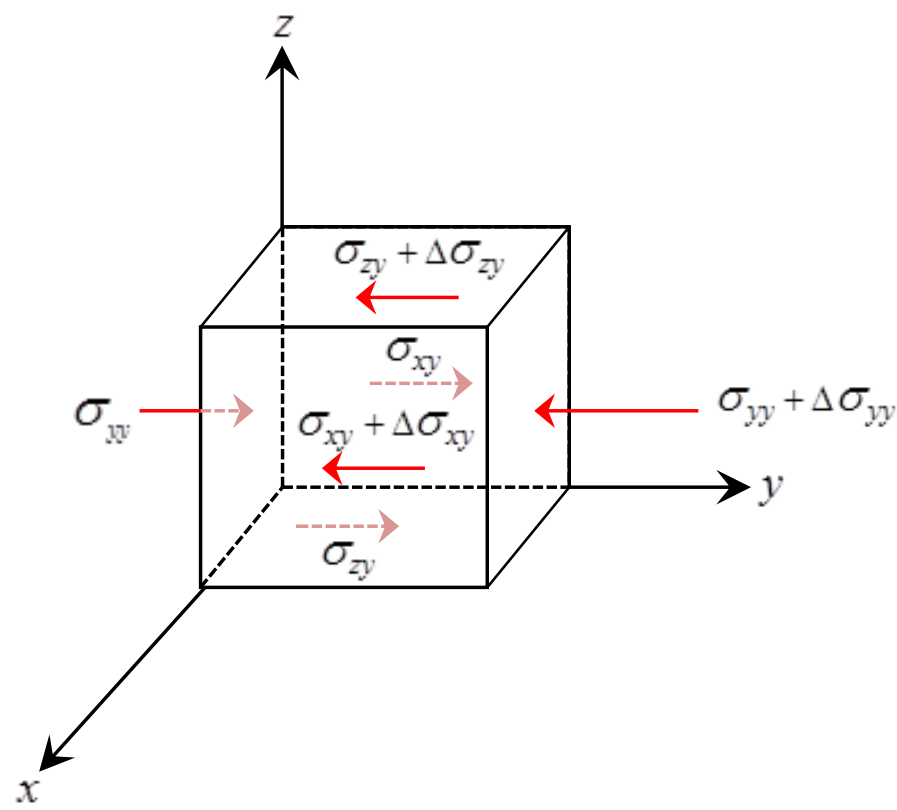

Figura 2.8Equilíbrio dos elementos

$$
\begin{aligned}
& \frac{\partial \sigma_{x x}}{\partial x}+\frac{\partial \sigma_{y x}}{\partial y}+\frac{\partial \sigma_{z x}}{\partial z}-f_{x}=0 \\
& \frac{\partial \sigma_{x y}}{\partial x}+\frac{\partial \sigma_{y y}}{\partial y}+\frac{\partial \sigma_{z y}}{\partial z}-f_{y}=0 \\
& \frac{\partial \sigma_{x z}}{\partial x}+\frac{\partial \sigma_{y z}}{\partial y}+\frac{\partial \sigma_{z z}}{\partial z}-f_{z}=0
\end{aligned}
$$

Onde $f_{x}, f_{y}$ e $f_{z}$ são os componentes das forças de corpo. Além destas equações de equilíbrio, existem também as equações de equilíbrio de momento, devido haver uma simetria entre os tensores, conforme Eq. (2.60).

$$
\sigma_{x y}=\sigma_{y x}, \quad \sigma_{y z}=\sigma_{z y}, \quad \sigma_{z x}=\sigma_{x z}
$$

As tensões nas Eq. (2.59) e (2.60) são as tensões normais. Estas são consideradas positivas para compressão, prática usualmente utilizada na mecânica dos solos. Os princípios de tensões totais em relação à tensão efetiva dos princípios de Terzaghi apresentados na Eq. (2.12) são aplicados agora com as tensões normais de acordo com a Eq. (2.61).

$$
\begin{array}{lll}
\sigma_{x x}=\sigma_{x x}^{\prime}+\alpha p, & \sigma_{x y}=\sigma_{x y}^{\prime}, & \sigma_{x z}=\sigma_{x z}^{\prime} \\
\sigma_{y y}=\sigma_{y y}^{\prime}+\alpha p, & \sigma_{y z}=\sigma_{y z}^{\prime}, & \sigma_{y x}=\sigma_{y x}^{\prime} \\
\sigma_{z z}=\sigma_{z z}^{\prime}+\alpha p, & \sigma_{z x}=\sigma_{z x}^{\prime}, & \sigma_{z y}=\sigma_{z y}^{\prime}
\end{array}
$$


Observa-se que as tensões de cisalhamento são transmitidas pelo esqueleto do sólido. Isto pode parecer violar as suposições consideradas pela Lei de Darcy, onde o cisalhamento é transmitido entre as partículas sólidas e fluídicas. Porém Polubarinova-Kochina (1962) demonstra que as tensões de cisalhamento são muito pequenas em comparação aos níveis de tensão normal do solo, e isto justificaria o fator das tensões de cisalhamento entre o fluído e as partículas sólidas, não serem consideradas nas equações de equilíbrio do solo como um todo.

As tensões efetivas são determinadas conforme a deformação do solo. Podendo ser observado na Eq. (2.62).

$$
\begin{aligned}
& \sigma_{x x}^{\prime}=-\left(K-\frac{2}{3} G\right) \varepsilon-2 G \varepsilon_{x x}, \quad \sigma_{x y}^{\prime}=-2 G \varepsilon_{x y}, \quad \sigma_{x z}^{\prime}=-2 G \varepsilon_{x z} \\
& \sigma_{y y}^{\prime}=-\left(K-\frac{2}{3} G\right) \varepsilon-2 G \varepsilon_{y y}, \quad \sigma_{y z}^{\prime}=-2 G \varepsilon_{y z}, \quad \sigma_{y x}^{\prime}=-2 G \varepsilon_{y x} \\
& \sigma_{z z}^{\prime}=-\left(K-\frac{2}{3} G\right) \varepsilon-2 G \varepsilon_{z z}, \quad \sigma_{z x}^{\prime}=-2 G \varepsilon_{z x}, \quad \sigma_{z y}^{\prime}=-2 G \varepsilon_{z y}
\end{aligned}
$$

Onde $K$ e $G$ são os coeficientes elásticos do material, ou seja, são os módulos de compressão e módulos de cortes respectivamente. Os componentes do tensor de tensão para este caso é representado pela variável $\sigma$.

\subsubsection{Relação deformação-Deslocamento}

O volume de tensão $\varepsilon$ é definido por $\varepsilon=\varepsilon_{x x}+\varepsilon_{y y}+\varepsilon_{z z}$. Na mecânica dos meios contínuos o coeficiente elástico é frequentemente representador como $\lambda$ e $\mu$ , conhecidas como constantes de Lamé. A relação com $K$ e $G$ são representadas por (2.63).

$$
\lambda=K-\frac{2}{3} G, \quad G=\mu
$$

O módulo de compressão (módulo de Bulk) $K$ é 0 inverso da compressibilidade $C_{m}$ do meio poroso, ou seja $K=1 / C_{m}$.

Os componentes das tensões são relacionadas com os componentes dos deslocamentos pela compatibilidade das equações, representados pela Eq. (2.64). 


$$
\begin{array}{lll}
\varepsilon_{x x}=\frac{\partial u_{x}}{\partial x}, & \varepsilon_{x y}=\frac{1}{2}\left(\frac{\partial u_{x}}{\partial y}+\frac{\partial u_{y}}{\partial x}\right), & \varepsilon_{x z}=\frac{1}{2}\left(\frac{\partial u_{x}}{\partial z}+\frac{\partial u_{z}}{\partial x}\right) \\
\varepsilon_{x x}=\frac{\partial u_{y}}{\partial y}, & \varepsilon_{y z}=\frac{1}{2}\left(\frac{\partial u_{y}}{\partial z}+\frac{\partial u_{z}}{\partial y}\right), & \varepsilon_{y x}=\frac{1}{2}\left(\frac{\partial u_{y}}{\partial x}+\frac{\partial u_{x}}{\partial y}\right) \\
\varepsilon_{z z}=\frac{\partial u_{z}}{\partial z}, & \varepsilon_{z x}=\frac{1}{2}\left(\frac{\partial u_{z}}{\partial x}+\frac{\partial u_{x}}{\partial z}\right), & \varepsilon_{x y}=\frac{1}{2}\left(\frac{\partial u_{z}}{\partial y}+\frac{\partial u_{y}}{\partial z}\right)
\end{array}
$$

O sistema de equações pode ser simplificado considerando a eliminação da tensão e deformação, resultando em uma equação de equilíbrio para deslocamentos de materiais homogêneos, considerando $K$ e $G$ como constantes. Estas equações simplificadas estão conforme Eq. (2.65).

$$
\begin{aligned}
& \left(K+\frac{1}{3} G\right) \frac{\partial \varepsilon}{\partial x}+G \nabla^{2} u_{x}-\alpha \frac{\partial p}{\partial x}+f_{x}=0 \\
& \left(K+\frac{1}{3} G\right) \frac{\partial \varepsilon}{\partial y}+G \nabla^{2} u_{y}-\alpha \frac{\partial p}{\partial y}+f_{y}=0 \\
& \left(K+\frac{1}{3} G\right) \frac{\partial \varepsilon}{\partial z}+G \nabla^{2} u_{z}-\alpha \frac{\partial p}{\partial z}+f_{z}=0
\end{aligned}
$$

Onde o volume de tensão $\mathcal{E}$ pode ser expressado pela Eq. (2.66).

$$
\varepsilon=\frac{\partial u_{x}}{\partial x}+\frac{\partial u_{y}}{\partial y}+\frac{\partial u_{z}}{\partial z}
$$

O sistema completo de equações diferenciais consiste na equação de armazenamento conforme a Eq. (2.38), e nas equações de equilíbrio de acordo com a Eq. (2.65). Estas são quatro equações com quatro variáveis são elas $p, \boldsymbol{u}_{x}, \boldsymbol{u}_{y}$ e $u_{z}$

Pode-se notar que o volume de volume $\varepsilon$ não é uma variável independente, conforme pode ser visto na Eq. (2.66). 


\section{CONSTANTES DE COMPORTAMENTO POROELÁSTICO}

Estas constantes relacionam-se principalmente com a parte volumétrica de um material poroso isotrópico e linear. As descrições destes materiais tem sido objeto de muitas formulações diferentes, e estas aqui apresentadas seguem os padrões de Detournay e Cheng (1993). As relações para apresentação destas constantes foram tratadas em meio totalmente completo por fluído, onde as contribuições individuais das partes sólidas e líquidas são obtidas a partir de formulações micromecânicas.

Para um domínio de baixa frequência, pode ser visto o estudo detalhado em Bonnet e Auriault (1985) com caracterização de domínios saturados e deformação do meio poroso. Já para alta frequência pode ser encontrado estudo em Biot (1956b). A seguir, são apresentadas algumas das constantes do contínuo poroelástico, e a descrição dos testes laboratoriais que as caracterizam, podem ser vistos em Rice e Cleary (1976).

\subsection{Módulo de elasticidade Linear $(E)$}

Módulo de elasticidade ou módulo de Young mede a relação tensão deformação obtida em um teste de tração ou compressão. Para pequenos valores de tensão e deformação, esta relação pode ser considerada constante (materiais homogêneos e isotrópicos) conforme a Eq. (3.1).

$$
E=\frac{\sigma_{11}}{\varepsilon_{11}}=\frac{\sigma_{22}}{\varepsilon_{22}}=\frac{\sigma_{33}}{\varepsilon_{33}}
$$

O módulo de elasticidade das rochas ou solos podem ser obtidos através de testes de compressão uniaxial, consistindo na aplicação de uma força de compressão na amostra sob condições drenadas, permitindo a livre entrada e/ou saída de fluído da amostra, com isso não há variação de pressão no poro. Portanto é feito a medição da deformação pela aplicação de carga inserida, tais medidas são obtidas na direção da carga.

O módulo de Young possui dimensão de tensão e no Sistema Internacional, sua unidade de medida é o Pascal $(\mathrm{Pa})$. Os valores normalmente encontrados para os Módulos de Young das rochas estão na faixa de $2 \times 10^{10}$ a $4 \times 10^{10} \mathrm{~Pa}$. 


\subsection{Módulo de Cisalhamento $(G)$}

Conhecido como módulo de cisalhamento, módulo de corte, módulo de elasticidade angular ou módulo de rigidez, mede a relação entre uma tensão de cisalhamento e a deformação angular por ela produzida, ou seja, para o estado plano de deformação ele pode ser escrito conforme a Eq. (3.2).

$$
G=\frac{\sigma_{12}}{2 \varepsilon_{12}}=\frac{\sigma_{21}}{2 \varepsilon_{21}}
$$

O módulo de cisalhamento relaciona-se ainda com os módulos de elasticidade linear e Poisson drenado, podendo ser visto de acordo com a Eq. (3.3).

$$
G=\frac{E}{2(1+v)}
$$

Para obter o valor do módulo de cisalhamento, basta que seja aplicada uma tensão de cisalhamento a um corpo de prova sob condições drenadas, e medir a deformação angular decorrente. No Sistema Internacional, terá como unidade o Pascal $(P a)$ e seus valores em situações reais para as rochas estão na faixa entre $7 \times 10^{9}$ a $1,7 \times 10^{10}(\mathrm{~Pa})$

\subsection{Coeficiente de Poisson $(v)$}

O coeficiente de Poisson mede a relação entre as deformações transversais e longitudinais, em relação à direção do carregamento em um teste de tração uniaxial. Esta expressão pode ser vista conforme a Eq. (3.4).

$$
v=-\frac{\varepsilon_{22}}{\varepsilon_{11}}
$$

Para se obter o valor do módulo de Poisson em laboratório, aplica-se uma compressão uniaxial na amostra sob condições drenadas, e mede-se as deformações na direção do carregamento, e na direção perpendicular do mesmo. Estes valores são obtidos em grandezas unidimensionais, e seus valores estão entre 0 e 0,5 . $O$ limite superior é atingido por materiais incompressíveis. Valores típicos para o módulo de Poisson das rochas encontram-se na faixa de 0,15 a 0,45. 


\subsection{Coeficiente de Poisson não drenado $\left(v_{u}\right)$}

Assim como para o coeficiente de Poisson, o coeficiente de Poisson drenado também mede a relação entre a deformação transversal e a deformação longitudinal em um teste de tração uniaxial. A diferente entre eles é que para o Poisson não drenado, não é permitido um fluxo de fluido para dentro ou para fora da amostra (por isso a titulação de não drenado). O valor para este coeficiente não drenado é no máximo de 0,5. Este limite é atingido quando ambos os constituintes da amostra (sólido e liquido) são incompressíveis. E o limite inferior é atingido quando o fluido dos poros é altamente compressível. Ambos os coeficientes de Poisson e Poisson drenado são exclarecidos em detalhes em Skempton (1954).

\subsection{Coeficiente de Skempton $(B)$}

O coeficiente de Skempton também conhecido como coeficiente de pressão de poro, mede a relação entre uma variação de pressão de poro e a variação de tensão hidrostática na amostra, sob condições não drenadas. Esta formulação é apresentada detalhadamente em Skempton (1954), e o coeficiente de Skempton é dado pela Eq. (3.5).

$$
B=-\frac{3 \Delta p}{\Delta \sigma_{k k}}
$$

Valendo a notação indicial, índices repetidos significam um somatório. Para obtenção do valor do coeficiente de Skempton em laboratório, deve-se aplicar uma tensão hidrostática a uma amostra e, sob condições não drenadas, medir a variação de pressão de poro correspondente. Este coeficiente é uma grandeza adimensional, e seu valor está entre 0 e 1. Para o valor máximo, o limite é atingido por materiais cujos constituintes sejam incompressíveis, já para o limite inferior, quando o fluido dos poros é altamente compressível.

\subsection{Coeficientes de Biot $(\alpha)$ e $(R)$}

Os coeficientes de Biot são módulos volumétricos drenados e medem a relação entre a tensão hidrostática aplicada e a variação volumétrica decorrente por unidade de volume do material. 
A tensão efetiva de Biot $(\alpha)$ é descrita em detalhes em Biot (1956르 e 1956b) e pode ser visto conforme a Eq. (3.6).

$$
\alpha=\frac{3\left(v_{u}-v\right)}{B(1-2 v)\left(1+v_{u}\right)}
$$

E $R$, conhecido como o coeficiente constitutivo poroelástico apresentado por Biot e Willis (1956) conforme expresso pela Eq. (3.7).

$$
R=\frac{2 \phi^{2} G B^{2}(1-2 v)\left(1+v_{u}\right)^{2}}{9\left(v_{u}-v\right)\left(1-2 v_{u}\right)}
$$

\subsection{Coeficiente de permeabilidade $(\kappa)$}

O coeficiente de permeabilidade $(\kappa)$ mede o grau de resistência oferecido por um material poroso em relação à passagem de um determinado fluido. Ou seja, pode ser a relação entre o diferencial de pressão aplicado a uma amostra de rocha e a vazão de fluído correspondente. A permeabilidade depende das características da rocha, principalmente da porosidade dos canais que unem os poros e da viscosidade do fluído, esta relação pode ser vista na Eq. (3.8).

$$
\kappa=\frac{\lambda}{\mu}
$$

Onde a permeabilidade intrínseca é $\lambda=2 v G / 1-2 v$ e $\mu=G$ é a viscosidade do fluído. Ela pode variar muito, pois depende da rocha e dos fluidos nela contidos. Para se medir a permeabilidade de uma rocha a um determinado fluido, satura-se esta rocha, e aplica-se um diferencial de pressão sobre a amostra, e mede-se a vazão de fluido decorrente. No Sistema Internacional, a permeabilidade é medida em metro2/Pascal/segundo $\left(\mathrm{m}^{2} / \mathrm{Pa} / \mathrm{s}\right)$.

\subsection{Tabela de constantes poroelásticos}

A Tabela 1 foi apresentada por Detournay e Cheng (1993), esta apresenta as parcelas micromecânicas do contínuo poroelástico para alguns tipos de rochas. Estas caracterizações são provenientes de estudos feitos por testes laboratoriais de Rice e Cleary (1976). Os parâmetros de permeabilidade $\left(K_{u}\right)$, Poisson não drenado $\left(v_{u}\right)$, 
coeficiente de Skempton $(B)$ e compressibilidade do solo $(C)$ são dependentes do fluído, e para este efeito o utilizado foi $K_{f}=3,3 \times 10^{3} \mathrm{MPa}$. Estas análises micromecânicas assim como feito por Rice e Cleary (1976), também podem ser encontradas em Fatt (1958) e Yew et al. (1979), onde a ideia básica consistiu em demostrar as amplas variações de constantes poroelásticas que podem ser encontradas.

Tabela 1 - Constantes poroelásticas para vários materiais

\begin{tabular}{|c|c|c|c|c|c|}
\hline & $\begin{array}{c}\text { Arenito de } \\
\text { Ruhr }\end{array}$ & $\begin{array}{c}\text { Mármore do } \\
\text { Tennessee }\end{array}$ & $\begin{array}{l}\text { Granito } \\
\text { Carvão } \\
\text { Vegetal }\end{array}$ & $\begin{array}{c}\text { Arenito de } \\
\text { Berea }\end{array}$ & $\begin{array}{l}\text { Granito } \\
\text { d'Oeste }\end{array}$ \\
\hline$G\left(N / m^{2}\right)$ & $1.3 \times 10^{10}$ & $2.4 \times 10^{10}$ & $1.9 \times 10^{10}$ & $6.0 \times 10^{9}$ & $1.5 \times 10^{10}$ \\
\hline$v$ & 0.12 & 0.25 & 0.27 & 0.20 & 0.25 \\
\hline$v_{u}$ & 0.31 & 0.27 & 0.30 & 0.33 & 0.34 \\
\hline$K\left(N / m^{2}\right)$ & $1.3 \times 10^{10}$ & $4.0 \times 10^{10}$ & $3.5 \times 10^{10}$ & $8.0 \times 10^{9}$ & $2.5 \times 10^{10}$ \\
\hline$K_{u}\left(N / m^{2}\right)$ & $3.0 \times 10^{10}$ & $4.4 \times 10^{10}$ & $4.1 \times 10^{10}$ & $1.6 \times 10^{10}$ & $4.2 \times 10^{10}$ \\
\hline$B$ & 0.88 & 0.51 & 0.55 & 0.62 & 0.85 \\
\hline$c\left(m^{2} / s\right)$ & $5.3 \times 10^{-3}$ & $1.3 \times 10^{-5}$ & $7.0 \times 10^{-6}$ & $1.6 \times 10^{0}$ & $2.2 \times 10^{-5}$ \\
\hline$\eta$ & 0.28 & 0.08 & 0.08 & 0.30 & 0.16 \\
\hline$\alpha$ & 0.65 & 0.19 & 0.27 & 0.79 & 0.47 \\
\hline$K_{s}\left(N / m^{2}\right)$ & $3.6 \times 10^{10}$ & $5.0 \times 10^{10}$ & $4.5 \times 10^{10}$ & $3.6 \times 10^{10}$ & $4.5 \times 10^{10}$ \\
\hline$\phi$ & 0.02 & 0.02 & 0.02 & 0.19 & 0.01 \\
\hline \multirow[t]{2}{*}{$k(m d)$} & $2.0 \times 10^{-1}$ & $1.0 \times 10^{-4}$ & $1.0 \times 10^{-4}$ & $1.9 \times 10^{2}$ & $4.0 \times 10^{-4}$ \\
\hline & $\begin{array}{c}\text { Arenito de } \\
\text { Weber }\end{array}$ & $\begin{array}{l}\text { Arenito } \\
\text { d'Ohio }\end{array}$ & $\begin{array}{l}\text { Arenito de } \\
\text { Pecos }\end{array}$ & $\begin{array}{l}\text { Arenito de } \\
\text { Boise }\end{array}$ & \\
\hline$G\left(N / m^{2}\right)$ & $1.2 \times 10^{10}$ & $6.8 \times 10^{9}$ & $5.9 \times 10^{9}$ & $4.2 \times 10^{9}$ & \\
\hline$v$ & 0.15 & 0.18 & 0.16 & 0.15 & \\
\hline$v_{u}$ & 0.29 & 0.28 & 0.31 & 0.31 & \\
\hline$K\left(N / m^{2}\right)$ & $1.3 \times 10^{10}$ & $8.4 \times 10^{9}$ & $6.7 \times 10^{9}$ & $4.6 \times 10^{9}$ & \\
\hline$K_{u}\left(N / m^{2}\right)$ & $2.5 \times 10^{10}$ & $1.3 \times 10^{10}$ & $1.4 \times 10^{10}$ & $8.3 \times 10^{9}$ & \\
\hline B & 0.73 & 0.50 & 0.61 & 0.50 & \\
\hline$c\left(m^{2} / s\right)$ & $2.1 \times 10^{-2}$ & $3.9 \times 10^{-2}$ & $5.4 \times 10^{-3}$ & $4.0 \times 10^{-1}$ & \\
\hline$\eta$ & 0.26 & 0.29 & 0.34 & 0.35 & \\
\hline$\alpha$ & 0.64 & 0.74 & 0.83 & 0.85 & \\
\hline$K_{s}\left(N / m^{2}\right)$ & $3.6 \times 10^{10}$ & $3.1 \times 10^{10}$ & $3.9 \times 10^{10}$ & $4.2 \times 10^{10}$ & \\
\hline$\phi$ & 0.06 & 0.19 & 0.20 & 0.26 & \\
\hline$k(m d)$ & $1.0 \times 10^{0}$ & $5.6 \times 10^{0}$ & $8.0 \times 10^{-1}$ & $8.0 \times 10^{2}$ & \\
\hline
\end{tabular}




\section{FUNDAMENTOS TEÓRICOS}

\subsection{Equações básicas para poroelasticidade dinâmica}

Seguindo a teoria de Biot (1956a), as equações de equilíbrio para poroelasticidade linear é expresso conforme as Eq. (4.1) e Eq. (4.2).

$$
\begin{gathered}
\tau_{i j, j}+X_{i}=\frac{\partial^{2}}{\partial t^{2}}\left(\rho_{11} u_{i}+\rho_{12} U_{i}\right)+b \frac{\partial}{\partial t}\left(u_{i}-U_{i}\right) \\
\tau_{, j}+X_{i}^{\prime}=\frac{\partial^{2}}{\partial t^{2}}\left(\rho_{12} u_{i}+\rho_{22} U_{i}\right)+b \frac{\partial}{\partial t}\left(u_{i}-U_{i}\right)
\end{gathered}
$$

onde $\tau_{i j}$ é a tensão no sólido, $\tau$ corresponde à tensão no fluído relativo à pressão no fluído $p$ de acordo com Eq. (4.3).

$$
\tau=-\beta p
$$

onde $\beta$ é a porosidade, $u_{i}$ e $U_{i}$ são os deslocamentos sólidos e do fluído respectivamente, $\rho_{11}, \rho_{12}$ e $\rho_{22}$ são as densidades de massas e $X_{i}$ e $X_{i}^{\prime}$ correspondem a força de corpo atuando no sólido e fluído, respectivamente.

As relações entre as equações de equilíbrio lineares e as variáveis mecânicas podem ser vistos na Eq. (4.4) para a parcela de tensão no sólido e na Eq. (4.5) para a tensão no fluído.

$$
\begin{gathered}
\tau_{i j}=\left(\lambda+\frac{\alpha^{2}}{R}\right) \delta_{i j} e+2 \mu e_{i j}+\alpha \delta_{i j} \varepsilon \\
\tau=\alpha e+R \varepsilon
\end{gathered}
$$

onde $\delta_{i j}$ é o Delta de Kronecker, $e_{i j}=0.5\left(u_{i, j}+u_{j, i}\right)$ é a deformação do sólido, $\varepsilon=U_{i, i}$ e $e=u_{i, i}$ como dilatação do fluído e sólido, respectivamente, por fim as constantes elásticas $\lambda, \mu, \alpha$ e $R$. Substituindo a Eq. (4.4) na Eq. (4.1), os campos das equações governantes em termos de deslocamentos ficaram conforme Eq. (4.6) e Eq. (4.7). 


$$
\begin{gathered}
\mu \Delta u_{i}+\left(\lambda+\mu+\frac{\alpha^{2}}{R}\right) e_{, i}+\alpha \varepsilon_{, i}+X_{i}= \\
\frac{\partial^{2}}{\partial t^{2}}\left(\rho_{11} u_{i}+\rho_{12} U_{i}\right)+k \frac{\partial}{\partial t}\left(u_{i}-U_{i}\right) \\
(\alpha e+R \varepsilon)_{, i}+X_{i}^{\prime}=\frac{\partial^{2}}{\partial t^{2}}\left(\rho_{12} u_{i}+\rho_{22} U_{i}\right)-k \frac{\partial}{\partial t}\left(u_{i}-U_{i}\right)
\end{gathered}
$$

onde $\Delta$ é o operador de Laplace.

\subsection{Domínio da Frequência}

Assumindo excitação e solução harmônica com dependência temporal $\exp (i w t)$, a Eq. (4.6) e Eq. (4.7) podem ser reescritas de acordo com Eq. (4.8) e Eq (4.9).

$$
\begin{gathered}
\mu \Delta u_{i}+\left(\lambda+\mu+\frac{\alpha^{2}}{R}\right) e_{, i}+\alpha \varepsilon_{, i}+X_{i}= \\
-\omega^{2}\left(\rho_{11} u_{i}+\rho_{12} U_{i}\right)+i \omega b\left(u_{i}-U_{i}\right) \\
(\alpha e+R \varepsilon)_{, i}+X_{i}^{\prime}=-\omega^{2}\left(\rho_{12} u_{i}+\rho_{22} U_{i}\right)-i \omega b\left(u_{i}-U_{i}\right)
\end{gathered}
$$

\subsection{Relação pressão-deslocamento}

Os seis deslocamentos da Eq. (4.8) e (4.9) não são independentes e podem estar expressos em termos das variáveis de deslocamentos do sólido $\boldsymbol{u}_{\boldsymbol{y}}$ e tensão no fluído $\tau$. Usando as Eq. (4.5) e (4.9) o deslocamento no fluido pode ser escrito de acordo com a Eq. (4.10).

$$
U_{i}=\frac{\tau_{, i}+X_{i}^{\prime}+\left(i \omega b+\omega^{2} \rho_{12}\right) u_{i}}{i \omega b-\omega^{2} \rho_{22}}
$$

Substituindo as Eq. (4.5) e (4.10) na Eq. (4.8) é obtida a equação (4.11). 


$$
\begin{aligned}
& \mu \Delta u_{i}+(\lambda+\mu) e_{, i}+\tau_{, i}\left(\frac{\alpha}{R}+\frac{i \omega b+\rho_{12} \omega^{2}}{i \omega b-\omega^{2} \rho_{22}}\right) \\
& +u_{i} \omega^{2}\left(\frac{\omega^{2}\left(-\rho_{11} \rho_{22}+\rho_{12}^{2}\right)+i \omega b\left(\rho_{11}+\rho_{22}+2 \rho_{12}\right)}{i \omega b-\omega^{2} \rho_{22}}\right) \\
& +X_{i}+\frac{i \omega b+\rho_{12} \omega^{2}}{i \omega b-\omega^{2} \rho_{22}} X_{i}^{\prime}=0
\end{aligned}
$$

A Eq. (4.11) depende somente das três componentes de deslocamento do sólido e do fluido. Esta equação pode ser escrita para $i=1,2$ e 3 . As quatro equações, que completam o sistema são obtidas levando em consideração a substituição da Eq. (4.9) na Eq. (4.5), obtendo-se assim a Eq. (4.12).

$$
\Delta \tau+\frac{\tau}{R}\left(-i \omega b+\omega^{2} \rho_{22}\right)+e\left[i \omega b\left(1+\frac{\alpha}{R}\right)+\omega^{2}\left(\rho_{12}-\rho_{22} \frac{\alpha}{R}\right)\right]+X_{i, i}^{\prime}=0
$$

\subsection{Formulação integral de contorno}

A formulação integral de contorno surge a partir da relação recíproca entre os termos de deslocamentos do sólido, condições de contorno de tração no sólido, tensão no fluido, condições de contorno de deslocamentos normais no fluido e forças de corpo em ambas as faces. As relações recíprocas podem ser obtidas a partir das equações de equilíbrio de comportamento harmônico, conforme Eq. (4.13).

$$
\begin{gathered}
\tau_{i j, i}+X_{i}=-\omega^{2}\left(\rho_{11} u_{i}+\rho_{12} U_{i}\right)+i \omega b\left(u_{i}-U_{i}\right) \\
\tau_{, i}+X_{i}^{\prime}=-\omega^{2}\left(\rho_{11} u_{i}+\rho_{22} U_{i}\right)-i \omega b\left(u_{i}-U_{i}\right)
\end{gathered}
$$

Ponderando a primeira equação com funções de deslocamentos $u_{i}^{*}$ e a segunda com $U_{i}^{*}$, e integrando-as sobre o corpo $\Omega$ através de integração por partes, duas vezes como normalmente é feito para derivação de relação recíproca para problema de estática ou dinâmica, as relações agora são obtidas de acordo com Eq. (4.14).

$$
\begin{aligned}
& \int_{\Gamma}\left(t_{i} u_{i}^{*}+\tau U_{n}^{*}\right) d \Gamma+\int_{\Omega}\left(X_{i} u_{i}^{*}+X_{i}^{\prime} U_{i}^{*}\right) d \Omega \\
& =\int_{\Gamma}\left(t_{i}^{*} u_{i}+\tau^{*} U_{n}\right) d \Gamma+\int_{\Omega}\left(X_{i}^{*} u_{i}+X_{i}^{\prime *} U_{i}\right) d \Omega
\end{aligned}
$$


Onde $\Gamma$ é o contorno do corpo $\Omega, t_{i}=\tau_{i j} n_{j}$ e $U_{n}=U_{i} n_{i}, n$ como sendo a normal do contorno. As variáveis com * são aquelas associadas com os campos de deslocamento. A representação integral do deslocamento sólido $u_{i}$ é obtida pela substituição da solução fundamental derivada a partir da força de corpo conforme Eq. (4.15).

$$
\begin{aligned}
& X_{i}^{*}=\delta(x-\xi) \delta_{i j} \\
& X_{i}^{\prime *}=0
\end{aligned}
$$

Onde $\delta(x-\xi)$ é a função Delta de Dirac, $\xi$ indica o ponto de aplicação da função Delta de Dirac e $\delta_{i j}$ é o Delta de Kronecker. As relações recíprocas serão representadas pela Eq. (4.16).

$$
\begin{gathered}
c_{i j} u_{i}+\int_{\Gamma} t_{i j}^{*} u_{i} d \Gamma+\int_{\Gamma} \tau_{j}^{*} U_{n} d \Gamma \\
=\int_{\Gamma} u_{i j}^{*} t_{i} d \Gamma+\int_{\Gamma} \tau U_{i j}^{*} d \Gamma+\int_{\Omega}\left(X_{i} u_{i j}^{*}+X_{i}^{\prime} U_{i j}^{*}\right) d \Omega
\end{gathered}
$$

A Eq. (4.15) e (4.16) contém três soluções individuais, portanto $j=1,2$ e 3 . O coeficiente $c_{i j}$ tem como valor $\delta_{i j}$ para pontos dentro do $\Omega$ e zero para fora do $\Omega$ e estão relacionadas com Teorema de Cauchy, com valores principais $c=1$ para dentro do $\Omega$ e $c=0$ para pontos fora do $\Omega$. Os valores de $c$ para os pontos no contorno $\Gamma$ é $0,5 \delta_{i j}$, e esta representação pode ser vista na Figura 4.1 .

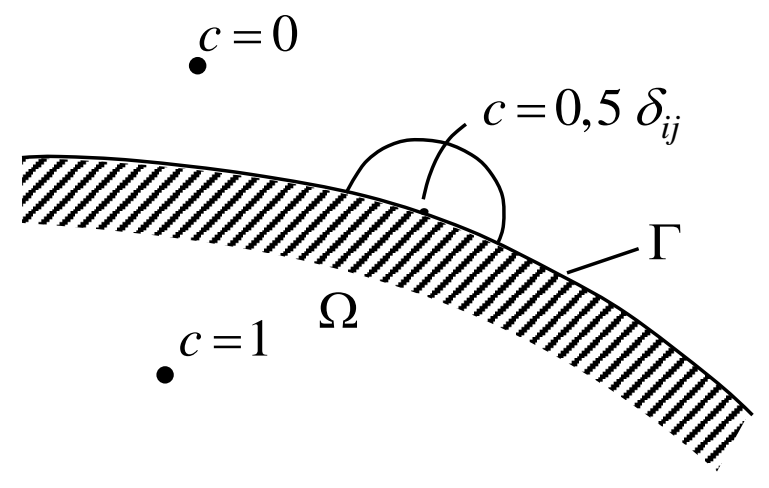

Figura 4.1 - Força de corpo

Para obter as representações integrais de tensão do fluido a solução fundamental corresponde as seguintes forças de corpo, de acordo com a Eq. (4.17). 


$$
\begin{aligned}
& X_{i}^{\prime *}=\left[\frac{1}{2 \pi} \ln r\right]_{, \mathrm{i}} \\
& X_{i}^{*}=\frac{i \omega b+\omega^{2} \rho_{12}}{-i \omega b+\omega^{2} \rho_{22}} X_{i}^{\prime *}
\end{aligned}
$$

Onde $r$ é a distância em relação ao ponto $\xi$ na qual representa a tensão do fluido. As forças de corpo são aplicadas em todas as direções simultaneamente e são direcionados para o contorno. Usando a força de corpo e a Eq. (4.10), o último termo da Eq. (4.14) pode ser escrita de acordo com a Eq. (4.18).

$$
\begin{gathered}
\int_{\Omega}\left(X_{i}^{*} u_{i}+X_{i}^{\prime *} U_{i}\right) d \Omega=-\int_{\Omega} X_{i}^{\prime *} \frac{\tau_{, i}+X_{i}^{\prime}}{-i \omega b+\omega^{2} \rho_{22}} d \Omega \\
=-\int_{\Gamma} X_{i}^{\prime *} \frac{\tau n_{i}}{-i \omega b+\omega^{2} \rho_{22}} d \Gamma+\int_{\Omega} X_{i, i}^{\prime *} \frac{\tau}{-i \omega b+\omega^{2} \rho_{22}} d \Omega-\int_{\Omega} \frac{X_{i}^{\prime *} X_{i}^{\prime}}{-i \omega b+\omega^{2} \rho_{22}} d \Omega
\end{gathered}
$$

Tendo em conta que $X_{i, i}^{\prime}{ }^{*}=\delta(x-\xi)$, então a relação recíproca pode ser reescrita conforme a Eq. (4.19).

$$
\begin{gathered}
\int_{\Omega}\left(X_{i}^{*} u_{i}+X_{i}^{\prime *} U_{i}\right) d \Omega=\frac{\tau}{-i \omega b+\omega^{2} \rho_{22}} \\
-\int_{\Gamma} \tau \frac{X_{i}^{\prime *} n_{i}}{-i \omega b+\omega^{2} \rho_{22}} d \Gamma-\int_{\Omega} \frac{X_{i}^{\prime *} X_{i}^{\prime}}{-i \omega b+\omega^{2} \rho_{22}} d \Omega
\end{gathered}
$$

A integral que representa a tensão no fluido é obtida através da substituição da Eq. (4.19) na Eq. (4.14), representada pela Eq. (4.20).

$$
\begin{aligned}
\frac{c \tau}{-i \omega b+\omega^{2} \rho_{22}} & +\int_{\Gamma}\left(t_{i j}^{*} u_{i}+\tau_{j}^{*} U_{n}\right) d \Gamma=\int_{\Gamma}\left[t_{i} u_{i j}^{*}+\tau\left(U_{n j}^{*}+\frac{X_{i}^{\prime *} n_{i}}{-i \omega b+\omega^{2} \rho_{22}}\right)\right] d \Gamma \\
& +\int_{\Omega}\left[X_{i} u_{i j}^{*}+X_{i}^{\prime}\left(U_{i j}^{*}+\frac{X_{i}^{\prime *}}{-i \omega b+\omega^{2} \rho_{22}}\right)\right] d \Omega
\end{aligned}
$$

onde o índice $j$ corresponde para este caso como a solução fundamental devido a força de corpo de segundo tipo.

Vale uma ressalva, forças de corpo usadas para obter a representação integral da tensão no fluido correspondem ao ponto de pressão do fluido, e podem ser vistos na Eq. (4.12). A força de corpo aplicada na fase sólida $X_{i}^{*}$, equilibra a direção da ação de força do fluido transmitido por inercia e dissipação. As forças de corpo 
aplicadas ao sólido são somadas de tal forma que os termos das forças externas se tornam nulos.

As equações (4.16) e (4.20) são as equações integrais para domínio harmônico poroelástico. O volume das integrais incluídos nestas equações envolvem somente as forças de corpo e os valores das soluções fundamentais.

\subsection{Soluções Fundamentais}

As equações (4.16) e (4.20) foram obtidas usando os conjuntos de soluções fundamentais das equações de poroelasticidade (4.11) e (4.12). As trações no sólido e deslocamentos normal do fluido, precisam das derivadas das formulações do Contorno para serem resolvidas.

As equações para força de corpo podem ser escritas de acordo com a expressão (4.21).

$$
B V=0
$$

Onde $B$ é um operador $3 \times 3$ e $V$ é um vetor onde carrega as informações de deslocamentos e tração no sólido ou tensão no fluído, representado de acordo com eq. (4.22).

$$
V=\left[\begin{array}{l}
u_{1} \\
u_{2} \\
\theta
\end{array}\right]
$$

Estas soluções podem ser escritar para qualquer função escalar, conforme Eq. (4.23).

$$
B B^{\prime} \phi=I \operatorname{det}(B) \phi
$$

Onde $B^{\prime}$ é a transposta da matris de cofatores, calculada pela matriz $B$, e $I$ é a identidade da matriz. $\bigcirc \phi$ está de acordo com o $\operatorname{det}(B)=-\delta(x)$, então a função escalar é reescrita de acordo com Eq. (4.24).

$$
B B^{\prime} \phi+I \delta(\xi)=0
$$

O $B^{\prime} \phi$ corresponde a solução fundamental, e a solução do $\operatorname{det}(B) \phi+\delta(\xi)=0$ é dado pela Eq. (4.25) 


$$
\phi=\frac{1}{2 \pi(\lambda+2 \mu)} \sum_{m=1}^{3} \frac{K_{0}\left(i \lambda_{m} r\right)}{\left(\lambda_{m+1}^{2}-\lambda_{m}^{2}\right)\left(\lambda_{m+2}^{2}-\lambda_{m}^{2}\right)}
$$

Onde $K_{0}\left(i \lambda_{m} r\right)$ corresponde a solução modificada das funções de Bessel, $r$ é a distância do ponto de colocação $\xi$. A função $\phi$ pode ser escrita de acordo com os termos da função de Hankel. $O$ termo $B^{\prime} \phi$ correspondente a matriz da solução fundamental é preenchida de acordo com acordo com Eq. (4.26).

$$
\psi_{k j}=\sum_{m=1}^{3}\left\{\begin{array}{l}
A_{k j m} K_{0}\left(i \lambda_{m} r\right)+\left(B_{k j m} r_{, j}+C_{k j m} r, k_{, k}+D_{k j m} \frac{1}{r}\right) \\
K_{1}\left(i \lambda_{m} r\right)+E_{k j m} r_{, k} r_{, j} K_{2}\left(i \lambda_{m} r\right)
\end{array}\right\}
$$

Onde $K_{1}$ e $K_{2}$ são as funções de Bessel de segundo tipo de primeira e segunda ordem, respectivamente. $A_{k j m}, B_{k j m}, C_{k j m}, \mathrm{D}_{\mathrm{kjm}}$ e $\mathrm{E}_{\mathrm{kjm}}$ são tensores para solução da expressão. $\bigcirc \lambda$ correspondem ao numero de onda de dilatação e rotação. $\alpha=1,2$ e $\beta=1,2$.

A solução fundamental então para a parte sólida é escrita de acordo com a Eq. (4.27).

$$
t_{\alpha j}^{*}=\left(\lambda e_{j}^{*}+\frac{\alpha}{R} \psi_{3 j}\right) n_{\alpha}+2 \mu e_{\alpha j}^{*}
$$

E solução fundamental para fluído de acordo com Eq. (4.28).

$$
U_{n j}^{*}=J\left(\psi_{3 j, \alpha}+\frac{1}{2 \pi} \frac{r_{\alpha}}{r} \delta_{3 j}\right) n_{\alpha}+Z \psi_{\alpha j} n_{\alpha}
$$

Os tensores $J$ e $Z$ correspondem conforme as Eq. (4.29) e (4.30) respectivamente.

$$
\begin{gathered}
J=\frac{1}{i \omega b-\omega^{2} \rho_{22}} \\
Z=J\left(i \omega b+\omega^{2} \rho_{12}\right)
\end{gathered}
$$

\subsection{Elementos de Contorno (Elementos Constantes)}

A representação integral das equações (4.16) e (4.20) podem ser escritas para domínios bidimensionais na ausência de forças de corpo, de acordo com Eq. (4.31) e (4.32). 


$$
\begin{gathered}
c_{\alpha \beta} u_{\alpha}+\int_{\Gamma} t_{\alpha \beta}^{*} u_{\alpha} d \Gamma+\int_{\Gamma} \tau_{\beta}^{*} U_{n} d \Gamma=\int_{\Gamma} u_{\alpha \beta}^{*} t_{\alpha} d \Gamma+\int_{\Gamma} \tau U_{n \beta}^{*} d \Gamma \\
\int_{\Gamma} t_{\alpha 3}^{*} u_{\alpha} d \Gamma+\int_{\Gamma} \tau_{3}^{*} U_{n} d \Gamma=\int_{\Gamma} u_{\alpha 3}^{*} t_{\alpha} d \Gamma+\int_{\Gamma} \tau\left(U_{n 3}^{*}-J X_{\alpha}^{\prime *} n_{\alpha}\right) d \Gamma+J c_{33} \tau
\end{gathered}
$$

onde $J$ é definido pela Eq. (4.33).

$$
J=\frac{1}{i \omega b-\omega^{2} \rho_{12}}
$$

Usando notação vetorial, as integrais podem ser escritas de acordo com Eq. (4.34).

$$
c^{i} u^{i}+\int_{\Gamma} p^{*} u d \Gamma=\int_{\Gamma} u^{*} p d \Gamma
$$

Onde $u$ e $p$ são os campos de vetores variáveis para deslocamento e tensão, respectivamente, conforme Eq. (4.35). As variáveis $p^{*}$ e $u^{*}$ são os tensores de soluções fundamentais de acordo com Eq. (4.36).

$$
\begin{gathered}
u=\left[\begin{array}{c}
u_{1} \\
u_{2} \\
\tau
\end{array}\right] \text { e } p=\left[\begin{array}{c}
t_{1} \\
t_{2} \\
U_{n}
\end{array}\right] \\
p^{*}=\left[\begin{array}{ccc}
t_{11}^{*} & t_{21}^{*} & -U_{n 1}^{*} \\
t_{12}^{*} & t_{22}^{*} & -U_{n 2}^{*} \\
t_{13}^{*} & t_{23}^{*} & -\hat{U}_{n 3}^{*}
\end{array}\right] \text { e } u^{*}=\left[\begin{array}{lll}
u_{11}^{*} & u_{21}^{*} & -\tau_{1}^{*} \\
u_{12}^{*} & u_{22}^{*} & -\tau_{2}^{*} \\
u_{13}^{*} & u_{23}^{*} & -\tau_{3}^{*}
\end{array}\right]
\end{gathered}
$$

Onde $\quad \hat{U}_{n 3}^{*}=U_{n 3}^{*}-J X_{\alpha}^{\prime *} n_{\alpha}=\left(J \tau_{3, \alpha}^{*}+Z u_{\alpha 3}^{*}\right) n_{\alpha}, \quad Z=J\left(i \omega b+\omega^{2} \rho_{12}\right), \quad c^{i}$ correspondem a Eq. (4.37) para pontos fracos no contorno (singularidade fraca).

$$
c^{i}=\frac{1}{2}\left[\begin{array}{ccc}
1 & 0 & 0 \\
0 & 1 & 0 \\
0 & 0 & -J
\end{array}\right]
$$

Considerando agora que o domínio do contorno em estudo é discretizado por elementos constantes, onde os valores de $u$ e $p$ são constantes ao longo do comprimento e igual quantidade de valores nodais, a Eq. (4.34) pode ser escrita de acordo com Eq. (4.38). 


$$
c^{i} u^{i}+\sum_{j=1}^{N}\left\{\int_{\Gamma_{j}} p^{*} d \Gamma\right\} u^{j}=\sum_{j=1}^{N}\left\{\int_{\Gamma_{j}} u^{*} d \Gamma\right\} p^{j}
$$

Onde cada integral estende-se ao longo de um seguimento de $\Gamma_{j}$, correspondendo ao elemento $" j "$. Usando a notação tradicional para o Método de Elementos de Contorno a Eq. (4.38) pode ser reescrita de acordo com Eq. (4.39) ou como Eq. (4.40).

$$
\begin{gathered}
c^{i} u^{i}+\sum_{j=1}^{N} \hat{H}^{i j} u^{j}=\sum_{j=1}^{N} G^{i j} p^{j} \\
\sum_{j=1}^{N} H^{i j} u^{j}=\sum_{j=1}^{N} G^{i j} p^{j}
\end{gathered}
$$

Para estas definições foram usadas os parâmetros da Eq. (4.41).

$$
\begin{array}{ll}
H^{i j}=\hat{H}^{\hat{\imath} j} & \text { quando } i \neq i \\
H^{i j}=\hat{H}^{\hat{\imath} j}+c^{i} & \text { quando } i=i
\end{array}
$$

De uma forma resumida o sistema de equações pode ainda ser escrito de acordo com Eq. (4.42).

$$
H u=G p
$$

onde $H$ e $G$ são matrizes de influência de ordem $3 N \times 3 N$. Observa-se que para cada nó $u_{1}$ ou $t_{1}, u_{2}$ ou $t_{2}$ e $\tau$ ou $U_{n}$ são conhecidas e consequentemente $3 N$ são desconhecidas. Portanto o sistema de equações (4.42) pode ser reordenado como de costume, passando todas as incógnitas desconhecidas para o lado esquerdo. Este sistema é apresentado conforme Eq. (4.43).

$$
A X=F
$$

onde $A$ é o rearranjo das variáveis, $X$ é o vetor das variáveis desconhecidas de $\boldsymbol{u}$ e $p, F$ são as variáveis conhecidas, obtidas através da multiplicação das colunas correspondentes de $\boldsymbol{H}$ e $G$. A equação (4.43) agora pode ser resolvida e todas as variáveis do contorno calculadas e conhecidas. 


\section{ALGORITMOS GENÉTICOS}

\subsection{Motivação}

As pesquisas sobre modelos computacionais inteligentes têm nos últimos anos se caracterizado pela tendência em buscar inspiração na natureza, onde existem inúmeros exemplos vivos de processos que podem ser ditos "inteligentes". Para cientistas da computação, matemáticos e engenheiros muitas das soluções que a mãe natureza encontrou para solucionar problemas de adaptação/sobrevivência forneceram modelos significativos para a comunidade acadêmica. Físicos, biólogos e outros cientistas tentam desvendar os princípios que regem os fenômenos da natureza, enquanto que os matemáticos, cientistas e engenheiros buscam ideias que possam ser copiadas ou pelo menos imitadas.

A descoberta feita por pesquisadores ao estudar o comportamento de colônias de formigas, observaram que, mesmo elas sendo tão simples e irracionais possuem um mecanismo natural de otimização. Isto é, são capazes de encontrar um caminho mais curto entre o ninho e uma fonte de comida sem usar sugestões visuais, mesmo que ocorram mudanças no ambiente original, como a introdução de um obstáculo, conforme pode ser visto na Figura 5.1.

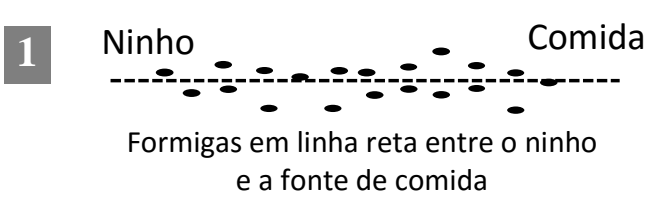

2

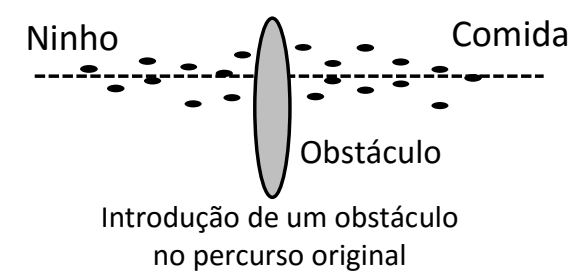

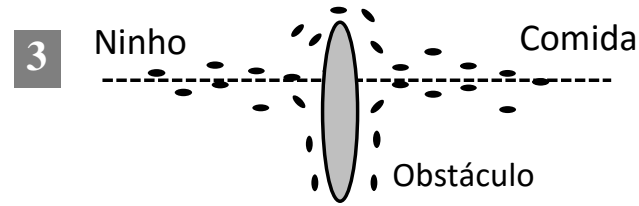

Divisão mediana das formigas pelos dois novos percursos

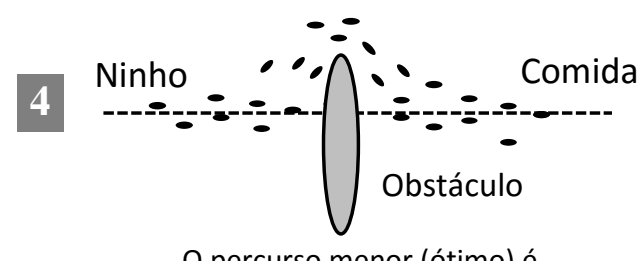

O percurso menor (ótimo) é escolhido com o passar do tempo

Figura 5.1 - Processo natural de otimização por uma colônia de formigas

As explicações para este caminho ótimo percorrido pelas formigas se deve ao fato de durante as suas caminhadas estas depositarem certa quantidade de feromônio, este sendo descartado juntamente com a urina, fazendo com que as formigas prefiram seguir uma trajetória mais rica em tal substância. Quando as formigas se deparam com um obstáculo no caminho habitual, as mesmas se dividem 
por trajetórias possíveis até que o alvo seja alcançado, como pelo menor caminho terão passados mais formigas, liberando uma quantidade maior de feromônios, este será o novo trajeto então adotado por elas.

A necessidade de otimização, seguida até mesmo por animais como as formigas em conjunto com a seleção natural, escolhendo os mais aptos no processo de evolução (evolução Darwiniana), torna-se um campo eficiente para as complexas metodologias utilizadas em diversas áreas de aplicação, como nas áreas de engenharias e na ciência biológica, por exemplo.

Este processo utilizado pelas formigas é conhecido na comunidade acadêmica como metodologia de Computação Evolucionária (CE), onde são incorporadas as teorias da evolução Darwiniana como processo adaptativo de otimização, sugerindo um modelo em que populações de estruturas computacionais evoluam de modo a melhorar, em média o desempenho geral da população com respeito a um dado problema.

Atualmente o CE engloba alguns métodos computacionais tais como: Programação Evolucionária (PE) apresentada por Fogel et al (1966) como um estudo de inteligência artificial através da evolução simulada. Estratégias Evolucionárias (EE) apresentada por Rechenberg (1973) como análise de evolução e técnicas de otimização por sistemas de evolução biológica e Rechenberg (1994) como estratégia de evolução. Programação Genética (PG) apresentado por Koza (1992) com uma programação computacional através da seleção natural e também exposto por Koza (1994) como uma descoberta referente aos programas automáticos reutilizáveis. Algoritmos Genéticos (AG), que será utilizada no presente trabalho, entre outras.

Os AGs são muito utilizados em problemas onde, dado um conjunto de elementos ou indivíduos, deseja-se encontrar aquele ou aqueles que melhor atendam a certas condições previamente especificadas. A partir de uma população de indivíduos, cada um com um valor de adaptabilidade associado, chamado aptidão, desenvolvem, através de operações genéticas como cruzamentos e mutações, uma nova geração de indivíduos usando os princípios Darwinianos de reprodução e sobrevivência dos mais aptos. Cada indivíduo na população representa uma possível solução para um dado problema. O que o AG faz é procurar a melhor solução visando à otimização da função objetivo.

O desempenho do AG pode, em muitos casos, ser melhorado forçando a escolha do melhor indivíduo encontrado em todas as gerações do algoritmo. Outra 
opção é simplesmente manter sempre o melhor indivíduo da geração atual na geração seguinte, estratégia essa conhecida como seleção celetista (Fogel, 1994).

Alguns estudos mais aprofundados sobre AGs podem ser encontrados de forma mais detalhada por Holland (1975) com um sistema de adaptação natural e artificial aplicando os sistemas da metodologia do AG. No mesmo ano Dejong (1975) fez uma análise de comportamento de um sistema adaptativo através do sistema AG, anos depois Goldberg (1989) apresentou um AG de busca para otimização e utilização em aprendizagem de máquinas. Davis (1991) apresentou um manual de Algoritmo Genético, e posteriormente uma perspectiva da utilização de AG's nos últimos 25 anos.

Michell (1998) reapresentou uma introdução de sistemas complexos aplicando AG e no mesmo ano Barboza (1998) também reapresentou uma introdução ao AG para otimização em engenharia. Uma aplicação de otimização estrutural através dos métodos de AG foi apresentada por Lemonge (1999).

\subsection{Estrutura dos Algoritmos Genéticos}

A representação da estrutura do Algoritmo Genético deve proporcionar um desempenho de busca o mais simples possível, sem perder características de representação do problema tratado, e existem diversas formas de representa-las, tais como: binária, números inteiros ou números reais.

A maioria dos trabalhos desenvolvidos até hoje, utilizam a codificação binária, onde cada cromossomo é um vetor composto por zeros e uns, com cada bit representando um gene do mesmo.

Segundo Castro (2001) em problemas de otimização com variáveis reais, uma codificação binária pode ser introduzida pela conversão de valores numéricos de ponto flutuante para valores binários de comprimentos fixados, sempre necessitando posteriormente a realização do caminho inverso para avaliação da função de aptidão.

Inspirados no princípio Darwiniano o AG é simples. O princípio de seleção garante que os indivíduos mais aptos tenham mais chances de reprodução. Os Indivíduos com mais descendentes têm maior probabilidade de perpetuarem seus códigos genéticos nas gerações próximas. Esses códigos constituem a identificação de cada indivíduo e estão representados nos cromossomos. Este cromossomo no AG é uma estrutura de dados que representa uma das possíveis soluções, e são 
submetidos a um processo evolucionário, que ao longo de um processo de vários ciclos, fornecem os mais aptos a situação encontrada, a Tabela 2 demostra os termos básicos da genética ligada aos AGs.

Tabela 2 - Termos básicos AGs

\begin{tabular}{|c|c|}
\hline \multicolumn{2}{|r|}{ Algoritmo Genético } \\
\hline Nomenclatura & Termos oriundos da genética aplicados ao AG \\
\hline Cromossomo & $\begin{array}{l}\text { Cadeia de caracteres (Alelo) que representa alguma } \\
\text { informação das variáveis do problema, sendo que cada um } \\
\text { desses cromossomos pode representar uma possível solução. }\end{array}$ \\
\hline Gene & Descreve cada uma das variáveis do problema \\
\hline População & Conjunto de possíveis soluções \\
\hline Geração & Número da iteração que o algoritmo genético executa \\
\hline Fenótipo & Representa a informação contida nos cromossomos \\
\hline $\begin{array}{l}\text { Função } \\
\text { Objetivo }\end{array}$ & $\begin{array}{l}\text { Função a ser minimizada, com informações numéricas com } \\
\text { desempenho de cada cromossomo da população, também } \\
\text { conhecida como função de aptidão ou fitness. }\end{array}$ \\
\hline
\end{tabular}

A Figura 5.2 ilustra o esquema da analogia da Tabela 2.

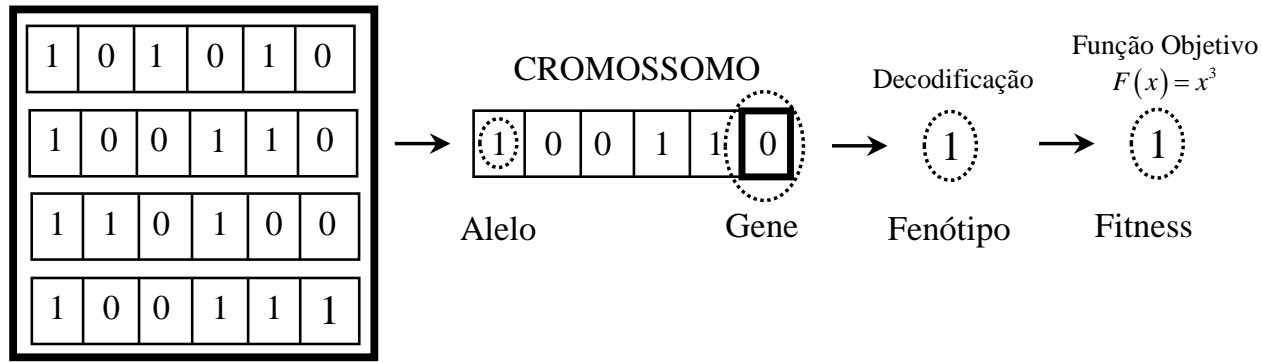

Figura 5.2 - Analogia entre os AGs e a teoria da genética

Holland (1975) decompôs o funcionamento dos AGs nas etapas de inicialização, avaliação, seleção, cruzamento, mutação, atualização e finalização do tratamento dos dados da população, e demostra as aplicações destes processos conforme pode ser visto na Figura 5.3. 


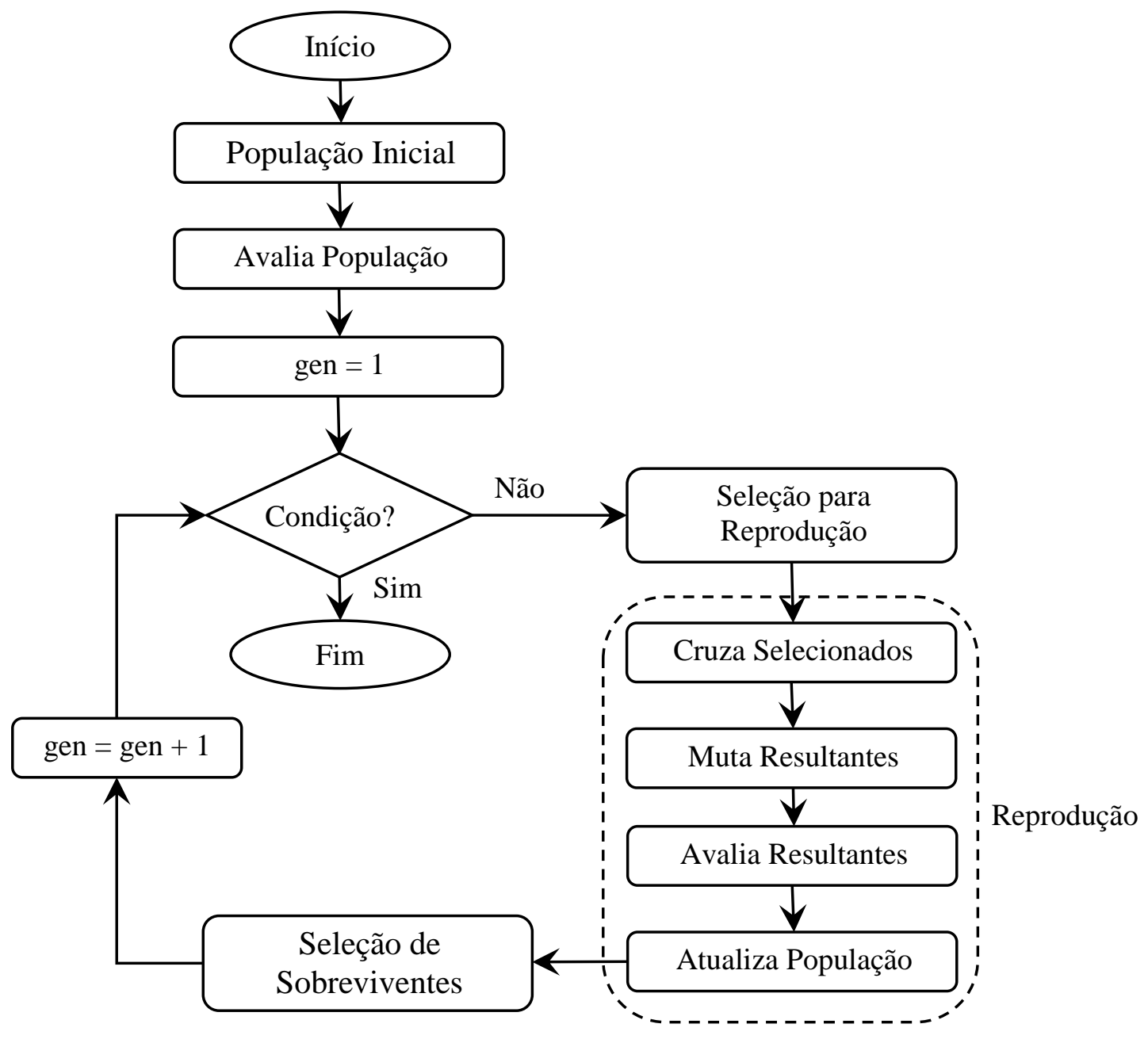

Figura 5.3 - Estrutra AG

Basicamente o que um AG faz é criar uma população de possíveis respostas para o problema a ser tratado para depois submetê-la ao processo de evolução.

\subsection{População Inicial}

Fazendo analogia com a genética o gene (conjunto de variáveis), constitui um cromossomo, que representa um indivíduo que pode ser caracterizado por mais de um cromossomo. O AG inicializa seu processo iterativo com um grande número de cromossomos, formando a população inicial. Ela é iniciada geralmente de forma aleatória, com a utilização de funções randômicas nas rotinas do código computacional.

Através de cada iteração, apenas parte dos melhores indivíduos (50\%), são selecionados para o grupo de reprodução: o restante é descartado. Tal processo se repete a cada iteração. 
Se uma população inicial pequena for gerada aleatoriamente, provavelmente, algumas regiões do espaço de busca não serão representadas. Este problema pode ser minimizado gerando a população inicial com uma distribuição abrangente. Outra alternativa é gerar a primeira metade da população aleatoriamente e a segunda metade a partir da primeira, invertendo os bits, isto garante que cada posição da cadeia de bits tenha um representante na população com os valores 0 e 1 .

Pode ser interessante usar uma população inicial maior que a utilizada nas gerações subsequentes, visando melhorar a representação do espaço de busca. Segundo Silva (2001) uma técnica denominada "seeding" pode ser útil em vários problemas práticos, pois consiste em colocar, na população inicial, soluções encontradas por outros métodos de otimização, isto garante que a solução gerada pelos AGs seja, no mínimo, tão boa quanto a gerada por esses métodos.

\subsection{Avaliação da população}

A população é avaliada através da função de aptidão, onde indica a "qualidade" de cada indivíduo, para problemas de otimização ela está intimamente ligada à função objetivo que se deseja extremar. Com o processo natural da evolução, os indivíduos passam a ter aptidão cada vez mais semelhante entre si, podendo necessariamente aumentar a seleção pela adoção de alguma estratégia relacionada a função objetivo do problema.

A função objetivo fornece para cada indivíduo uma medida de quão bem adaptado ao ambiente ele está, ou seja, quanto maior o valor da função objetivo, maiores serão as chances dos indivíduos sobreviverem no ambiente e reproduzir-se, passando parte de seu material genético a gerações futuras.

\subsection{Seleção}

Os mecanismos de seleção no $A G$ emulam os processos de reprodução assexuada e seleção natural. A seleção dos indivíduos da população baseia-se no princípio da "sobrevivência dos melhores indivíduos", onde os cromossomos com mais alta probabilidade de sobrevivência são copiados de forma semi-randômica uma ou mais vezes para um novo conjunto que formará a próxima geração, denominada população temporária. Em contrapartida, os indivíduos com baixa aptidão serão descartados da população. 


\subsection{Reprodução ou Cruzamento (Pc)}

O processo de seleção não introduz novos indivíduos na população temporária, apenas os chamados genitores, que servirão como pais para a nova geração, "nascendo" assim os filhos.

$\mathrm{Na}$ etapa de reprodução, o algoritmo tenta criar novas e melhores soluções (indivíduos mais aptos). A forma mais simples e natural de cruzamento é o chamado "cruzamento em um ponto". O processo denominado "crossover" é o operador genético que cria iterativamente um ou mais descentes a partir dos cromossomos mais aptos no processo de seleção. É a primeira maneira de o AG explorar a possibilidade de soluções ótimas.

Ao cruzar pelo menos dois pais, uma ou mais novas soluções são criadas trocando informações genéticas dos genitores para as novas gerações. Geralmente a taxa de cruzamento varia entre 0.5 e 0.95 , mas estes números indicam apenas uma ordem de grandeza, já que existem inúmeros tipos possíveis de cruzamentos. O critério de "crossover" utilizado para este trabalho foi o de 0.5 , ou seja, cada filho carrega $50 \%$ de informação genética dos genitores.

O princípio básico é transformar a população através de sucessivas gerações, para obter um resultado satisfatório no final do processo. Deste modo, eles são extremamente necessários para que a população se diversifique e mantenha as características de adaptação adquiridas pelas gerações anteriores.

\subsubsection{Operadores de recombinação}

O cruzamento acontece quando a utilização de dois genitores, servem para produzir descentes, são eles:

a) Um ponto: Um ponto de cruzamento é escolhido e a partir dele as informações genéticas dos pais são trocadas, conforme Figura 5.4, onde os novos cromossomos substituirão os genitores na nova população, carregando informações genéticas dos pais. 


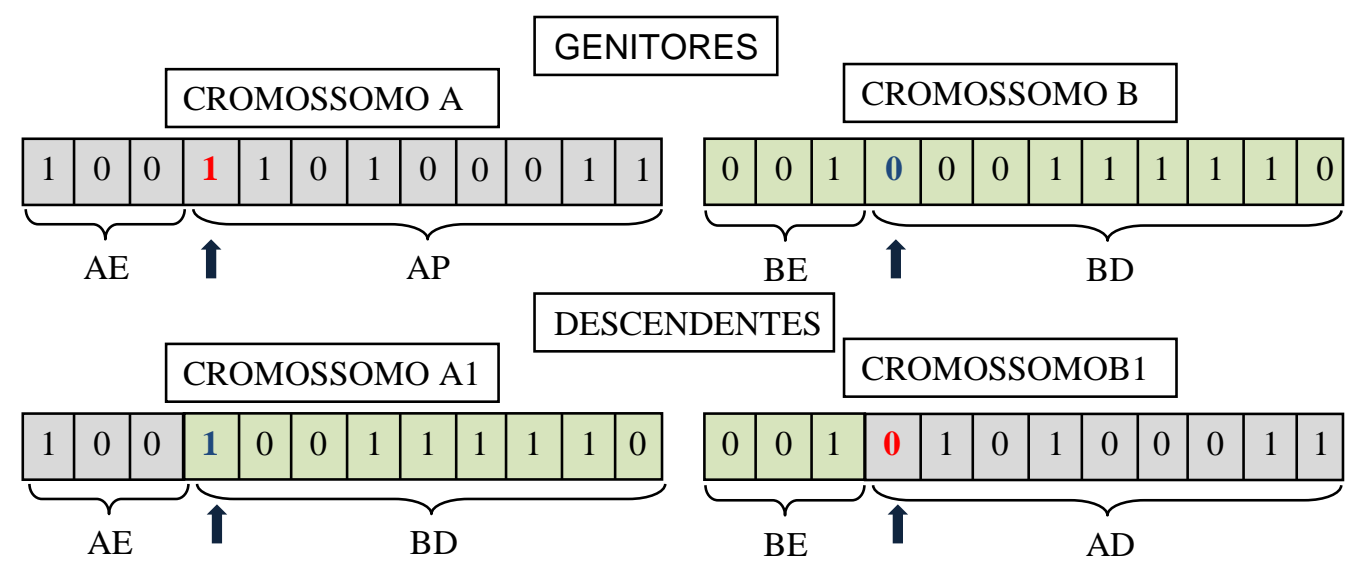

Figura 5.4 - processo de crossover

b) Multi ponto: É uma gereralização da idéia de troca de material genético, onde muitos pontos de cruzamento podem ser utilizados.

c) Uniforme: Não utiliza pontos de cruzamento, mas determina através de um parâmetro global, probabilidade dé cada variável ser herdada de cada pai.

\subsection{Mutação $(\mathrm{Pm})$}

O operador de mutação é necessário para a introdução e manutenção da diversidade genética na população, alterando arbitrariamente um ou mais componentes de uma estrutura escolhida, como ilustrado na Figura 5.5. Ele fornece assim, meios para a introdução de novos elementos na população, assegurando que a probabilidade de se chegar a qualquer ponto do espaço de busca nunca seja zero, com intuito de tentar contornar o problema de ótimos locais.

O operador de mutação é aplicado aos indivíduos com uma probabilidade dada pela taxa de mutação $P_{m}$, geralmente se utiliza uma taxa de mutação pequena (como na genética natural). A taxa de mutação utilizada neste trabalho foi de $10 \%$.

Antes da Mutação:

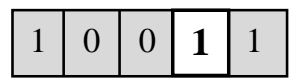

Depois da Mutação:

\begin{tabular}{|l|l|l|l|l|}
\hline 1 & 0 & 0 & $\mathbf{0}$ & 1 \\
\hline
\end{tabular}

Figura 5.5 - Exemplo de mutação 


\subsection{Parâmetros de influência e configuração}

A configuração correta dos parâmetros de influência é, sem dúvida, um dos aspectos mais relevantes dentro da estratégia dos AGs. Este procedimento é de muita importância para um bom desempenho do mecanismo de busca, já que a eficiência é altamente relacionada com os parâmetros de controle.

\subsubsection{Tamanho da população (N)}

O tamanho da população indica o número de cromossomos em cada população, normalmente constante durante a evolução. Com uma população pequena o desempenho pode cair, pois a mesma representaria apenas uma pequena parte do espaço de busca do problema. Uma grande população geralmente fornece uma cobertura representativa do domínio do problema, além de prevenir convergências prematuras para soluções locais ao invés de globais. No entanto para se trabalhar com grandes populações, são necessários maiores recursos computacionais, ou conviver com tempos maiores de processamentos.

Muitos pesquisadores sugerem a título de grandeza, tamanhos de população entre 20 e 200 cromossomos, podendo atingir valores bem mais altos, dependendo da necessidade.

\subsubsection{Recomendações}

Alguns autores fizeram algumas recomendações das configurações dos parâmetros de AGs a serem utilizados, com base em algumas análises de desempenho. De Jong (1975) observou desempenho de 5 exemplos de otimização via $A G$, nos quais incluem aspectos complicantes como descontinuidades, alta dimensão e ruído, e sugeriu para um desempenho satisfatório a seguinte configuração de parâmetros de acordo com a expressão (5.1).

$$
\left(N, P_{c}, P_{m}\right)=(50,0.6,0.001)
$$

Quando a média da função objetivo de cada geração é usada como índice a ser otimizado em simulações parecidas com as de De Jong, Grefenstette (1986) sugere a seguinte configuração conforme a expressão (5.2).

$$
\left(N, P_{c}, P_{m}\right)=(30,0.95,0.01)
$$


Já onde o índice a otimizar é a função objetivo do melhor cromossomo na população, normalmente o indicador mais usado para rotinas de otimização, ele recomenda os seguintes valores de acordo com a expressão (5.3).

$$
\left(N, P_{c}, P_{m}\right)=(80,0.45,0.01)
$$

Seguindo os mesmos parâmetros apresentados por Grefenstette (1986) onde a otimização da função objetivo provém da melhor população, carregando o melhor código genético, foram utilizados a seguinte sequencia conforme a expressão (5.4).

$$
\left(N, P_{c}, P_{m}\right)=(100,0.50,0.01)
$$

\subsection{Algoritmos Evolucionários para Otimização Multi-Objetivo (AEOM)}

Problemas de otimização multi-objetivo tem despertado grande interesse na área de Otimização. Nesses problemas, a qualidade da solução é definida com base na sua adequação em relação a diversos objetivos possivelmente conflitantes (Deb, 2001).

O objetivo do método de otimização multi-objetivo é reduzir os problemas com o uso das funções objetivo, e depois buscar a melhor solução. Uma classe baseada nos princípios de otimização foi apresentada por Arenales et al. (2007), em que utilizou um método baseado em pesos, onde são atribuídos diferentes valores as funções objetivos.

Com este mesmo princípio, métodos que tentam encontrar soluções que apresentam um compromisso com os vários objetivos, não existindo somente uma solução para o problema, mas sim um conjunto de soluções ótimas, sem a utilização de pesos, passaram a ser explorados também por Eiben \& Smith (2003) e Deb, (2001).

O primeiro Algoritmo Evolucionário para otimização multi-objetivo (AEOM) desenvolvido foi proposto por Schaffer (1985) e denominado VEGA (do inglês, "Vector Evaluated Genetic Algorithm"). Este algoritmo é um AG modificado que avalia cada objetivo separadamente, um dos problemas do algoritmo proposto por Schaffer é que as soluções de fronteiras obtidas, em geral, possuem baixa diversidade.

Goldberg (1989) criou um procedimento que ordena as soluções baseadas no conceito de dominância, onde fornece um valor de aptidão para uma solução proporcional ao número de soluções que esta domina, com isso a solução com maior número de dominados possui maior aptidão e, assim, tem uma maior quantidade de 
cópias na lista de soluções. Com o objetivo de manter a diversidade das soluções, Goldberg sugeriu a utilização de um método de compartilhamento que calcula o nicho de cada solução dentro da fronteira que a solução pertence. Com base nas ideias de Golderbeg, foram propostos vários modelos de AEOMs.

A principal diferente entre os Algoritmos Evolucionários (AEs) tradicionais e os AEOMs é o operador de seleção, onde o conceito de dominância deve ser realizado para comparar as soluções de pareto. Algumas propostas foram apresentadas, como o "Multi-objetive Genetic Algorithm - MOGA" por Fonseca \& Fleming (1993) e "Strenght Pareto Evolutionary Algorithm - SPEA" por Zitzler e Thiele (1998), em que o valor de aptidão é proporcional à dominâncias das soluções. Outro método onde utilizam somente a dominância e não calcula um valor de aptidão foi apresentado por Horn et al., (1994) e denominado como "Niched-Pareto Genetic Algorithm - NPGA".

Os modelos de AEMO são usualmente classificados em dpois grupos segundo Eiben \& Smith (2003), são eles:

a) Não elitistas: compreendem os modelos que com o próprio nome indica, não utilizam nenhuma forma de elitismo nas suas iterações;

b) Elitistas: compreendem os modelos que empregam alguma forma de elitismo. Por exemplo, SPEA e PESA apresentado por Corne et al., (2000) em que utilizam uma população externa para armazenar as soluções não dominadas encontradas até o momento. No mesmo ano Deb et al., (2000) apresentou um dos métodos em que é mais utilizado o NSGA - II "Elitist Non-Dominated Sorting Genetic Algorithm", onde é combinada a população atual com as populações geradas, presenvando as melhores soluções de ambas.

Estudo realizado por Zitzler et al., (2000) concluiu que o elitismo melhora as soluções encontradas por um modelo de AEMO e a Tabela 3 apresenta os principais modelos. 
Tabela 3 - Modelos de AEMOs

\begin{tabular}{ll}
\hline Sigla & Nome do Modelo \\
\hline VEJA & Vector Evaluated Genetic Algorithm \\
WBGA & Weight Based Genetic Algorithm \\
MOGA & Mltiple Objective Genetic Algorithm \\
NSGA & Non-Dominated Sorting Genetic Algorithm \\
NPGA & Niched-Pareto Genetic Algorithm \\
PPES & Predator-Prey Evolution Strategy \\
REMOEA & Rudoph's Elitist Multi-Objective Evolutionary Algorithm \\
NSGA-II & Elitist Non-Dominated Sorting Genetic Algorithm \\
SPEA & Strengh Pareto Evolutionary Algorithm 1 e 2 \\
SPEA-2 & \\
TGA & Thermodynamical Genetic Algorithm \\
PAES & Pareto-Archived Evolutionary Strategy \\
MONGA-I & Multi-Objective Messy Genetic Algorithm \\
MONGA-II & \\
PESA-I & Pareto Envelope-Base Selection Algorithm \\
PESA-II & \\
\hline
\end{tabular}

\subsection{Escolha do AG NSA-II}

Com base em algumas aplicações bem sucedidas de problemas de otimização via NSGA-II encontradas na literatura, o "Elitist Non-Dominated Sorting Genetic Algorithm - NSGA-Il" foi escolhido neste trabalho para o processo de otimização, ressaltando que este implementa uma metodologia em que se aplicam simultaneamente conceitos sobre dominância e diversidade, tornando este algoritmo uma ferramenta bastante poderosa e eficiente no processo de busca e otimização da função objetivo. Este operador é uma variação do NSGA, em que busca aumentar a eficiência por meio da incorporação do conceito de elitismo, proposto por Deb et al., (2000). 


\subsubsection{NSGA (Non-Dominated Sorting Genetic Algorithm)}

Este método foi inserido por Srinivas \& Deb (1994) e aplica critérios de dominância na avaliação e classificação de soluções, assim como o conceito de diversidade da população. É utilizado um procedimento de seleção por ordenamento para enfatizar as soluções não dominantes e de um método, definido pelos autores como distância de agrupamento, voltado para a criação de nichos com o objetivo de manter a diversidade da população.

Para garantir as diversidades, o conceito de nichos foi apresentado por Mahfoud (1995), em que os nichos são grupos de indivíduos com características comuns localizados em uma vizinhança próxima e com valores similares de fitness. Eles apresentam estratégias em que consiste na atribuição a cada indivíduo pertencente ao mesmo nicho, um valor denominado fitness compartilhado, dessa maneira, as soluções de um nicho menos ocupado terão um fitness compartilhado mais alto, permitindo que as soluções menos representadas tenham um lugar de privilégio na sua classificação e, assim, possam ser selecionadas com maior probabilidade. Este valor denominado fitness também conhecido como função de aptidão, e é o resultado de um ajuste dos valores de fitness calculado inicialmente.

Segundo Castro (2001) as soluções não dominadas compartilham os seus valores de aptidão, segundo suas distâncias Euclidianas. O valor da aptidão de cada indivíduo é dividido pelo contador de nichos, que é proporcional ao número de vizinhos ao seu redor, então a reprodução é efetuada utilizando a aptidão compartilhada, ou seja, como o primeiro nível de soluções não dominadas possui as mais altas aptidões, um maior número de cópias dos indivíduos será realizado e levará a busca para a fronteira ótima de Pareto. Este procedimento proporciona a coexistência de pontos ótimos múltiplos na população.

Na Figura 5.6 é possível ver o princípio do NSGA, em que os indivíduos são ordenados considerando-se o nível de não dominância entre eles, formando fronteiras, ou seja, as soluções não dominadas da população corrente recebem valores elevados de fitness (aptidão), sendo os mesmos valores para todos os indivíduos não dominados, assim, assegurando-se o mesmo potencial reprodutivo. 


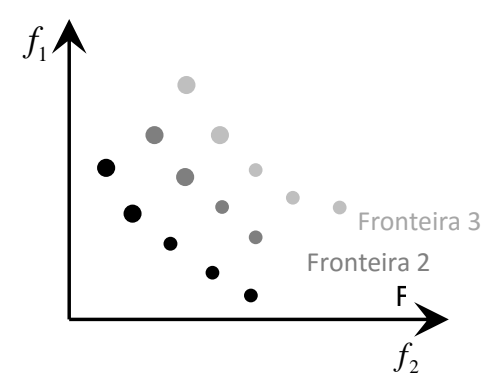

Figura 5.6 - Representação da classificação de indivíduos

Os indivíduos da primeira fileira sempre terão maiores valores de fitness, sendo assim maior possibilidade de reprodução, o que prioriza a busca de indivíduos não dominados.

\subsubsection{NSGA-II (Elitist Non-Dominated Sorting Genetic Algorithm)}

Desenvolvido por Deb et al. (2000) buscando superar algumas falhas do original NSGA, como a alta complexidade computacional, a carência de elitismo e a necessidade de especificar os parâmetros Deb et al. (2000) desenvolveu o NSGA-II com uma diferença, ele realiza a classificação dos indivíduos de uma determinada população utilizando o conceito de soluções dominadas e não dominadas e o conceito de elitismo, de uma forma mais rápida de procura por ordenamento e pela determinação da métrica da distância de agrupamento, que elimina a necessidade de um parâmetro externo definido pelo usuário.

Outro conceito importante apresentada foi o chamado "crowding" em que é técnica utilizada para garantir a diversidade das soluções e evitar a existências de nichos localizados. O "crowding" é um operador de comparação e aglomeração que dá prioridades aos indivíduos menos aglomerados. Os AGs buscam encontrar a maior quantidade de soluções pertencentes à fronteira de Pareto, porém, com este operador, o AG prioriza soluções menos aglomeradas, garantindo a diversidade da população. Dessa forma, as soluções que tiverem uma distância menor de aglomeração serão eliminadas.

A seguir, apresenta-se como funciona o NGSA II segundo Deb et al. (2000):

1. Geração da população inicial de tamanho ${ }_{n}$;

2. Identificação das frentes de dominância e as distâncias de aglomeração;

3. Aplicação dos operadores genéticos de cruzamento e mutação para a geração da população de descendentes de tamanho ${ }_{n}$; 
4. A população inicial (pais) e a população de descendentes (filhos) são reunidas em um mesmo conjunto de tamanho $2 n$;

5. Os indivíduos desse conjunto são classificados de acordo com as frentes de dominância, selecionando-se aqueles que têm maior grau de dominância;

6. A nova população é criada. Caso os indivíduos selecionados superem o tamanho ${ }_{n}$ da população, são eliminados aqueles que tenham a menor distância de aglomeração;

7. O critério de convergência é avaliado. Caso seja atingido, o processo é finalizado; caso contrário, deve-se retornar ao passo um e continuar até que o critério de convergência seja atingido.

A Figura 5.7 apresenta esquematicamente o procedimento NSGA-II.

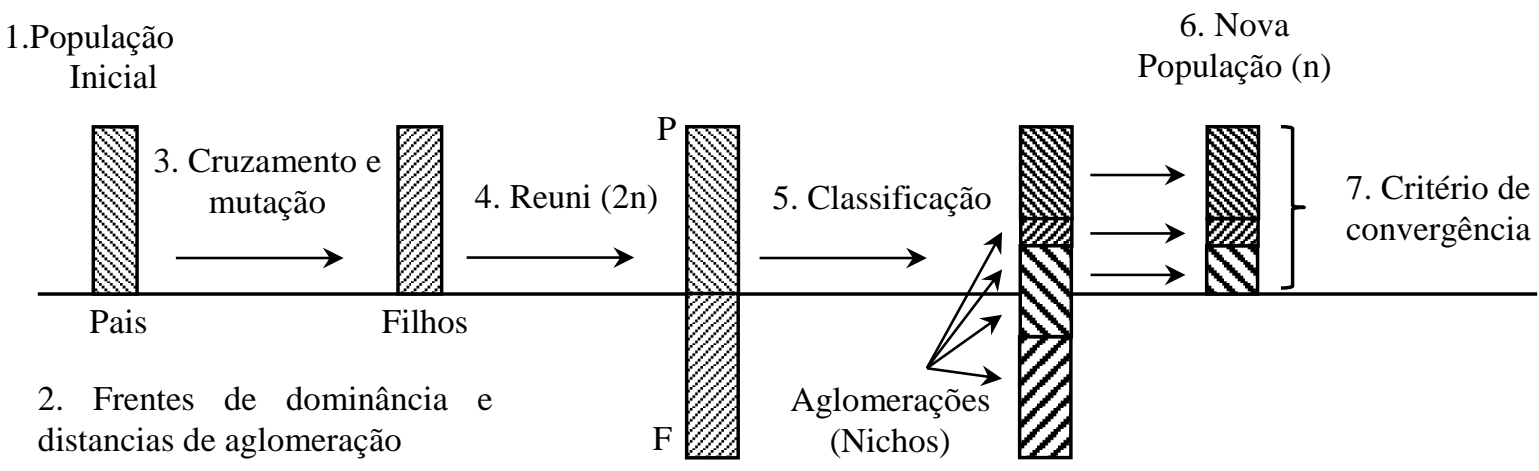

Figura 5.7 - Esquema do NGSA-II

Segundo Castro (2001) A população inicial considerada em um estudo com AGs pode trazer relevância aos resultados, caso seja considerada uma população inicial muito grande, o esforço computacional para poder testar todos os indivíduos pode onerar demasiadamente o estudo. Ao passo que a consideração de uma população pequena pode trazer deficiência de indivíduos para uma análise consistente.

A literatura técnica do NSGA-II sugere que a população inicial em um estudo deva ser na ordem de 2 vezes o número de variáveis utilizados no modelo, multiplicado pelo número de objetivos da otimização. O critério de parada normalmente utilizado é o número de gerações máximas, como pode ser a Figura 5.8. 


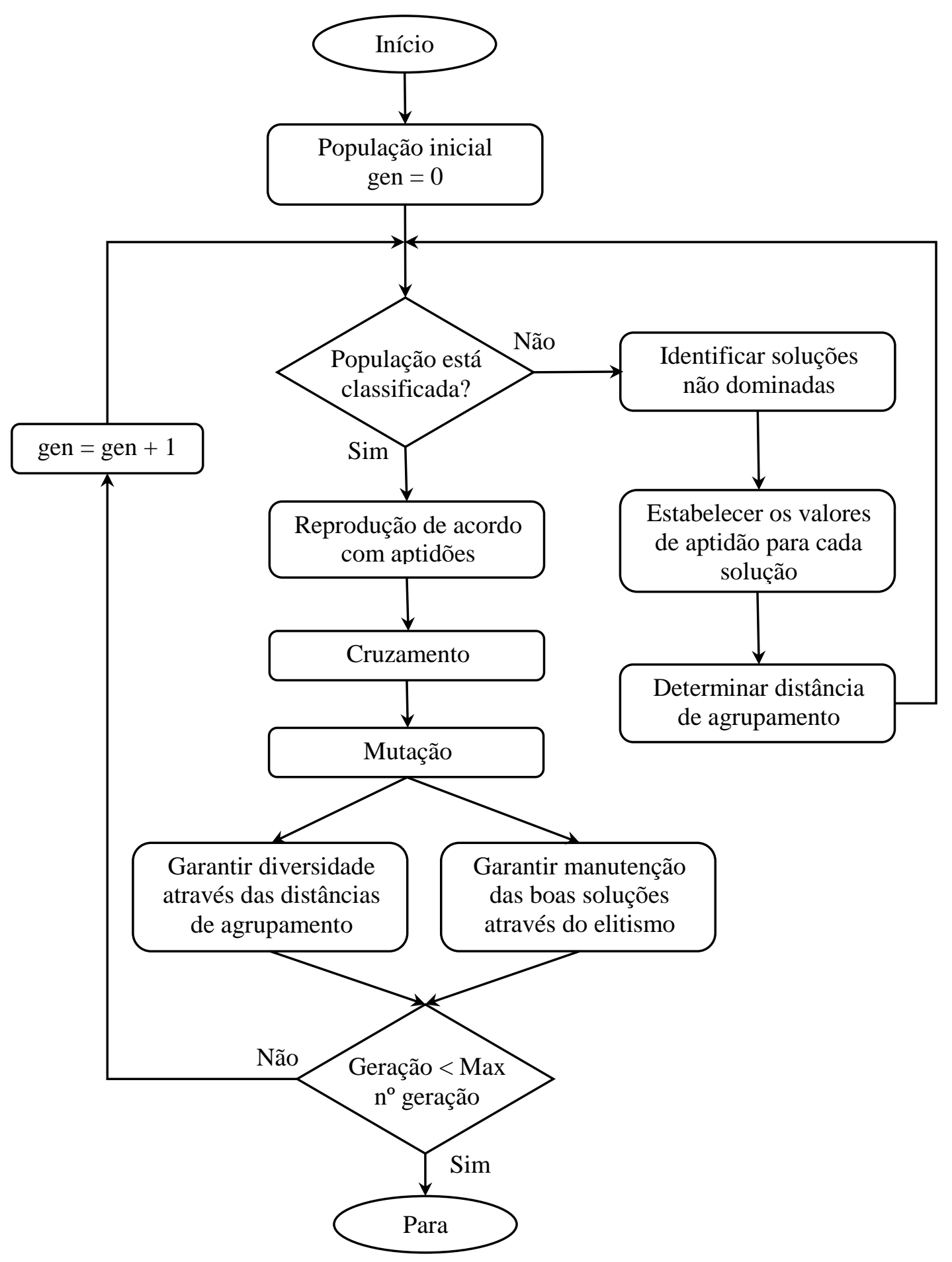

Figura 5.8 - Fluxograma do NSGA-II 


\section{IMPLEMENTAÇÃO COMPUTACIONAL}

\subsection{Rotina para solução do MEC}

A formulação apresentada por Domiguez (1993) foi implementada em linguagem FORTRAN 77, no entanto nesta edição os recursos de programação eram mais limitados. Neste trabalho as rotinas foram adaptadas a linguagem FORTRAN 90. Uma principal atenção foi dispensada aos scripts de entrada e saída para que houvesse uma melhor interação entre o código de poroelasticidade e o código de otimização.

O conjunto de rotinas desenvolvidas neste trabalho foram elaboradas para solução de um problema empregando o Método de Elementos de Contorno Constantes, Dinâmicos, Elástico e Harmônico. O fluxograma referente a rotina de Elemetos de Contorno está apresentada na Figura 6.1, onde demonstra-se todas as sub-rotinas utilizadas para solucionar o MEC com elementos constantes. No início da rotina de elementos de contorno, defini-se a dimensão máxima do sistema de equações, o número máximo de frequências, que podem ser estudados em cada simulação, bem como o número máximo de pontos internos, onde os deslocamentos são calculados.

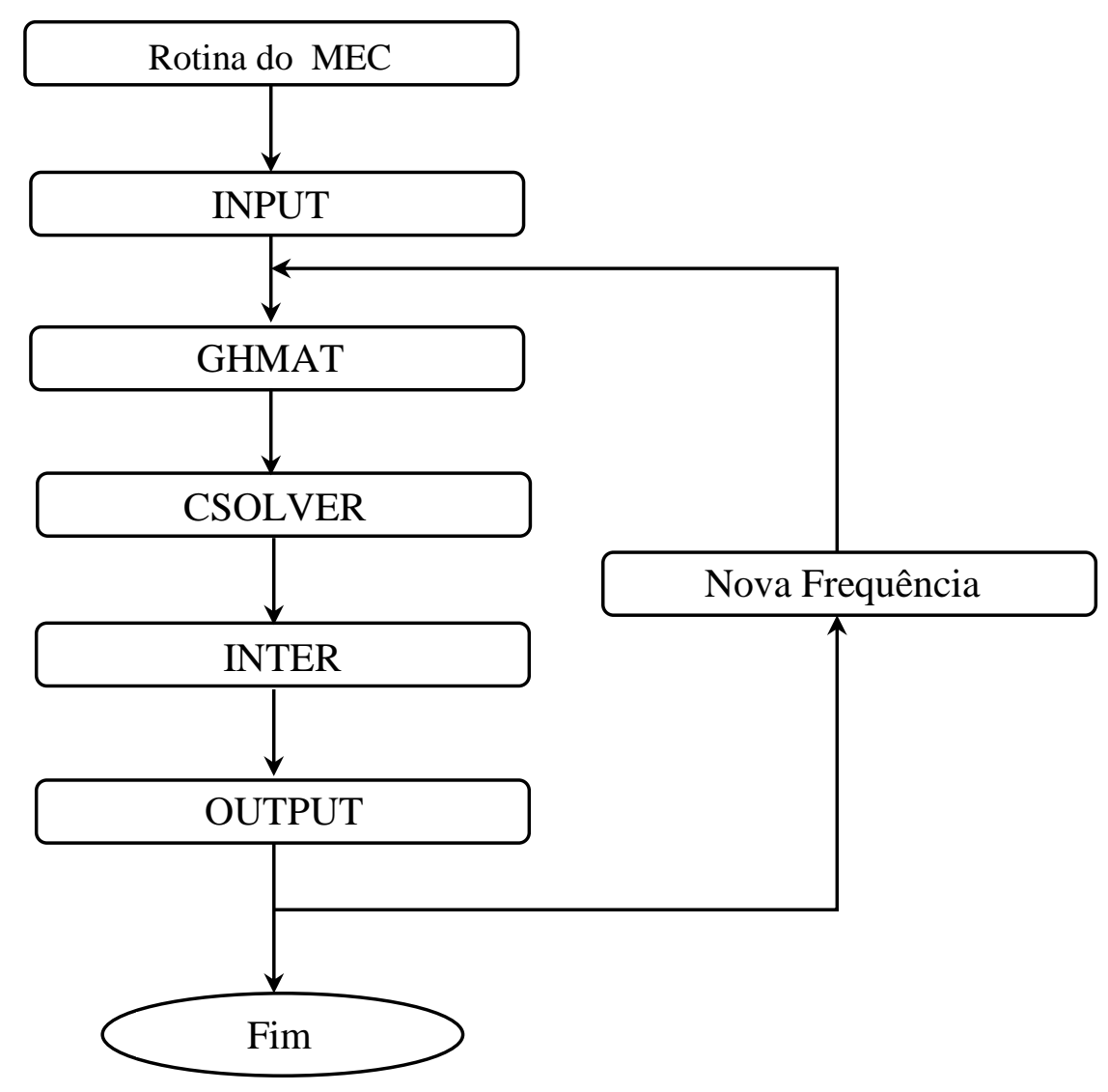

Figura 6.1 - Fluxograma da rotina do MEC 
A rotina do MEC chama as seguintes sub-rotinas: INPUT: Lê os dados de entrada de um arquivo previamente preparado cujo nome é solicitado pelo programa. Esta sub-rotina é chamada apenas uma vez, as outras sub-rotinas são chamadas itrativamente para cada nova frequência analisada. GHMAT: Monta o sistema de matrizes $\mathrm{H}$ e $\mathrm{G}$ e reorganiza de acordo com as condições de contorno. CSOLVER: Resolve o sistema complexo das equações. INTER: Calcula os valores de deslocamentos em pontos internos. OUTPUT: Faz a saída dos resultados.

\subsection{Programação de otimização}

Após o cálculo dos deslocamentos verticais com os seus critérios das partes sólidas e parte do fluido definidos obtidos via MEC, estes resultados são importados para o ModeFRONTIER (MF), para iniciar o processo de otimização. A otimização multiobjetivo é aplicada, com integração de processos e pós-processamento.

Quando se tem limitação por licença do MF, o uma característica do Modefrontier que deve ser ressaltada devese ao fato de que este software fornece a opção de o usuário rodar um projeto de modo batch,ou seja, este modo permite que a interface gráfica de programação trabalhe em segundo plano (off-load), diminuindo assim a interface gráfica de comunicação das rotinas durante o processo de otimização.

$\mathrm{Na}$ sequencia realiza-se a elaboração do workflow, ou seja, desenvolve-se a arquitetura da estrutura numérica ou corpo em que o processo de otimização trabalhará. Esta construção é baseada na utilização do DOSBatch29 (modo batch), onde este é uma das interfaces do software que permite a formulação do sistema através de um nó (Script Node) ou vários nós (Figura 6.2). Estes nós representam os dados de entrada e saída (Input e Output Templates) do processo de otimização. Neste código faz-se necessário a declaração das variáveis de entrada, portanto na implementação foram definidas 6 variáveis de entrada, as quais pode ser visualizada na Figura 6.2 o workflow (estrutura de otimização). Os parâmetros de entradas das variáveis a serem otimizadas são: módulo de corte $(G)$, Poisson $(v)$, Poisson drenado $\left(v_{u}\right)$, coeficiente de permeabilidade $(k)$, porosidade $(\phi)$ e coeficiente de Skempton $(B)$. Estes nós estão ligados as respectivas funções de cálculo, sendo Módulo de Corte, Poisson, Coeficiente de Permeabilidade e Porosidades interligadas 
como variáveis de entrada para base de cálculos dos deslocamentos, Poisson Drenado e Coeficiente de Skempton.

A solução do problema de poroelasticidade considerando as variáveis de projeto otimizadas são expressas graficamente através de curvas. Estas curvas são comparadadas com uma solução analíticas, onde a diferença do problema otimizado e o analítico é realizado através da minização do erros entre curvas. Este procedimento por simplicidade na construção dos gráficos é realizado usando o Matlab. Maiores detalhes referentes ao cálculo do erro entre curvas será apresentando na sequência deste capítulo.

Outros três nós são definidos no workflow para procedimento de otimização, são eles: DOE responsável por selecionar os métodos de geração dos pontos designs (famílias) iniciais, a partir dos quais o algoritmo fará as buscas até solução ótima. Dentre as opções de designs, foi utilizado o DOE Uniform Latin Hypercube (ULH), devido a capacidade de gerar para cada variável pontos uniformemente distribuídos em toda dimensão do domínio, sem que ocorra variáveis repetidas no processo de busca.

De acordo com Alba (2016) é importante salientar que a aleatoriedade na geração de pontos iniciais do processo de otimização pode trazer grandes benefícios, principalmente quando se trata de métodos baseados em gradientes, evitando em alguns casos a convergência para mínimos locais.

Outro nó inserido no script é o Scheduler, onde foi definido o algoritmo de otimização e as respectivas propriedades. O Scheduler é utilizado analisando os pontos iniciais definidos pelo DOE, aplicando um operador de otimização. Dentre os diversos operadores disponíveis para processamento de otimização, o escolhido foi o NSGA-II devido sua capacidade de operar com conceitos de dominâncias, e diversidade no campo de busca, conforme apresentado no capítulo 5.

O ultimo nó adicionado foi o Logic End, este indica o ponto final do processo de otimização, ou seja, assim que a função objetivo chegar a um determinado valor (para este caso, chegar ao valor $\cong 0$ ), a busca chega a um valor ótimo, e o processo é encerrado. 


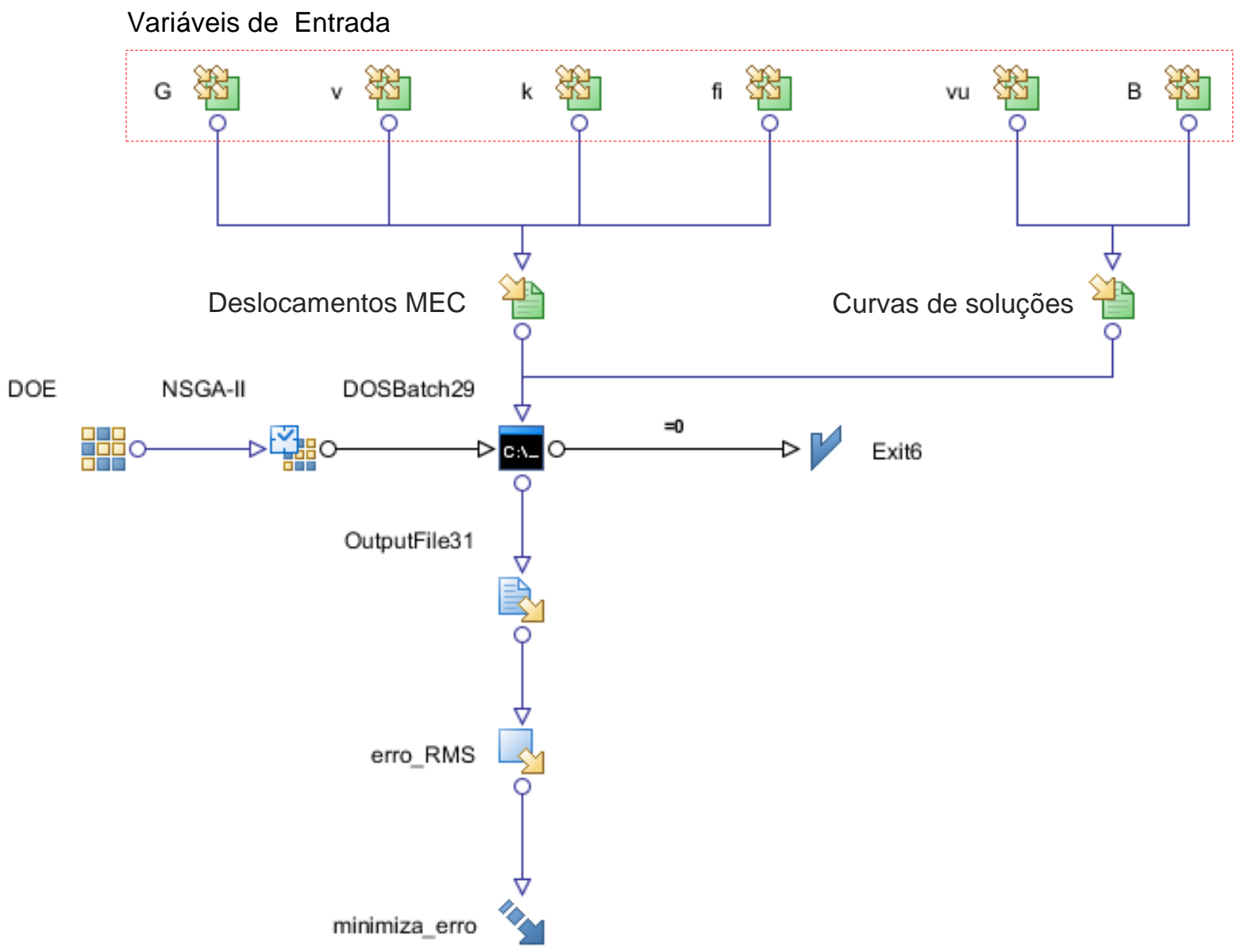

Figura 6.2 - Programação de otimização

A função objetivo está interligada ao nó denominado erro RMS. Este nó é responsável por minimizar o valor da função objetivo e aproximar os valores das variáveis de projetos, que carregam as informações das propriedades mecânicas do solo.

Através deste nó as curvas são graficadas pelo MatLab (curva analítica e curva otimizada). Se elas se sobrepuserem, significa que existem os mesmos valores nas variáveis de entrada. A equação que representa a função objetivo pode ser vista na Eq. (6.1).

$$
\text { erro_RMS }=\sqrt{\frac{(Y Y-Y)^{2}}{Y Y}}
$$

onde $Y Y$ são os valores de deslocamento $\left(u_{y}\right)$ para solução numérica apresentada por Dominguez (1993) e Yrepresenta os deslocamentos $\left(u_{y}\right)$ para solução analítica, apresentada por Cheng (1991). 
A Figura 6.3 demostra o procedimento de programação para otimização em todos os processos. Onde o processo de otimização utiliza o AG para calcular as variáveis. O cálculo do deslocamento e o erro são calculado de acordo com os critérios da solução analítica a fim de minimiza-lo (função objetivo).

Se a minimização é obtida a procura é parada e este é dado como o valor da solução, caso este ainda não seja o valor ideal, o procedimento é refeito, até chegar a um valor ideal, através da busca feita pelo operador.

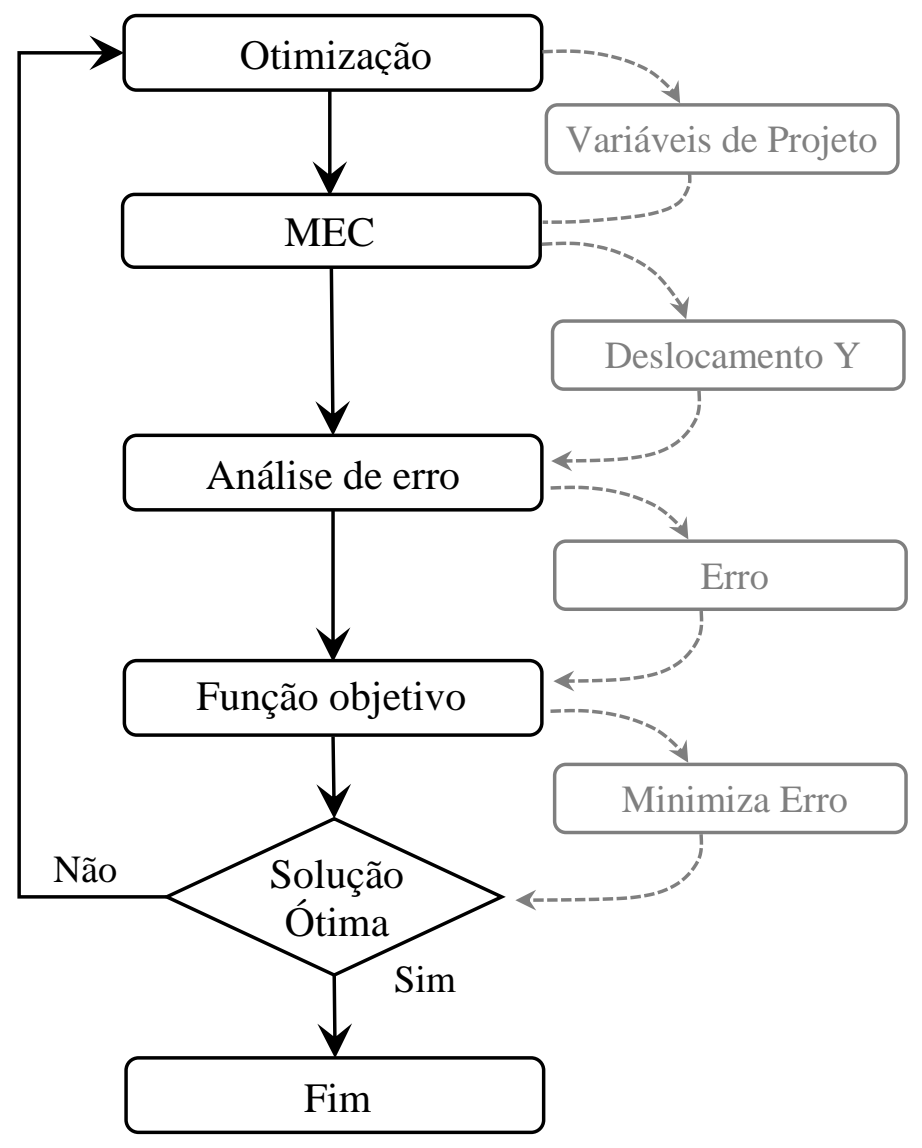

Figura 6.3 - Estrutura de programação

\subsection{Superfície de resposta}

Nos problemas de engenharia onde a solução pode demandar muito custo computacional de um CPU, o uso de modelos físicos requer configuração adequada (hardware), tendo em vista a solução com centenas de chamadas ao método de solução do problema físico.

Para tentar contornar/minimizar estas dificuldades, estudos de otimização baseados em soluções aproximadas foram adotados, permitindo que o algoritmo seja aplicado a modelos simplificados e de baixo custo computacional, na análise das 
otimizações. Para este contexto, destacam-se as soluções baseadas no Response Surface Method (RSM) ou Superfície de Resposta.

De acordo com Box et al. (1987), a metodologia do RSM é essencialmente um conjunto de técnicas estatísticas usadas em pesquisas, com a finalidade de analisar as melhores condições de soluções ao problema, e dar maior conhecimento sobre a natureza de certos fenômenos. Consiste em uma aproximação matemática, onde procura representar a resposta de um sistema a partir de interpolação de um conjunto de soluções existentes, composta por planejamento e análise de experimentos, que procuram relacionar respostas com os níveis de fatores quantitativos que afetam essas respostas.

Estes relações entre as respostas procuram atingir um dos objetivos:

a) Estabelecer relação de como uma resposta é afetada por um número de fatores em alguma região de interesse;

b) Estudar a explorar a relação entre várias respostas e extremos obrigatórios;

c) Localizar e explorar a vizinhança de resposta máxima ou mínima;

d) Determinar a influência das variáveis de projeto sobre dados obtidos da otimização, entre outros.

Para o presente trabalho utilizou-se o modelo de Decomposição em Valores Singulares (Polynominal SVD), este modelo promove a aproximação de respostas minimizando os quadrados das estimativas de erro para determinado conjunto de dados, sendo bastante útil para se obter uma ideia geral do comportamento das respostas. O RSM foi utilizado para encontrar uma superfície que apresente o menor erro entre os resultados virtuais gerados pelas superfícies de respostas. 


\section{APLICAÇÕES DO PROBLEMA}

\subsection{Problema}

Na natureza as características de porosidade são encontradas nas chamadas rochas sedimentares, conhecidas por possuírem capacidade de armazenamento de fluído através das propriedades de porosidade e permeabilidade. Estas propriedades caracterizam as rochas sedimentares como rochas reservatórios.

Portanto os reservatórios são aqueles onde existe acumulação de fluído (águas, petróleo, gás, etc.), e geralmente estão enquadradas por rochas impermeáveis, ou seja, rochas que impeçam a migração destes fluído, estas conhecidas como rochas de cobertura. Este conjunto reservatório-cobertura pode ser designada por "armadilha" e é, geralmente, ocupado pelos aquíferos no seio dos quais se encontram os fluídos. A Figura 7.1 demonstra uma aplicação das rochas reservatórios saturadas com óleo (Petróleo).

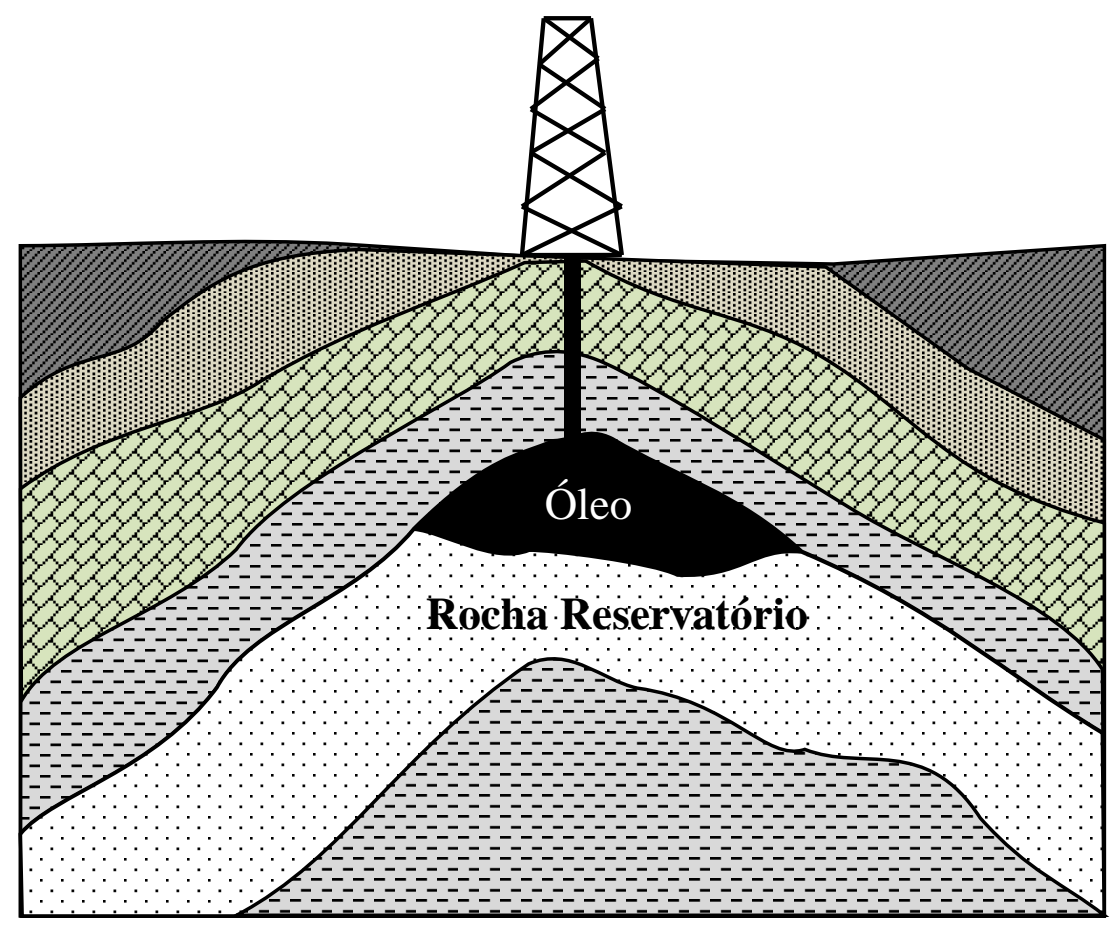

Figura 7.1 - Rochas reservatório

Outra aplicação do problema são as cargas de uma determinada estrutura como a de uma construção, por exemplo, onde são transmitidas cargas ao solo, gerando uma redistribuição dos estados de tensões, no qual irá provocar uma deformação em maior ou menor intensidade, em toda a área ou nas proximidades do carregamento. A compressão do solo se dá pelo processo no qual a massa do solo, sob ação de cargas variam de volume (deformação), mantendo sua forma ou 
deformando-a. Este processo de compressão pode ocorrer por compactação (redução de volume devido ao ar/gás contido nos vazios do solo) e pelo adensamento (redução do volume da água contido nos vazios do solo).

Segundo Caputo (1981) a compressibilidade é uma relação independente do tempo entre variação de volume (deformação) e tensão efetiva, é a propriedade que o solo tem de ser suscetível à compressão. $O$ adensamento é o processo dependente do tempo de variação de volume (deformação) do solo devido à drenagem da água dos poros.

A Figura 7.2 demonstra esta aplicação, onde ocorreu uma consolidação do solo, pendendo para o lado onde havia uma concentração de carga. Para este caso ocorreram pelo menos dois problemas consecutivos, sendo uma como fundação mal construída e a segunda como um solo mal consolidado.
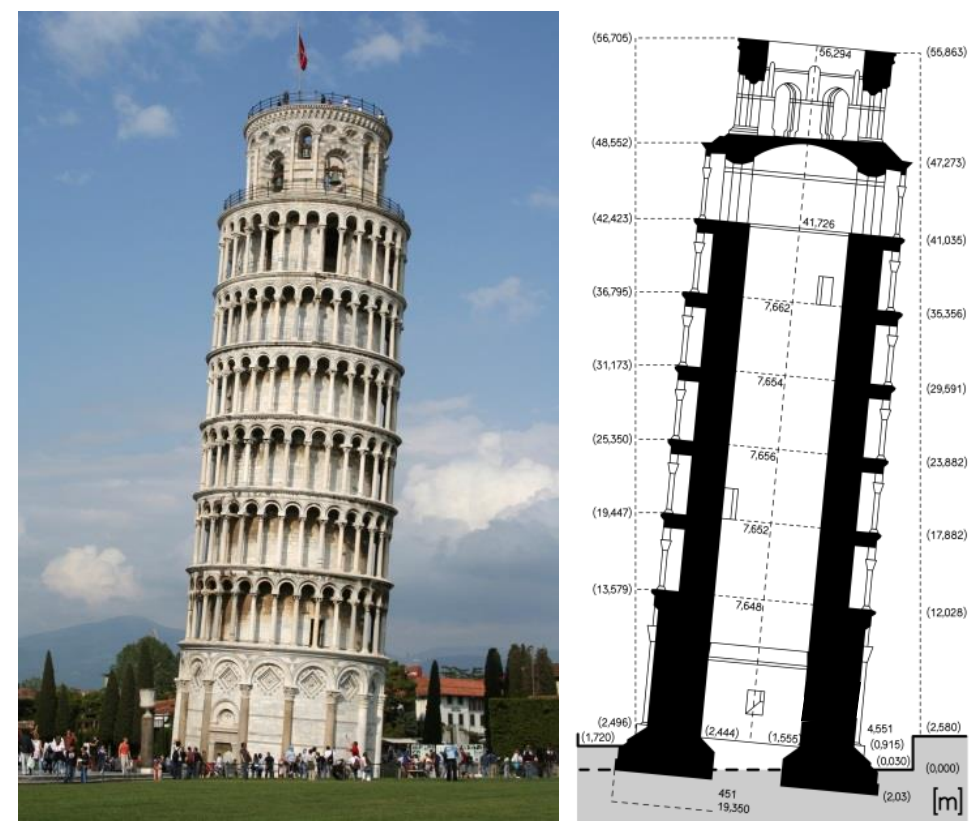

Figura 7.2 - Torre de Pisa na Itália.

Seguindo a mesma linha de raciocínio Cheng (1991) resolveu investigar um modelo de tensão em excitação no topo de uma coluna unidimensional saturado por um fluido, e observar o deslocamento vertical de acordo com a carga aplicada. Este modelo estudado por Cheng é apresentado na Figura $7.3 \mathrm{com}$ três possibilidades de excitação: tensão e pressão no topo da coluna e deslocamento na parte inferior. Estas excitaçõ foram analisadas separadamente por Cheng (1991), neste capítulo abordase somente a excitação de deslocamentos. 


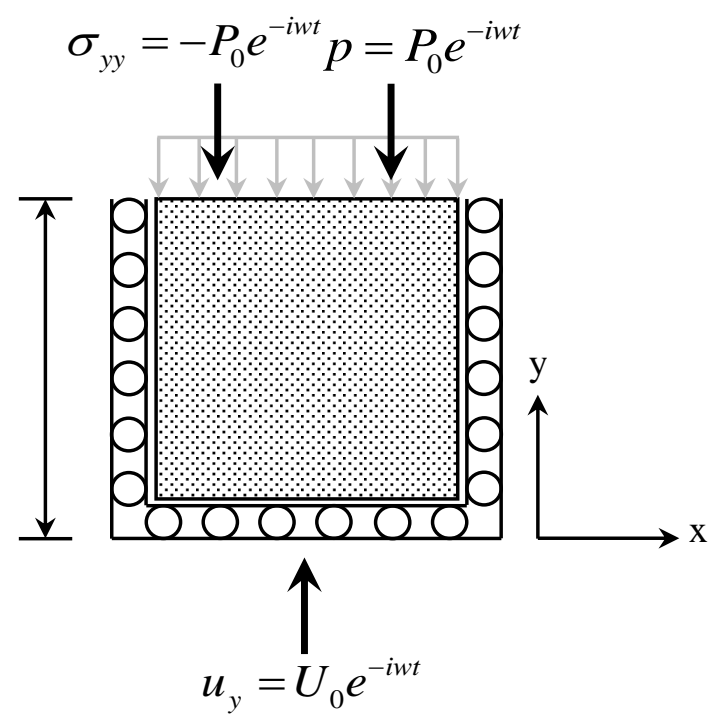

Figura 7.3 - Coluna de solo saturado sobre carregamento dinâmico

Foi assumida no topo da coluna uma tensão harmônica normal de $-P_{0} e^{-i w t} \mathrm{e}$ superfície drenada. A parte inferior e os lados foram considerados como rígidos, sem atritos e impermeáveis. As condições de contorno para o problema são apresentadas de acordo com a Eq. (7.1).

$$
\begin{aligned}
& \tilde{u}_{y}=0 ; \tilde{q}_{y}=0 \quad \text { para } \quad y=0 \\
& \tilde{\sigma}_{y y}=-P_{0} ; \tilde{p}=0 \quad \text { para } y=L
\end{aligned}
$$

A solução exata para o sistema poroelástico unidimensional em termos de deslocamento vertical pode ser obtida através da Eq. (7.2) seguido de alguns operadores.

$$
\begin{gathered}
\frac{E_{s} \tilde{u}_{y}}{P_{0} L}=\frac{d_{3}\left[e^{-\lambda_{1}(L-y)}-e^{-\lambda_{1}(L+y)}\right]}{L\left(\lambda_{3} d_{1}-\lambda_{1} d_{3}\right)\left(1+e^{-2 \lambda_{1} L}\right)}-\frac{d_{1}\left[e^{-\lambda_{3}(L-y)}-e^{-\lambda_{3}(L+y)}\right]}{L\left(\lambda_{3} d_{1}-\lambda_{1} d_{3}\right)\left(1+e^{-2 \lambda_{3} L}\right)} \\
E_{s}=\frac{2 G(1-v)}{(1-2 v)} \\
d_{i}=\frac{E_{s} \lambda_{i}^{2}+\omega^{2}\left(\rho-\beta \rho_{f}\right)}{\lambda_{i}(\alpha-\beta)} \\
\lambda_{1}=\sqrt{\frac{-B_{0}+\sqrt{B_{0}^{2}-4 A_{0} C_{0}}}{2 A_{0}}} ; \lambda_{1}=\sqrt{\frac{-B_{0}-\sqrt{B_{0}^{2}-4 A_{0} C_{0}}}{2 A_{0}}}
\end{gathered}
$$




$$
\begin{gathered}
A_{0}=\frac{E_{s} \beta}{\omega \rho_{f}} ; B_{0}=\frac{\omega \beta\left(\rho-\beta \rho_{f}\right)}{\rho_{f}}+\frac{E_{s} \omega \phi^{2}}{R}+\omega(\alpha-\beta)^{2} \mathrm{e} \\
C_{0}=\frac{\omega^{3} \phi^{2}\left(\rho-\beta \rho_{f}\right)}{R}
\end{gathered}
$$

Onde $E_{s}$ é o módulo de elasticidade drenado, $\omega$ é a excitação de frequência, $\rho$ são as densidades do solo ( $\rho_{s}$ é a densidade do sólido, $\rho_{f}$ é a densidade do fluido e $\rho_{a}$ é a densidade adicional) e $\lambda_{1}$ são as características de dilatação e dissipação das ondas em alta velocidade e $\lambda_{3}$ para baixa velocidade. Ondas de segundo tipo podem ser encontradas em Biot (1956a), assim como as características de dissipação das ondas apresentadas aqui.

Para o cálculo dos coeficientes $A_{0}, B_{0}$ e $C_{0}$ é preciso calcular o coeficiente de tensão efetiva de Biot $\alpha$ Biot (1956), o coeficiente constitutivo poroelástico $R$ Biot \& Willis (1956) e o campo de força $\beta$ obtido através da dependência de frequência, se o material apresentar comportamento viscoelástico Biot (1956c). Estas equações podem ser vistas nas Eq. (7.7) Eq. (7.8) e Eq. (7.9), respectivamente.

$$
\begin{gathered}
\alpha=\frac{3\left(v_{u}-v\right)}{B(1-2 v)(1+v u)} \\
R=\frac{2 \phi^{2} G B^{2}(1-2 v)\left(1+v_{u}\right)^{2}}{9\left(v_{u}-v\right)\left(1-2 v_{u}\right)} \\
\beta=\frac{\omega \phi^{2} \rho_{f} k}{i \phi^{2}+\omega k\left(\rho_{a}+\phi \rho_{f}\right)}
\end{gathered}
$$

Para esta análise foram utilizadas seis variáveis como propriedades que correspondem às propriedades mecânicas do solo: $G=6.0 \times 10^{9} \mathrm{~N} / \mathrm{m}^{2}, v=0,2 ; v_{u}=0,33$ $; \quad k=1.9 \times 10^{-10} \mathrm{~m}^{4} / \mathrm{N} \cdot \mathrm{s} ; \quad B=0,62 ; \phi=0,19 ; \quad \rho_{s}=2,800 \mathrm{~kg} / \mathrm{m}^{3} ; \quad \rho_{f}=1,000 \mathrm{~kg} / \mathrm{m}^{3}$; $\rho_{a}=150 \mathrm{~kg} / \mathrm{m}^{3}$ e o comprimento da coluna de $L=1$. Estas propriedades foram apresentadas por Rice \& Cleary (1976) em estudo sobre soluções básicas de difusão de tensão para meios poroelásticos saturados com componentes compressíveis. 


\subsection{Validação}

A formulação apresentada por Cheng (1991) foi definida em termos de diferentes parâmetros dinâmicos e cinemáticos, assim como ao estudo apresentado por Dominguez (1991). A escolha de um ou outro conjunto de parâmetros é apenas uma questão de preferência e as equações de equivalência das duas formulações podem ser vistas em Dominguez (1992).

Dominguez (1993) apresentou uma formulação de MEC em domínio dinâmico para problemas poroelásticos, iniciando pelas análises dos coeficientes de Biot (1956) e formulações de equações integrais de contorno em termos de deslocamentos sólidos e tensão no fluído. Selvadurai (1996) também apresenta uma análise de ondas para meios poroelásticos, aplicando as definições de Cheng (1991) e Dominguez (1993).

Para validar o sistema apresentado por Dominguez (1993) e aplicar a formulação proposta por Biot (1956), foi realizado o cálculo dos deslocamentos verticais obtidos através da excitação no topo da coluna. As soluções numéricas obtidas foram então analisadas e comparadas com solução analítica apresentada por Cheng (1991), usando os mesmos conjuntos de materiais, correspondente às propriedades mecânicas do solo, definidas por Rice \& Cleary (1976).

Os resultados são plotados em valores absolutos de deslocamento normalizado no topo da coluna $\tilde{u}_{y}(L) E_{u} / P_{0} L$ versus a frequência adimensional $\omega^{*}=\omega / \omega_{1}$, onde $\omega_{1}$ é a primeira frequência de ressonância baseada nas propriedades do material conforme Eq. (7.10). Segundo Selvadurai (1996) para frequências abaixo da primeira frequência natural, o deslocamento adimensional aproxima os valores dos deslocamentos poroelásticos ao comportamento elástico.

$$
\omega_{1}=\frac{\pi}{2 L} \sqrt{\frac{E_{u}}{\rho}}
$$

Onde $E_{u}$ é o módulo de elasticidade não drenado, conforme Eq. (7.11).

$$
E_{u}=\frac{2 G\left(1-v_{u}\right)}{\left(1-2 v_{u}\right)}
$$

Em conformidade com as representações feitas por Cheng (1991) e Dominguez (1991) os resultados foram representados com respostas em frequências normalizadas pela primeira frequência, correspondendo a um problema elástico. A 
mesma análise utilizando os princípios da teoria de Biot foi apresentada e analisada por Selvadurai (1996) também através da aplicação dos Elementos de Contorno para propagação de ondas em meio poroelástico saturado, com a mesma propriedade mecânica do solo.

Através da análise foram encontrados os picos de ressonância para baixa frequência de ordem natural $\omega_{n}=(2 n-1) \omega_{1}$, sendo $n=1,2,3, \ldots$ E a Figura 7.4 demonstra a curva da solução numérica sobrepondo a solução a analítica.

O problema inicialmente apresentado por Selvadurai (1996) aplicando as definições indicadas por Dominguez (1993) foi definido em 24 elementos constantes, 4 pontos de Gauss e um conjunto discreto de 44 frequências.

A Figura 7.4 apresenta a sobreposição das curvas até o nó $\omega=2.5 \omega_{1}$ onde a partir deste ponto é visível um pequeno deslocamento da solução numérica, este por influência das características mecânicas do solo.

Estas características mecânicas são chamadas de variáveis de projeto, e a partir destas variáveis, com influência de excitação de frequência no topo da coluna, o solo responde com deslocamentos verticais, em picos de ressonância. Esta representação pode ser vista na figura Figura 7.4.

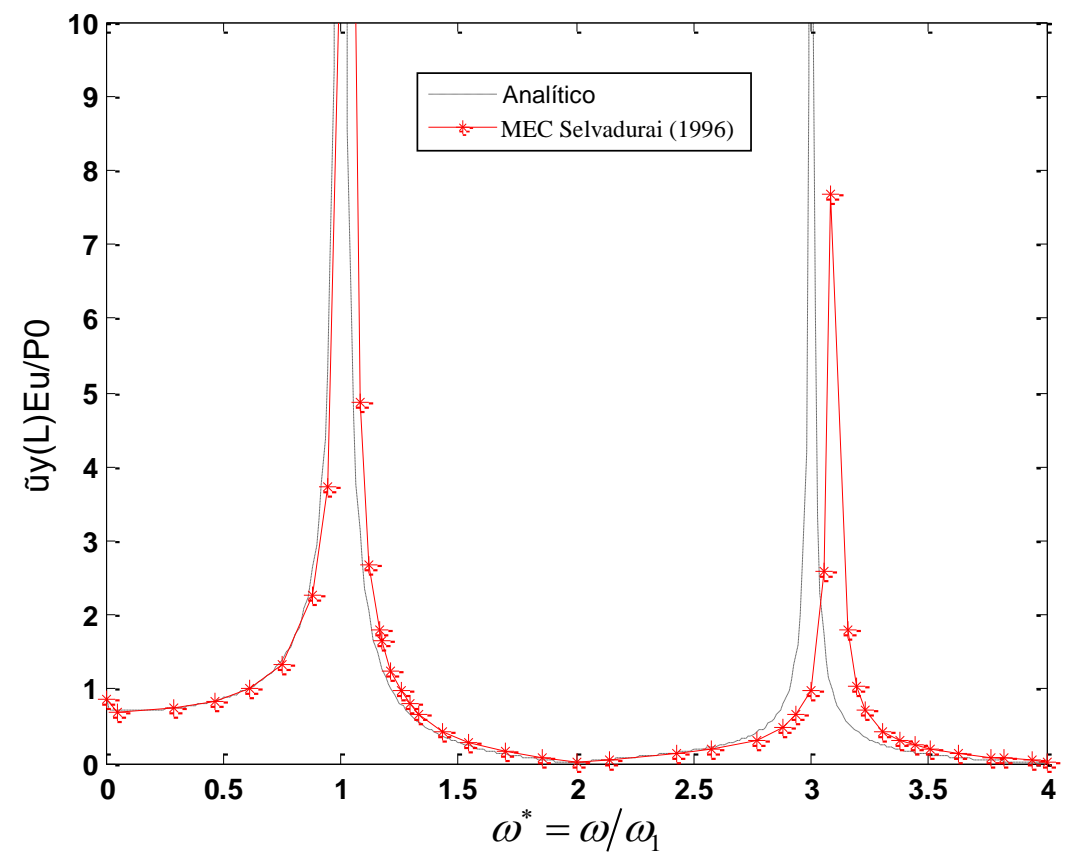

Figura 7.4 - Deslocamento no topo da coluna (tensão de excitação)

A normalização foi baseada em considerações de baixa permeabilidade relativa do material da rocha. Como consequência, o fluido é aprisionado nos poros e reage 
na deformação volumétrica junto com o sólido. A deformação da coluna é basicamente elástica, mas com a combinação das forças do sólido e fluído, esta combinação de forças são características das propriedades elásticas de materiais não drenados, segundo Cheng (1991). Assim, o módulo de elasticidade não drenado $E_{u}$ é utilizado ao invés do drenado $E_{s}$.

O deslocamento da curva analítica e numérica pode ser minimizado aplicando uma Função de Raiz Quadrada de Erro Médio (Root Mean Square Error), esta função pode ser visto na e Eq. (7.12) do erro RMS.

$$
\text { erro_RMS }=\sqrt{\frac{(Y Y-Y)^{2}}{Y Y}}
$$

Onde $Y Y$ são os deslocamentos da solução numérica e $Y$ os deslocamentos da solução analítica. 


\section{RESULTADOS E DISCUSÕES}

Sem a definição do tipo de solo, o terreno do ponto de vista da construção civil pode apresentar falhas em curto, médio ou longo prazo. O solo é responsável por suportar as cargas das edificações, e sem o estudo da definição das propriedades mecânicas a ele pertencente, podem surgir problemas de difícil recuperação e gerar custos adicionais.

As maneiras com que as propriedades do solo são caracterizadas, podem ser da maneira clássica, com uma sondagem do solo, onde é possível conhecer o tipo do terreno (argila, areia, rocha, etc), as camadas que constituem o local e suas resistências. Outra forma de caracterizar o solo é através da utilização do mapa geológico da região, apresentada pelo Serviço Geológico do Brasil (CPRM), com uma cartografia geológica do local. Esta cartografia define de forma ampla a geologia da região.

A definição do solo é importante para não colocar em risco a qualidade da obra. Neste sentido a formulação apresentada nesta dissertação, aplicando os elementos de contorno e a integração das plataformas do processo de otimização, aliada ao suporte da cartografia da região, possibilitará a definição do tipo solo do local. Tal metodologia dispensa a contratação do serviço de sondagem, por aplicar uma engenharia inversa do problema.

Considerando a possibilidade de que se tenha obtido experimentalmente o deslocamento no topo da coluna do problema apresentado na Figura 7.4 através de excitação dinâmica, foi possível desenvolver um código numérico aplicando um problema inverso, robusto o suficiente para que prediga dentro de um espaço de busca definido na geologia do local, qual o tipo de solo da região em estudo.

Aplicando a metodologia proposta e considerano o problema inverso fez-se uma definição de uma coluna de solo, com um vetor de 327 frequências, com sua geometria discretizada em 32 elementos constantes, e integrada numericamente com 6 pontos de Gauss.

Estas definições foram necessárias para que as respostas do processo de caracterização do solo fossem representadas por curvas, definindo melhor os deslocamentos obtidos por picos de ressonâncias. As curvas obtidas então são apresentadas na Figura 8.1, onde é possível observar que não houve a sobreposição total das curvas. Sabendo que as propriedades mecânicas do solo influenciam no comportamento do mesmo, pôde-se concluir que alguma ou algumas das variáveis de 
projeto tornam o cálculo das curvas de deslocamentos mais sensíveis. Neste sentido, busca-se determinar o grau de influência de cada uma destas variáveis de projeto, afim de determinar a suas perturbações no comportamento do solo.

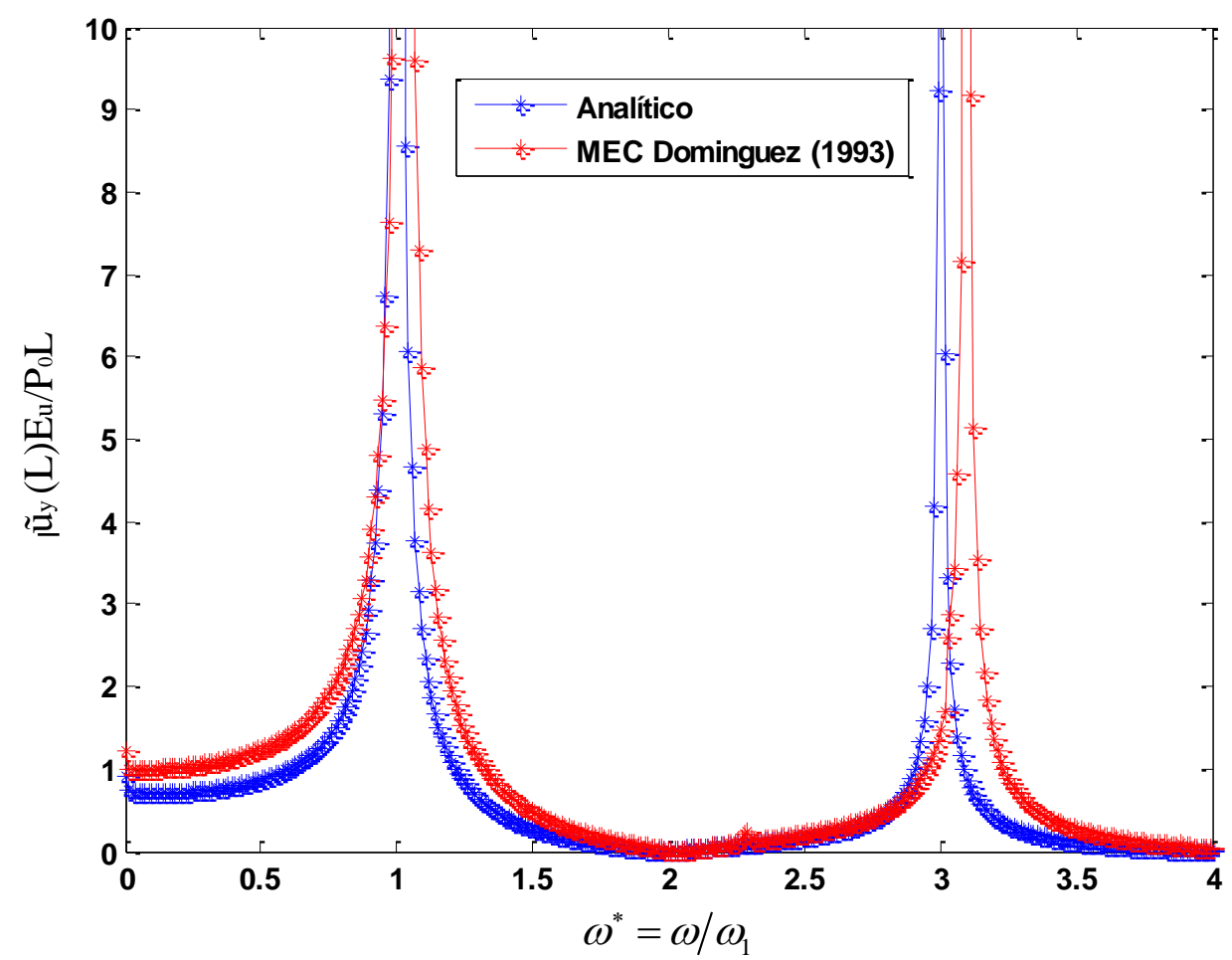

Figura 8.1 - Vetor com 327 frequências

O erro encontrado entre a solução numérica e analítica foi determinada a partir

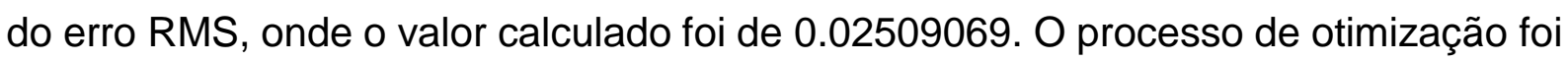
aplicado, no sentido de um problema inverso, para que as soluções se aproximem e apresentem um erro igual ou aproximado à zero. $\mathrm{O}$ ajuste das variáveis de projeto resultará na assertiva dos valores aproximados das propriedades mecânicas do solo. Para o processo de otimização foi considerado um intervalo de busca baseado nos tipos de solo daquela região em análise.

Sendo assim, o espaço de busca foi definido então entre os valores mínimos e máximos, de acordo com os seguintes materiais: Arenito de Berea, Granito d'Oeste, Arenito de Pecos e Arenito de Boise, retiradas da Tabela 1. Alternativamente, considerando outra região, tais limites poderiam ser definidos também pela cartografia geológica do local. A Tabela 4 ilustra os valores mínimos e máximos destes tipos de solos, adotados como espaço de busca das variáveis de projeto. 


\begin{tabular}{|c|c|c|}
\hline & Mínimo & Máximo \\
\hline$G$ & $1.5 \times 10^{10}$ & $6.0 \times 10^{9}$ \\
\hline$v$ & 0.15 & 0.25 \\
\hline$v_{u}$ & 0.31 & 0.34 \\
\hline$B$ & 0.50 & 0.85 \\
\hline$k$ & $4.0 e^{-4}$ & $8.0 \mathrm{e}^{2}$ \\
\hline$\phi$ & 0.01 & 0.26 \\
\hline
\end{tabular}

Para processos de otimização evolucionária há uma demanda de um elevado custo computacional, até que os critérios para alcançar a solução ótima sejam satisfeitos. A configuração utilizada para as simulações deste problema foi de um processador Intel ${ }^{\circledR}$ Core $^{\mathrm{TM}} \mathrm{i} 7-4820 \mathrm{~K}$ de $3.7 \mathrm{GHz}$ e $64 \mathrm{~Gb}$ de memória RAM. O tempo computacional utilizado para o processo foi de 85 horas e 71 minutos, para 10 mil iterações.

A Figura 8.2 representa o gráfico de coordenadas paralelas, e nele é possível verificar o comportamento de todos os controladores $\left(B, G, f i, k, v\right.$ e $\left.v_{u}\right)$ durante todo o processo de busca, em suas 10 mil iterações. Nesta mesma figura pode ser visto que o objetivo de minimizar a função foi alcançado, já que houve uma concentração cada vez maior no campo do erro RMS, minimizando estes valores.

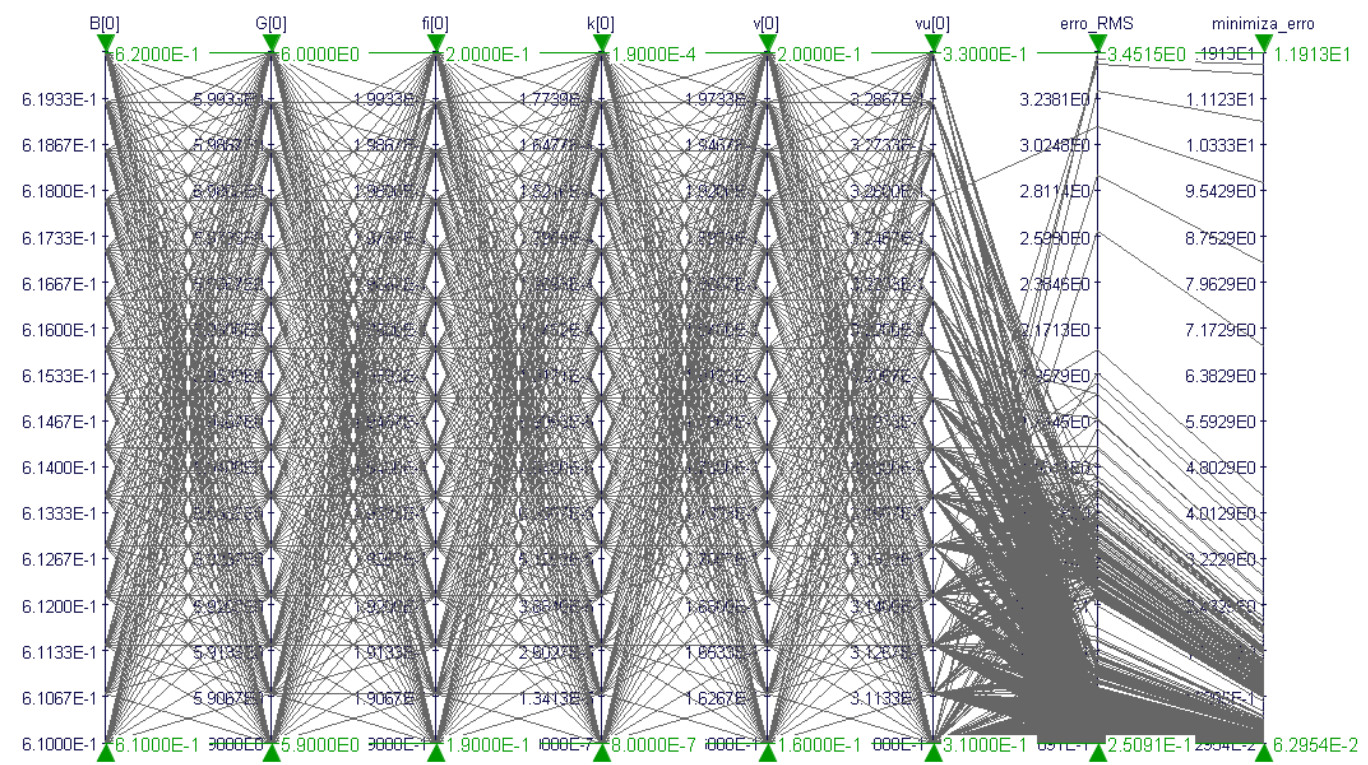

Figura 8.2 - Coordenadas Paralelas 
As famílias ou ID's são os conjuntos de variáveis a serem otimizadas, que logo após processo de busca, encontrou a melhor entre todas na iteração 5298. A Tabela 5 apresenta um conjunto de 60 ID's aleatórios no processo de otimização.

\begin{tabular}{cccccc}
\multicolumn{6}{c}{ Tabela 5 - Variáveis aleatórias } \\
\hline № & ID & № & ID & № & ID \\
\hline 1 & 258 & 21 & 3840 & 41 & 6172 \\
2 & 445 & 22 & 3970 & 42 & 6318 \\
3 & 622 & 23 & 3989 & 43 & 6483 \\
4 & 649 & 24 & 4046 & 44 & 7170 \\
5 & 664 & 25 & 4152 & 45 & 7179 \\
6 & 1031 & 26 & 4222 & 46 & 7200 \\
7 & 1061 & 27 & 4224 & 47 & 7245 \\
8 & 1154 & 28 & 4396 & 48 & 7257 \\
9 & 1182 & 29 & 4661 & 49 & 7292 \\
10 & 1358 & 30 & 4698 & 50 & 7757 \\
11 & 1600 & 31 & 4910 & 51 & 8145 \\
12 & 1606 & 32 & 5266 & 52 & 9126 \\
13 & 2014 & 33 & 5298 & 53 & 9402 \\
14 & 2409 & 34 & 5404 & 54 & 9670 \\
15 & 2467 & 35 & 5691 & 55 & 9765 \\
16 & 2542 & 36 & 5911 & 56 & 9776 \\
17 & 2831 & 37 & 5945 & 57 & 9897 \\
18 & 3031 & 38 & 6026 & 58 & 9940 \\
19 & 3333 & 39 & 6037 & 59 & 9990 \\
20 & 3424 & 40 & 6076 & 60 & 9991 \\
\hline
\end{tabular}

A Figura 8.3 demonstra graficamente todo o comportamento das variáveis do conjunto ID da Tabela 5, passando por todas as variáveis de projetos, de acordo com o procedimento de otimização, dando destaque a melhor solução durante o processo de busca (iteração 5298). 


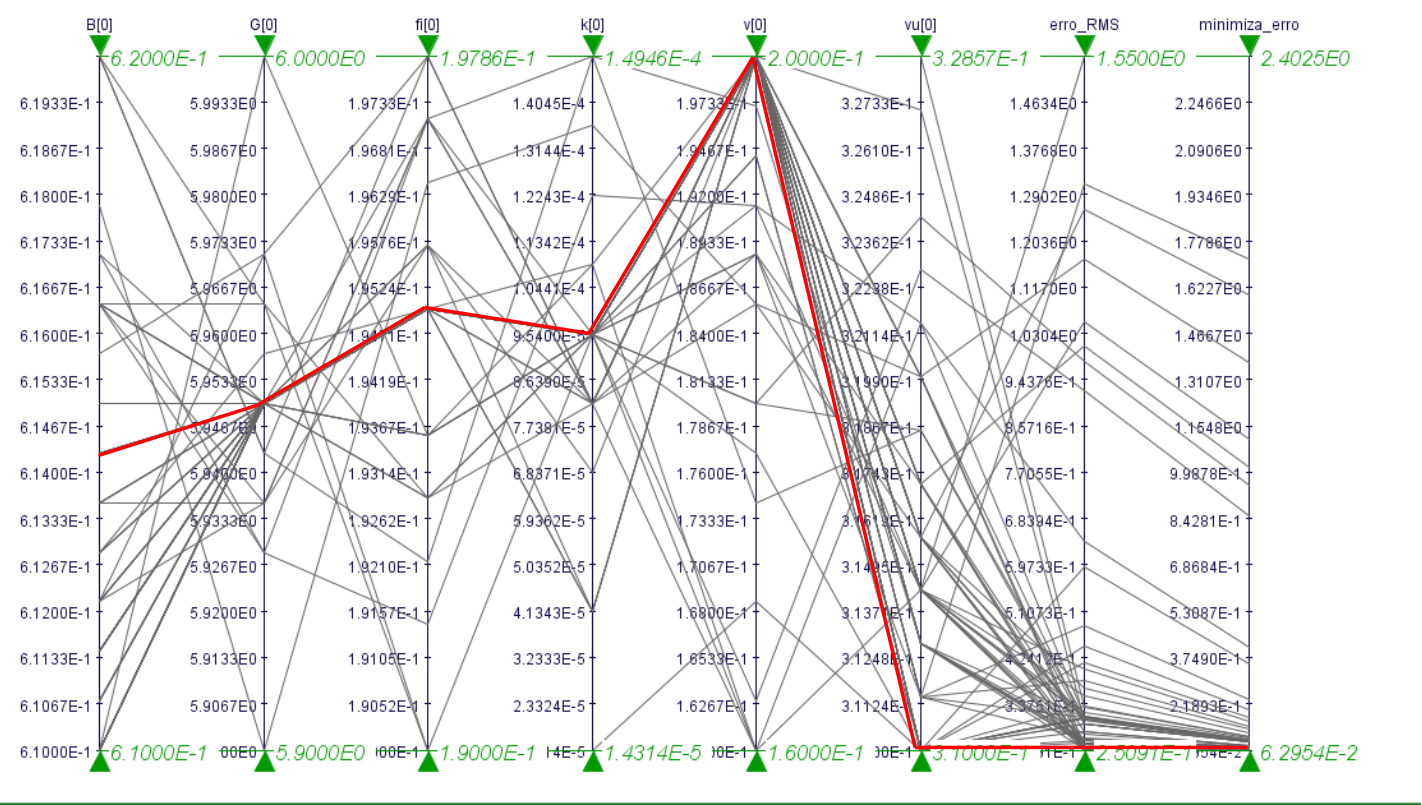

Figura 8.3 - Coordenadas paralelas aleatórias

A complexidade desta otimização está relacionada com a obtenção de uma solução fortemente dependente da maneira com que é distribuído os valores dos controladores de propriedades mecânicas do solo. O conjunto de soluções ótimas para um problema multiobjetivo é chamado de fronteira de Pareto. Esta técnica de tomada de decisão permite selecionar e priorizar um número pequeno de itens capazes de produzir grande efeito na melhoria dos processos. O conjunto das soluções ótimas é aplicado no contexto e representa o conjunto dos controladores que fornecem um desempenho ótimo.

O comportamento da função aplicado a todo processo pode ser visto na Figura 8.4. Onde através desta imagem pode-se observar o comportamento do erro RMS em função da minimização de seus valores. 


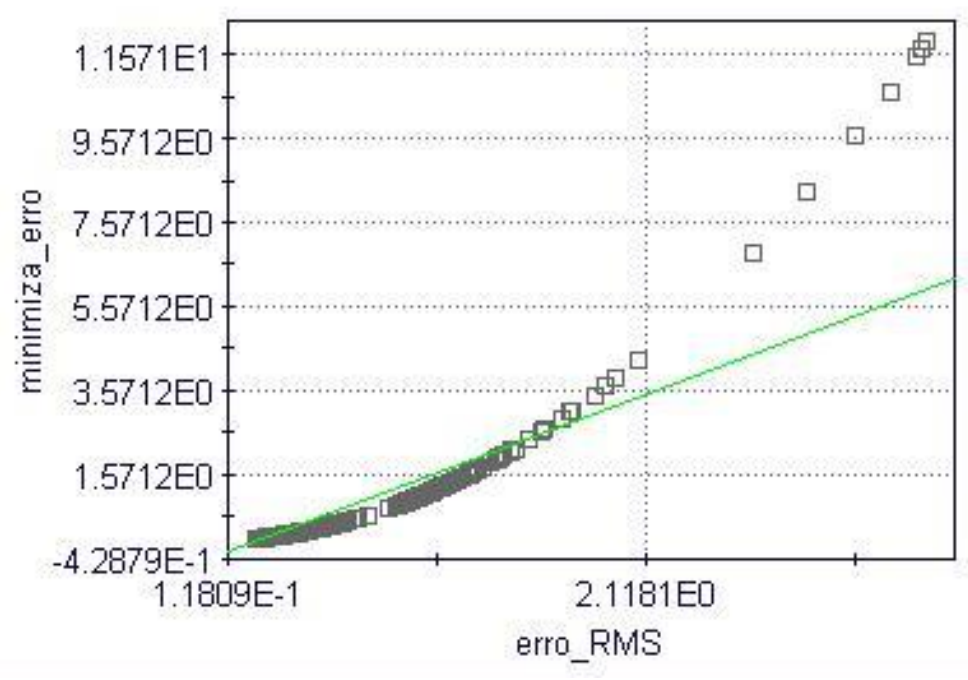

Figura 8.4 - Função de Pareto do processo de otimização

A tomada de decisão para ajuste das curvas que a função de Pareto utiliza é muito importante, pois as variáveis que são utilizadas como controladores de comportamento do solo, carregam a finalidade de melhorar o desempenho do sistema. Sabendo que não existe um controlador do sistema que possa melhorar o desempenho sem prejudicar pelo menos outro ou o sistema como um todo, vale ressaltar aqui quais controladores ou variáveis de projeto mais influenciaram no sistema causando menos prejuízo.

$\mathrm{Na}$ Figura 8.5 pode-se observar que a iteração 5298 obteve o melhor desempenho no processo de busca, e também pode se verificar quais variáveis mais influenciaram no comportamento do processo. Conforme apresentado na imagem, a permeabilidade $(k)$ do solo é uma das propriedades que mais influenciaram no comportamento do sistema, já que está relacionada com a quantidade de poros e a interligação entre elas, influenciando diretamente na percolação do fluído em sua estrutura.

Sabendo que a permeabilidade $(k)$ é a propriedade do solo em permitir o escoamento e adensamento da matriz, e que esta é uma das principais características do tipo de solo trabalhado (arenito). Será feita análise das variáveis em relação a permeabilidade, além de apresentar o comportamento das variáveis em relação ao sistema como um todo. 


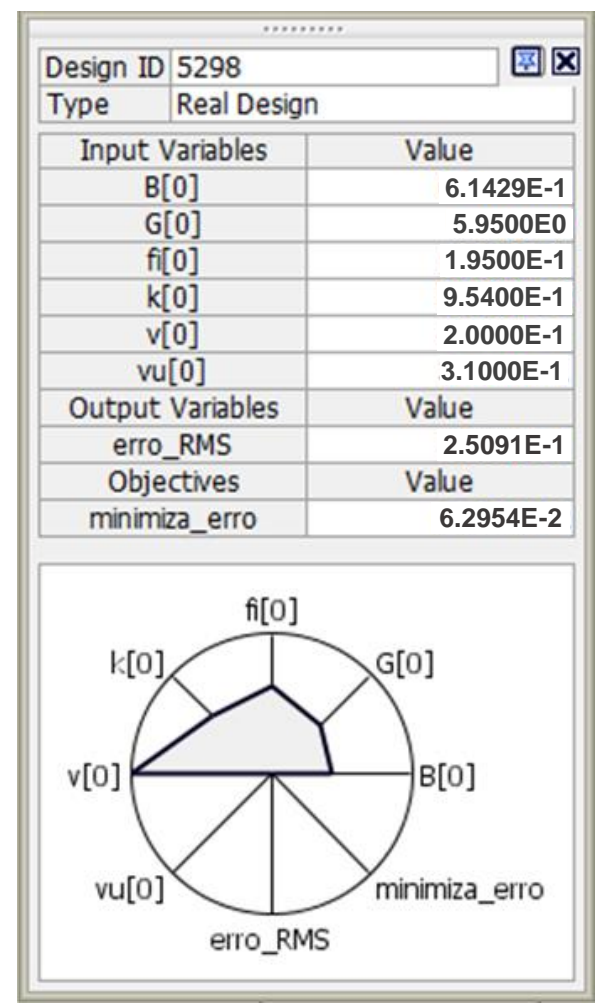

Figura 8.5 - Variáveis com maior influência na solução ótima

As influências serão apresentadas pela superfície de Pareto, e pelo RSM (Response Surface Method). A Figura 8.6 demonstra o comportamento do coeficiente de permeabilidade $(\kappa)$ em relação aos valores de minimização da função objetivo.

Sabendo que o processo de otimização armazena a melhor resposta através da função de Pareto, é possível verificar através do gráfico, uma concentração na linha onde existem as melhores respostas. E a iteração 5298 é indicada na Figura 8.6 como sendo o melhor resultado para a permeabilidade do sistema. 


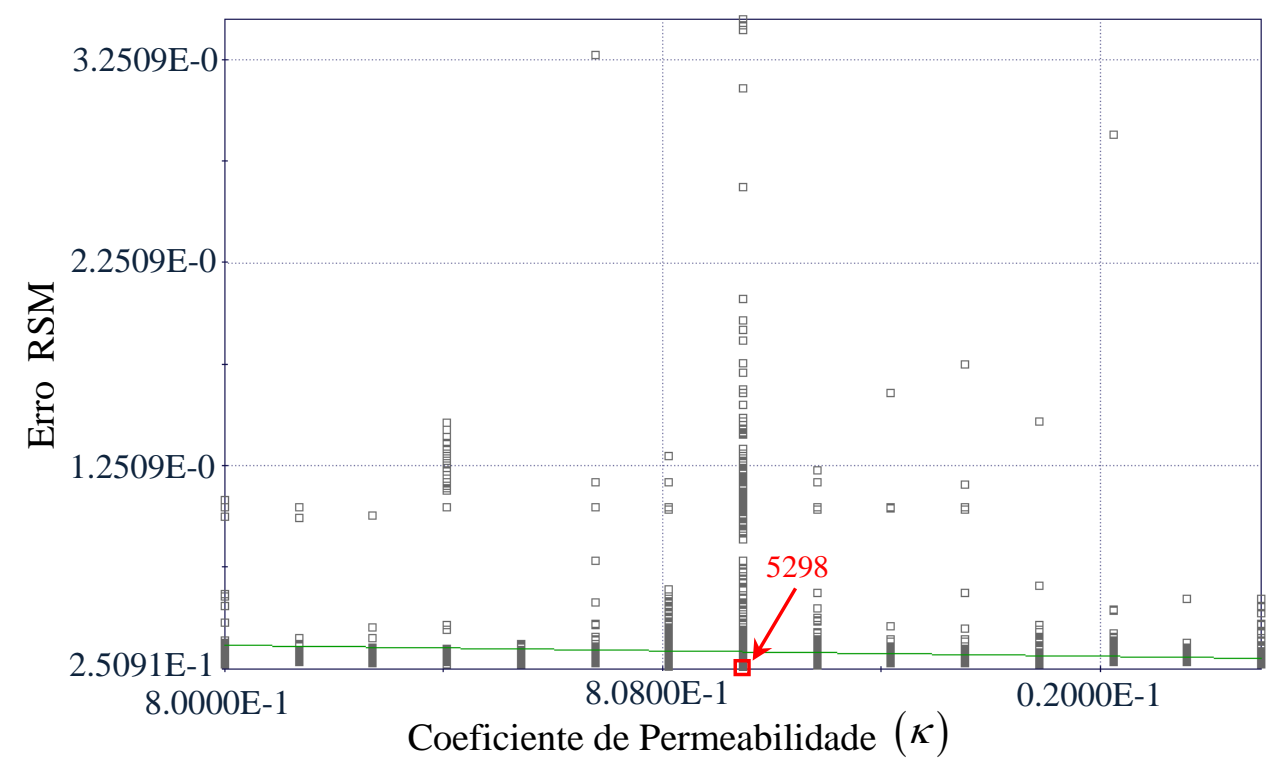

Figura 8.6 - Distribuição do Coeficiente de Permeabilidade

Logo após a avaliação da variável permeabilidade $(k)$, o coeficiente que mais influencia no comportamento do solo, pode ser considerado como o coeficiente de Poisson $(v)$. Sabendo que este é um parâmetro de deformabilidade importante do solo, pois embora o solo apresente deformações não recuperáveis após certo nível e tensão aplicada, este coeficiente mede a relação entre as deformações transversais e longitudinais em relação à direção do carregamento.

O desempenho deste coeficiente em relação a todo processo do sistema pode ser visto na Figura 8.7.

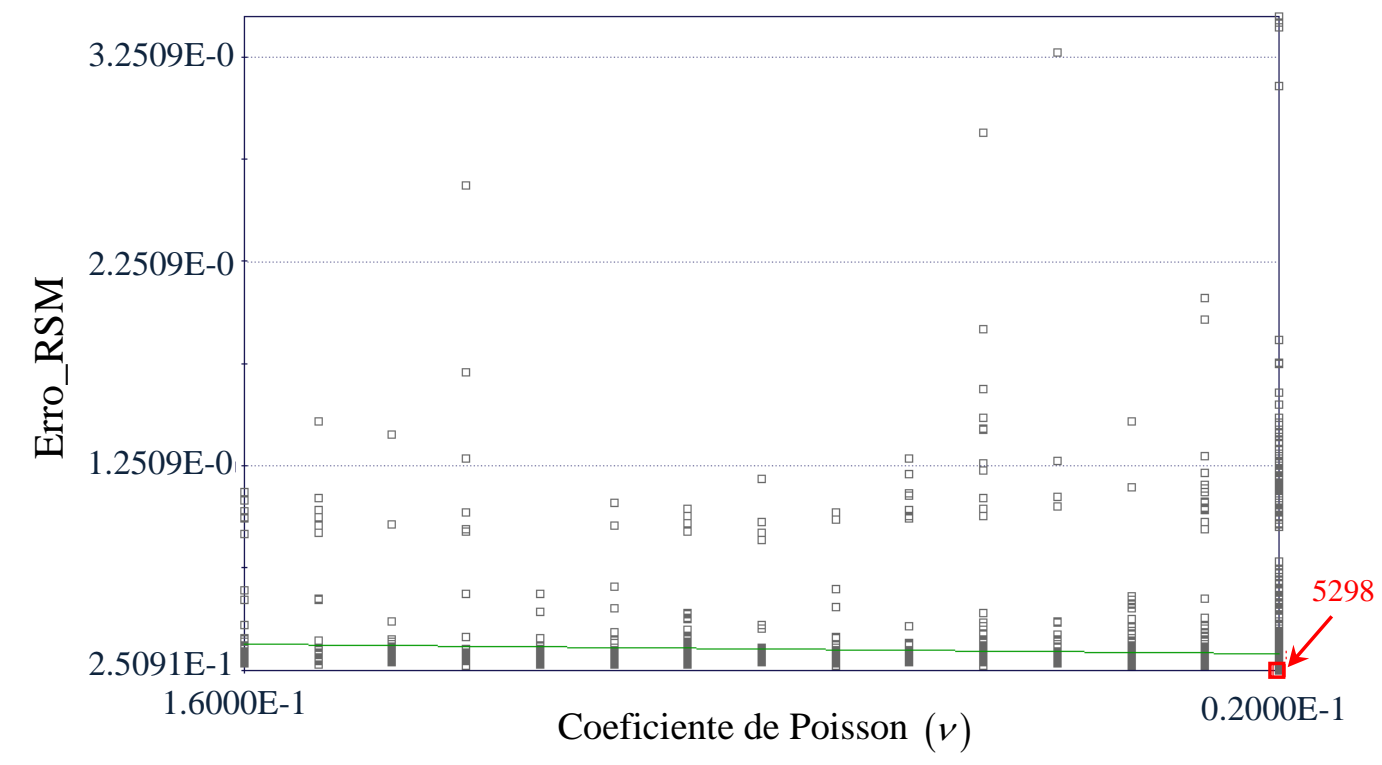

Figura 8.7 - Distribuição do coeficiente de Poisson 
É possível analisar pela Figura 8.7 os possíveis resultados de fronteira de Pareto para algumas soluções, havendo maior concentração no espaço tido como o de melhor comportamento em relação às outras variáveis. A indicando a iteração 5298 demonstra a linha onde se obteve um conjunto de melhores resultados.

Foi possível estimar o comportamento do coeficiente de Poisson através da ferramenta de análise de superfície (RSM), analisando a melhor situação do coeficiente sob influência das outras variáveis e também sobre a função objetivo do sistema.

Esta representação é apresentada em gráficos 2D e 3D através do comportamento no campo de otimização.

A Figura 8.8 apresenta o comportamento do coeficiente de Poisson $(v)$, onde na Figura 8.8 (A) verifica-se o comportamento da distribuição do coeficiente versus o coeficiente de permeabilidade $(k)$, e identifica os níveis, áreas e cores onde contêm os intervalos dos valores de busca.

No gráfico é possível identificar então uma concentração de busca nos campos entre $3.4334 \mathrm{e}-1$ e $4.0611 \mathrm{e}-1$. O valor final de coeficiente de Poisson $(v)$ foi encontrado em 2.0000e-1, não havendo diferença no valor inicialmente apresentado por Dominguez (1993). A Figura 8.8 (B) localiza no gráfico 2D o ponto onde foi obtido a melhor resposta do coeficiente de Poisson $(v)$, e a Figura 8.8 (C) representa o comportamento do coeficiente em todo processo de otimização, destacando o valor ótimo e o erro com função de raiz quadrada de erro médio (erro RMS) minimizado. 


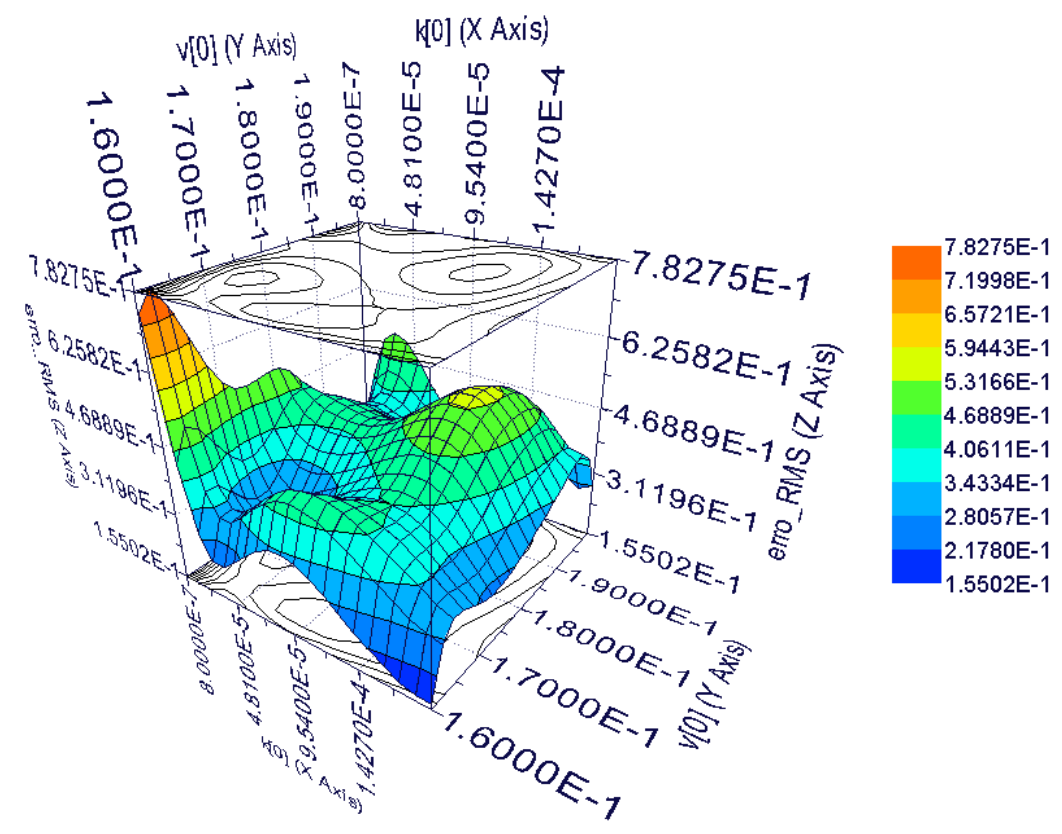

B

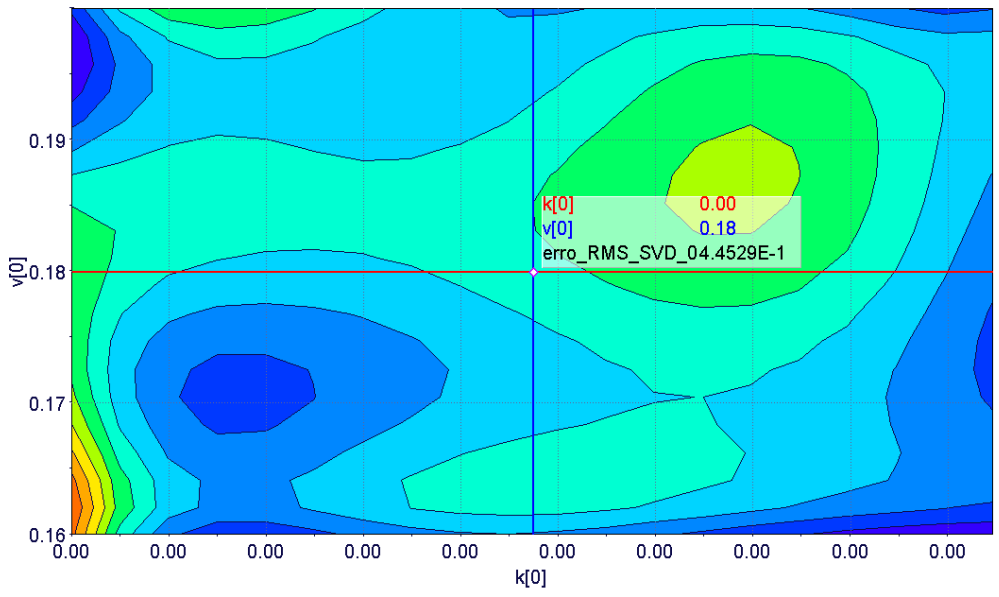

C

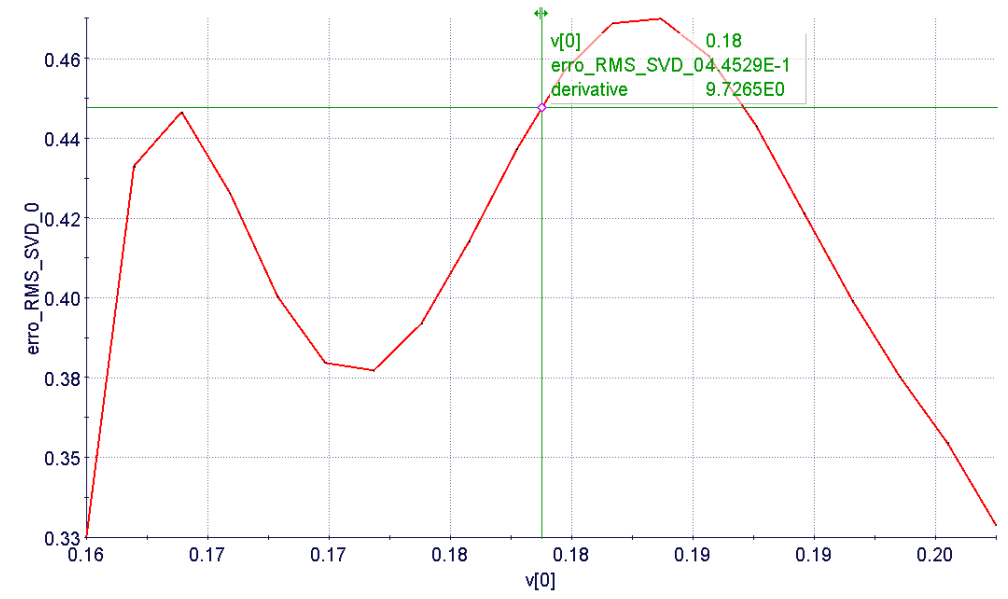

Figura 8.8 - (A) Gráfico RSM 3D (B) Gráfico RSM 2D (C) Comportamento do coeficiente Poisson 
Outro fator com grande importância durante a análise foi a porosidade, pois está diretamente relacionada com a textura e estrutura do solo, ou seja, influência na capacidade de drenagem interna e retenção de água de um perfil. A Figura 8.9 apresenta o comportamento e concentração da busca do processo de otimização do sistema, demostrando onde a solução ótima influenciada pela porosidade se encontra em relação a minimização da função da raiz quadrada do erro médio (erro RMS).

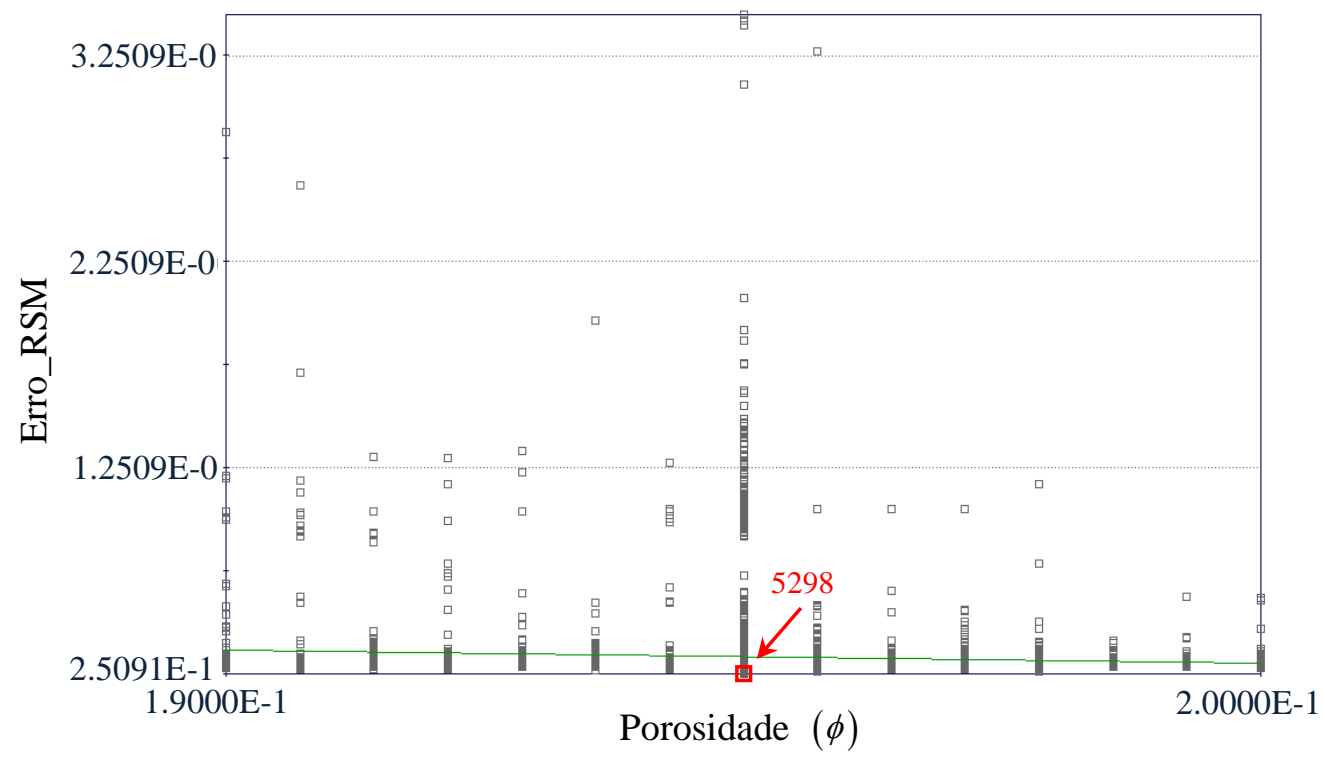

Figura 8.9 - Distribuição do coeficiente de porosidade

O conjunto de gráficos do método de avaliação de superfície de resposta RSM da Figura 8.10 analisa a porosidade durante o processo de otimização em relação ao coeficiente de permeabilidade. Sabendo que porosidade é diferente de permeabilidade, pois um solo ou rocha pode apresentar um nível alto de porosidade e baixa permeabilidade, pois o que define a permeabilidade é a interligação das porosidades e não quantidade de poros. Portanto o comportamento da porosidade para o sistema ficou da seguinte maneira. Houve uma concentração de intervalo de busca do processo entre $1.1545 \mathrm{e}-1$ e $2.9700 \mathrm{e}-1$. O valor final da porosidade não sofreu muita alteração ao valor apresentado por Dominguez (1993), representando valor final em 0.19500 e-1 após procedimento de otimização. A Figura 8.10 (A) apresenta o comportamento do coeficiente de porosidade $(\phi)$ versus permeabilidade $(k)$, em relação ao erro, através da função de raiz quadrada do erro médio (erro RMS), a Figura 8.10 (B) representa a parte 2D do sistema com a posição da solução ótima e a Figura 8.10 (C) o comportamento transversal. 

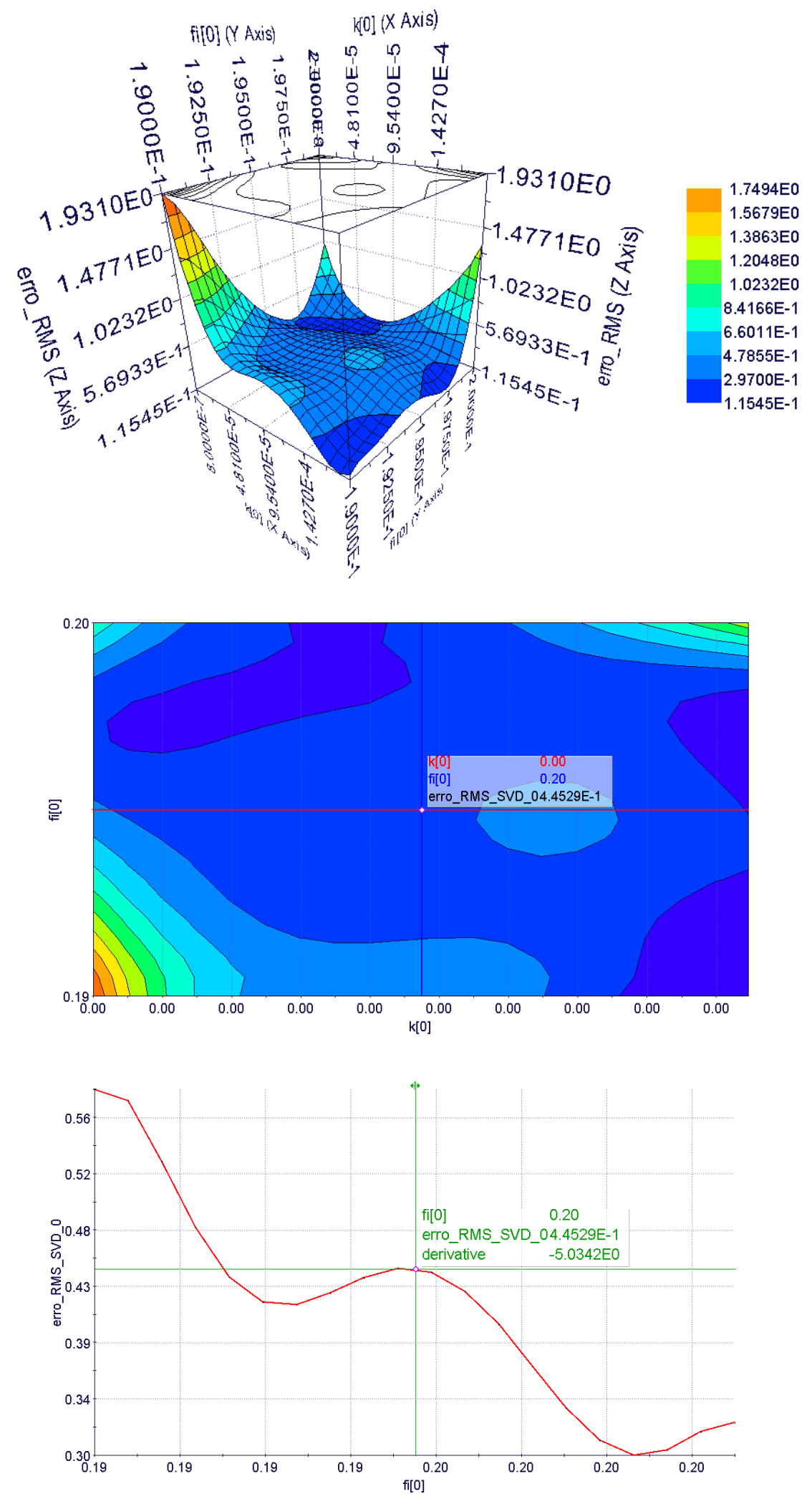

Figura 8.10 - (A) Gráfico RSM 3D (B) Gráfico RSM 2D (C) Comportamento do coeficiente porosidade

O carregamento externo aplicado na superfície, ou a própria geometria da superfície da massa do solo, contribui para o desenvolvimento de tensões tangenciais 
ou de cisalhamento, que podem chegar a valores próximos a máxima tensão cisalhante que o solo suporta sem haver a ruptura do material.

A Figura 8.11 apresenta uma concentração de soluções possivelmente ótimas para o módulo de cisalhamento, estando entre os intervalos de busca de $5.9000 \mathrm{e} 0 \mathrm{e}$ 6.0000e0. A resposta do sistema de otimização está representada pela seta indicando a iteração 5298 como ótima.

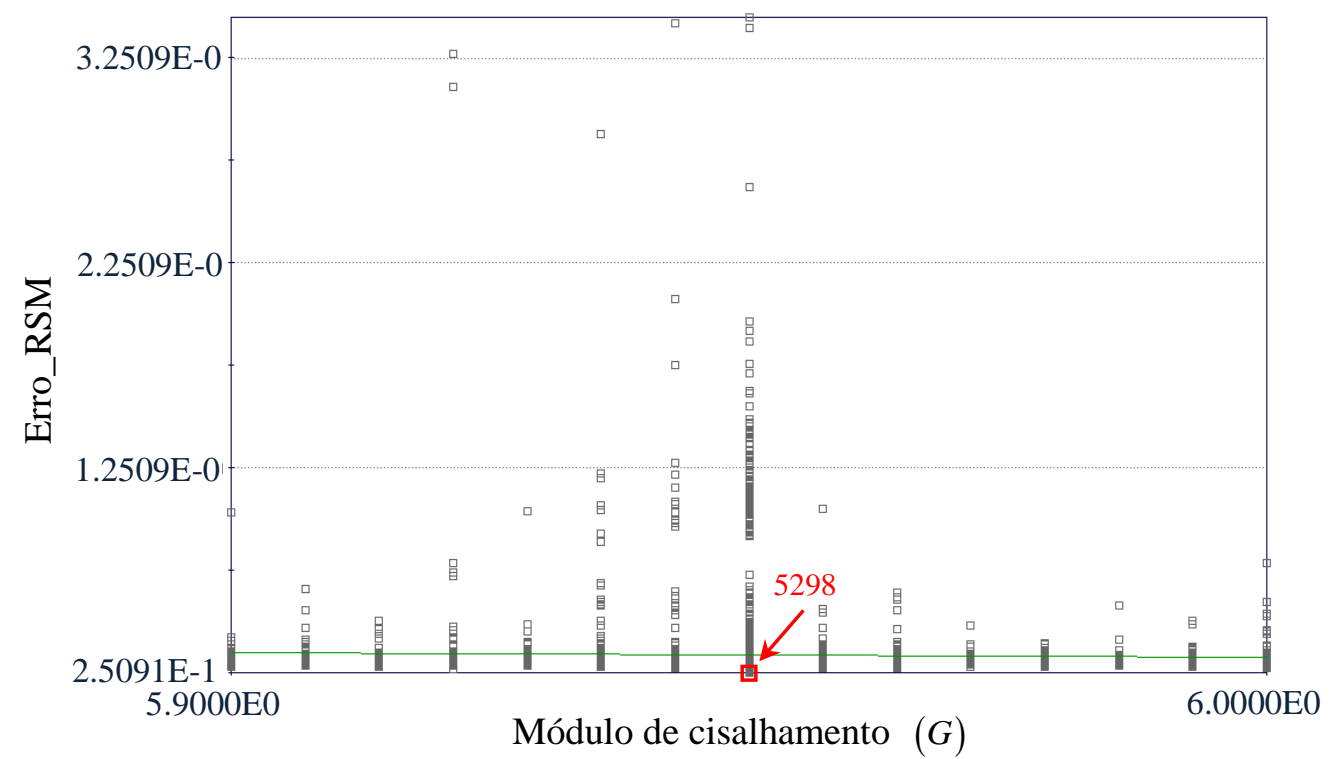

Figura 8.11 - Distribuição do módulo de cisalhamento

A capacidade do solo em suportar cargas depende de sua resistência ao cisalhamento, isto é, da tensão máxima que pode atuar no solo sem que haja a ruptura. O conjunto de gráficos de Coeficiente de avaliação de superfície RSM da Figura 8.12 apresenta o módulo de corte $(G)$ durante o processo de otimização, em relação ao coeficiente de permeabilidade $(k)$. Através do gráfico RSM pode-se identificar o módulo de corte final em 5.9500e0, um valor menor do que apresentado inicialmente por Dominguez (1993).

A Figura 8.12 (A) demonstra o comportamento do coeficiente $(G)$ versus permeabilidade $(k)$, em relação ao erro RSM, a Figura 8.12 (B) representa a parte 2D do sistema com a posição da solução ótima e a Figura 8.12 (C) o comportamento transversal. 

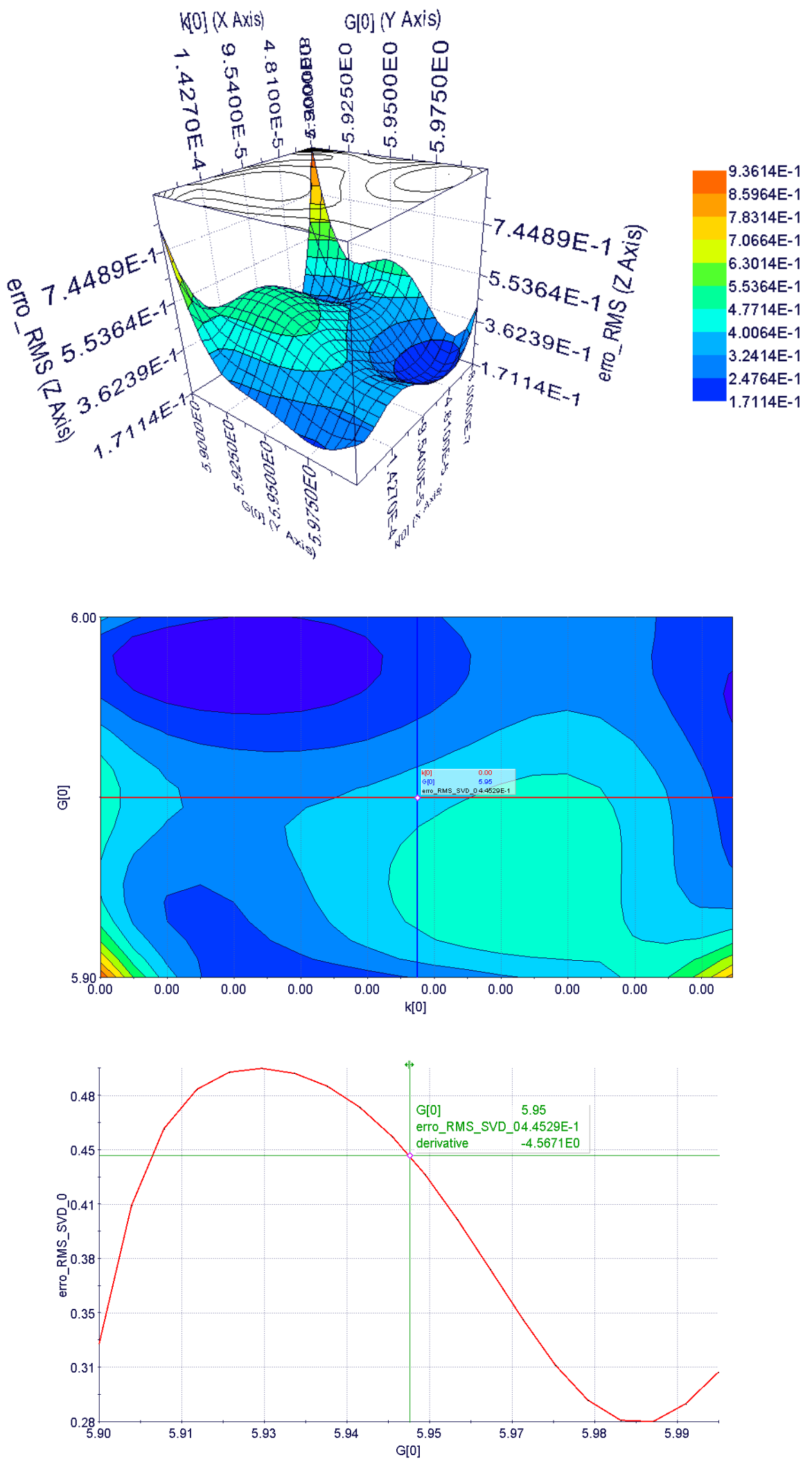

Figura 8.12 - (A) Gráfico RSM 3D (B) Gráfico RSM 2D (C) Comportamento do módulo de corte 
O coeficiente de Skempton analisa as teorias para cálculo de capacidade de carga e mede a relação entre a variação da pressão do poro. É uma grandeza adimensional e seu valor está entre 0 e 1 . Para valores máximos o limite é atingido por materiais que se comportam de maneira incompressíveis, e para o limite inferior, quando o fluido dos poros é altamente compressível. A Figura 8.13 apresenta o comportamento deste coeficiente durante as 10 mil iterações até a busca da solução ótima.

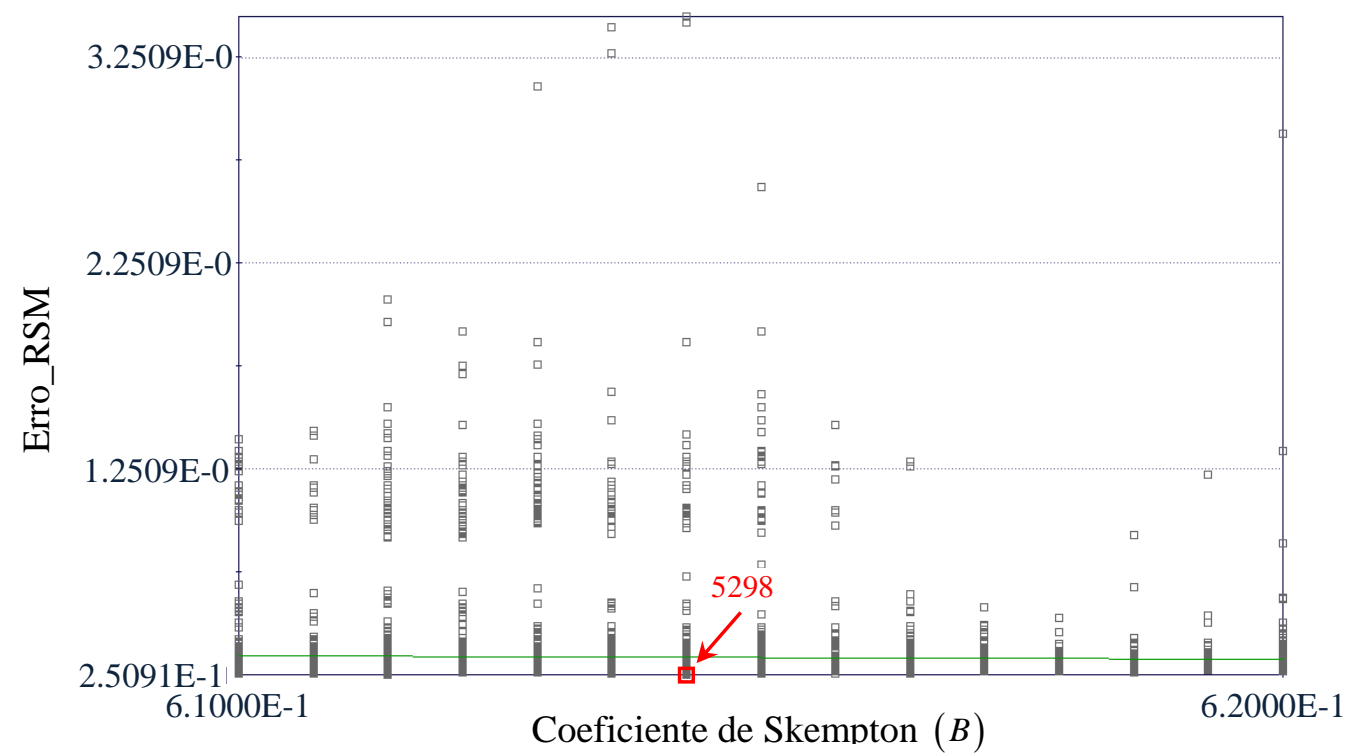

Figura 8.13 - Distribuição do coeficiente de skempton

O coeficiente apresentado por Skempton (1954) propôs a determinação da variação de pressão neutra em uma amostra de solos provenientes de rochas sedimentares, quando variam as tensões principais. Estas estruturas quanto mais complexas menos estáveis são, e uma vez destruídas, não poderão mais ser recompostas.

O coeficiente $(B)$ portanto é predominantemente influenciado pelo grau de saturação. E o conjunto de gráficos do método de avaliação de superfície de resposta (RSM) demonstra o comportamento do coeficiente de Skempton sobre o processo de otimização.

A Figura 8.14 apresenta uma concentração de intervalo de busca do processo entre os valores de 3.2858e-1 e 3.944e-1, e o valor final não sofreu muita alteração ao valor apresentado por Dominguez (1993) ficando em 6.1429e-1. A Figura 8.14 (A) desta figura demonstra o comportamento do coeficiente de Skempton $(B)$ versus 
permeabilidade $(k)$, em relação ao erro da função da raiz quadrada do erro médio (erro RMS), a Figura 8.14 (B) representa a parte 2D do sistema com a posição da solução ótima e a Figura 8.14 (C) o comportamento transversal.
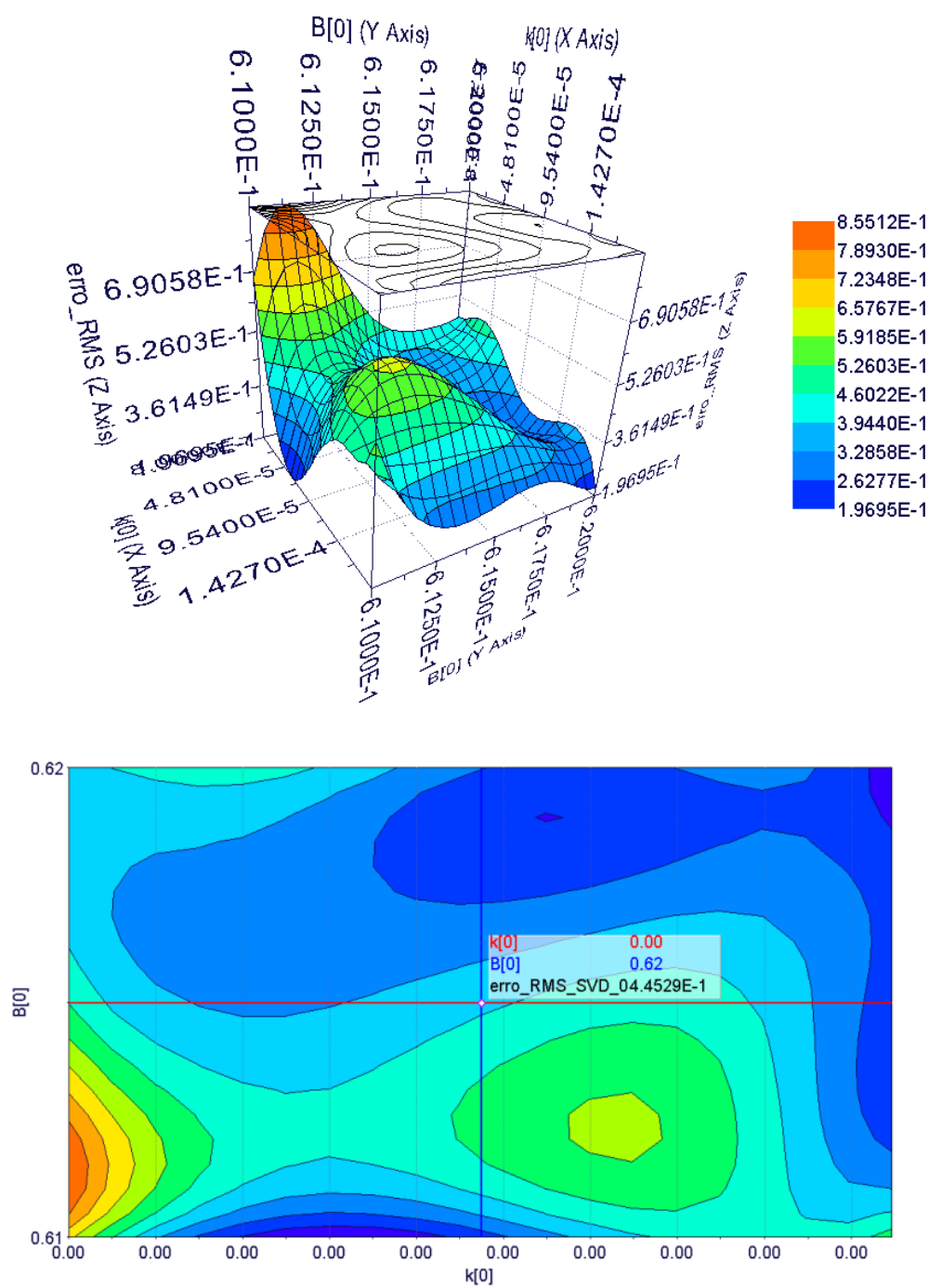

C

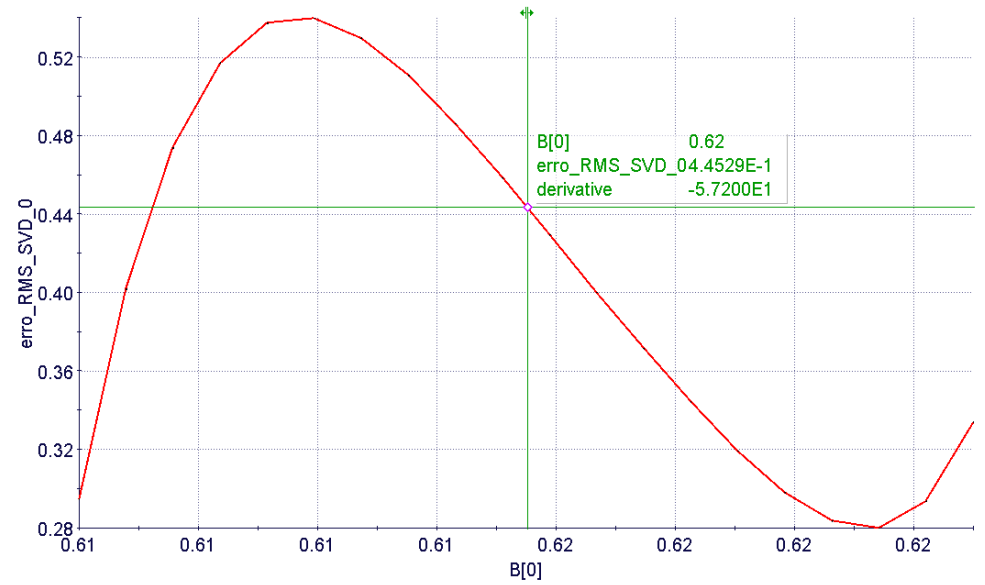

Figura 8.14 - (A) Gráfico RSM 3D (B) Gráfico RSM 2D (C) Comportamento do coeficiente de Skempton 
Nos solos argilosos ou arenosos saturados admite-se uma condição não drenada num carregamento rápido. Se a carga for mantida, deverá ocorrer drenagem e os deslocamentos crescerão com o tempo, ou seja, os deslocamentos aumentam e estes devem ser calculados com parâmetros drenados. A Figura 8.15 demostra o comportamento do coeficiente não drenado durante o processo de otimização, já que os carregamentos foram considerados como dinâmicos, destacando seta com iteração ótima 5298.

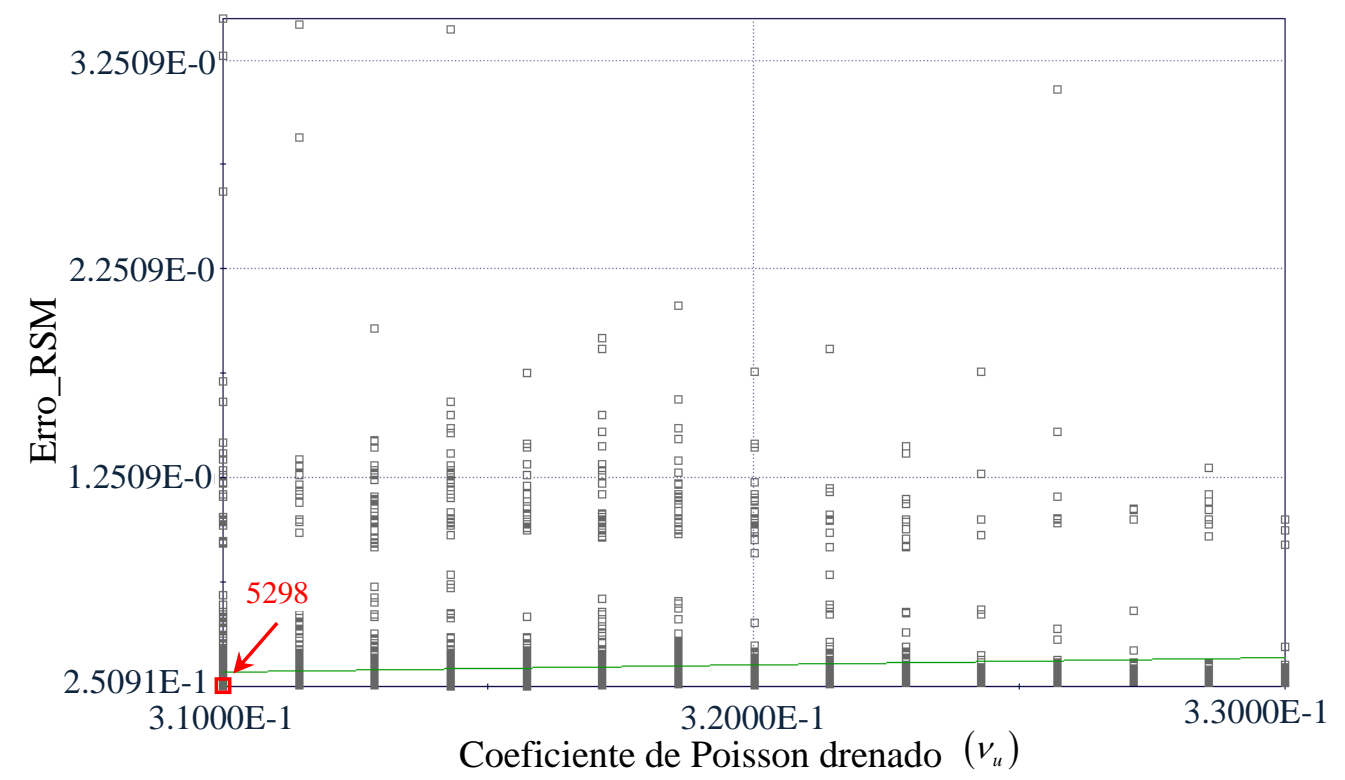

Figura 8.15 - Distribuição do coeficiente de Poisson drenado

O coeficiente de Poisson drenado $\left(v_{u}\right)$ teve uma pequena diferença ao apresentado por Dominguez (1993), e de acordo com o gráfico de resposta de superfície RSM, resultou em 3.1000e-1.

O conjunto de gráficos RSM apresenta o comportamento completo do coeficiente em relação ao sistema. A Figura 8.16 (A) da figura demonstra o comportamento do coeficiente de Poisson drenado $\left(v_{u}\right)$ versus a permeabilidade $(k)$ , em relação ao erro da função da raiz quadrada do erro médio (erro RMS), a Figura 8.16 (B) representa a parte 2D do sistema com a posição da solução ótima e a Figura 8.16 (C) o comportamento transversal. 

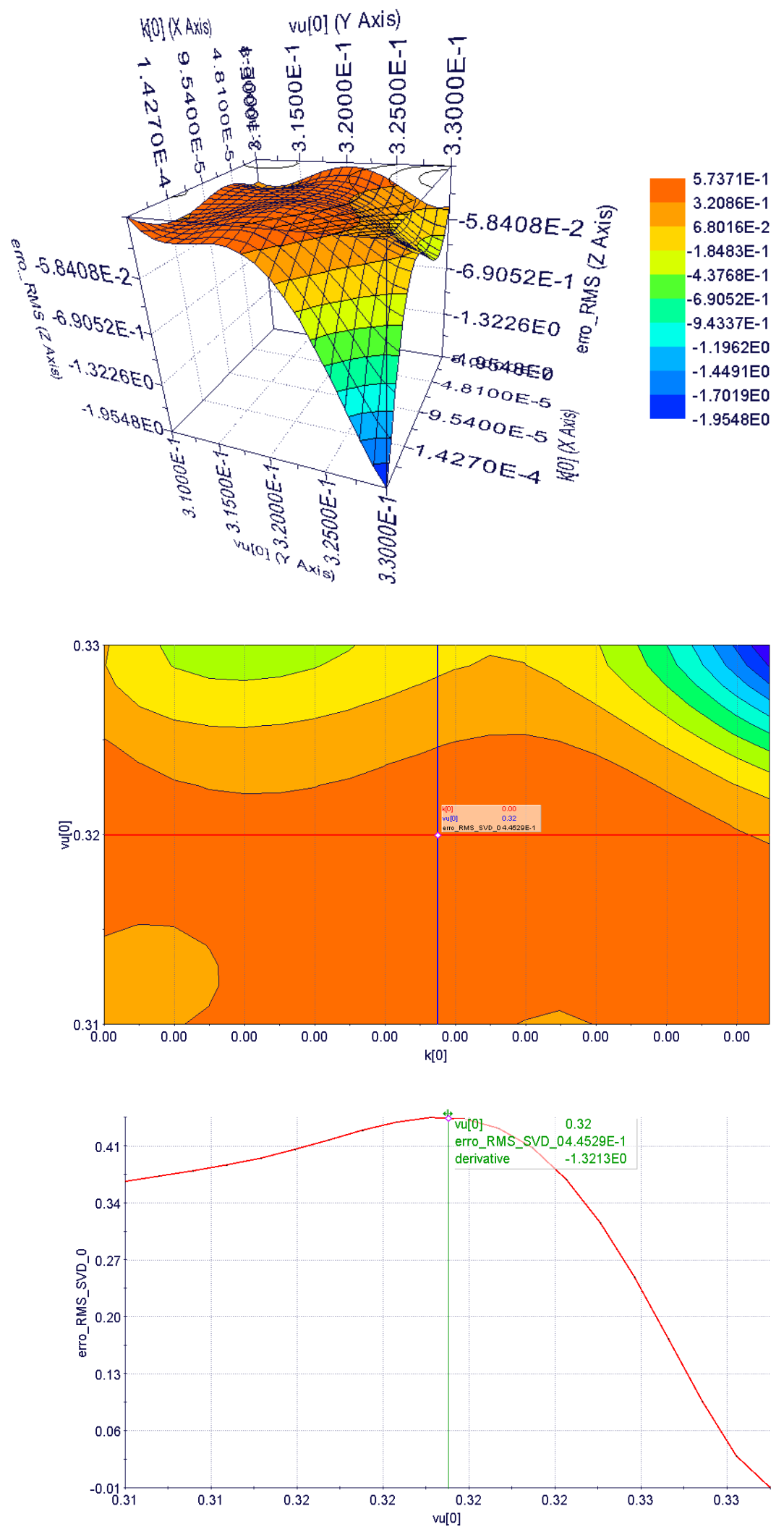

Figura 8.16 - (A) Gráfico RSM 3D (B) Gráfico RSM 2D (C) Comportamento do coeficiente de Poisson drenado 
Após o processo de otimização atingir um dos critérios de parada, o resultado ótimo foi alcançado na iteração 5298, e a Tabela 6 apresenta o intervalo de busca, juntamente com o resultado obtido da otimização.

Tabela 6 - Comparativo entre variáveis

\begin{tabular}{ccccc}
\hline Variaveis & $\begin{array}{c}\text { Intervalo } \\
\text { de busca }\end{array}$ & $\begin{array}{c}\text { Intervalo } \\
\text { de busca }\end{array}$ & Analítico & Otimizado \\
\hline$G$ & $6 \times 10^{9}$ & $6.8 \times 10^{9}$ & $6 \times 10^{9}$ & $5.95 \times 10^{9}$ \\
$v$ & 0.20 & 0.18 & 0.20 & 0.20 \\
$v_{u}$ & 0.33 & 0.28 & 0.33 & 0.31 \\
$B$ & 0.62 & 0.50 & 0.62 & 0.61428 \\
$k$ & $1.9 e^{2}$ & $5.6 \mathrm{e}^{0}$ & $1.9 e^{2}$ & $9.5400 \mathrm{e}^{-1}$ \\
$\phi$ & 0.19 & 0.19 & 0.19 & 0.195 \\
\hline
\end{tabular}

Quando o processo de otimização atingiu o critério de parada o valor do erro RMS obtido para as curvas numéricas foi de erro_ $R M S=0.02509069$. As curvas das soluções ficaram de acordo com a Figura 8.17.

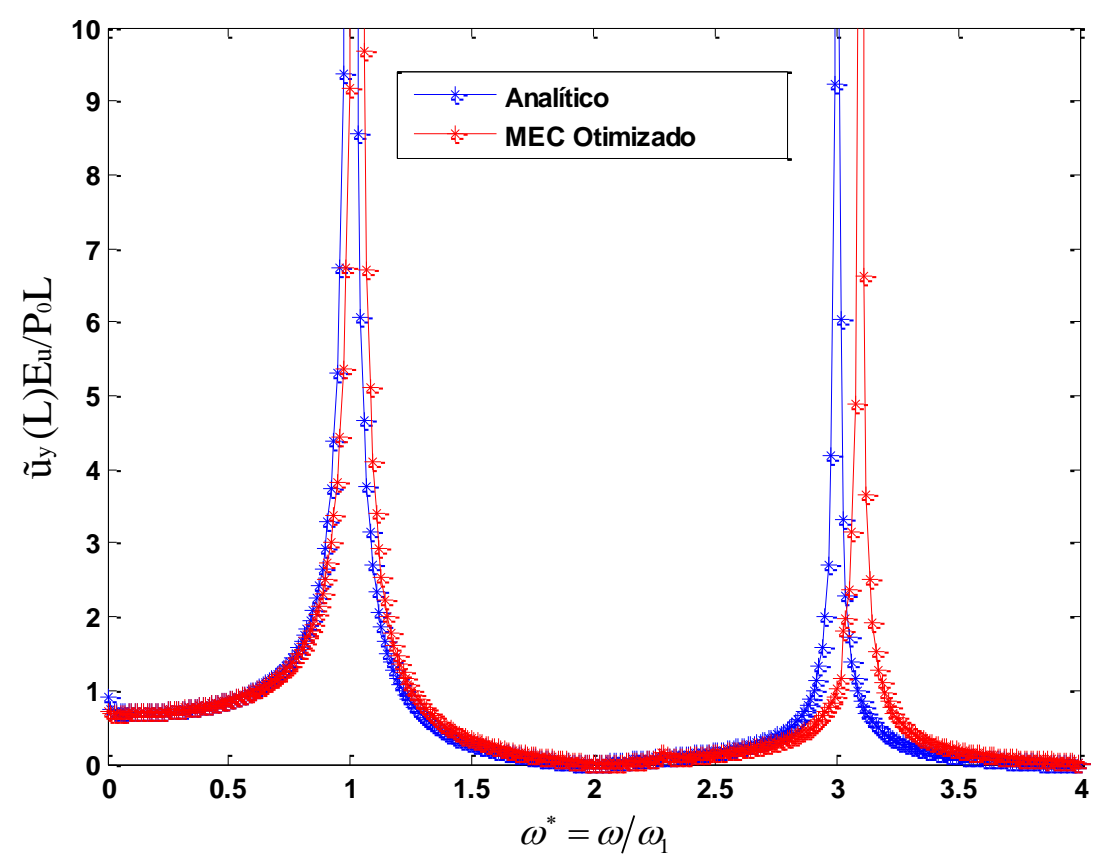

Figura 8.17 - Sobreposição das curvas analítica versus a otimizada

Portando houve uma aproximação nas variáveis de projetos, ou seja, houve uma aproximação entre os valores das propriedades mecânicas do solo, 
caracterizando assim o mesmo tipo de solo para ambas as curvas, em suas respostas nos picos de ressonância. A não sobreposição da segunda curva está relacionada com as funções de Bessel, onde é aplicada para expandir as equações, juntamente com seus argumentos e as ondas. Portanto para a total sobreposição, sugere-se que as funções de Bessel sejam analisadas e ajustadas, até se obter a resposta esperada.

\subsection{Conclusão}

Neste trabalho foi utilizada uma extensão da Teoria de Biot para explicar o contexto da teoria de poroelasticidade dinâmica, considerando o comportamento de ondas sob domínio harmônico em meio saturado. Um fator fundamental para a solução do problema foram os controladores das propriedades mecânicas do solo, no qual eram aplicadas as forças.

A excitação no topo da coluna para um problema poroelástico é compreendida em duas parcelas: a primeira para fluxo, que corresponde com as equações de conservação, lei de Darcy e equação de estado. A segunda parcela é relacionada com a parte mecânica, e são combinadas as equações de equilíbrio em termos de tensão efetiva, poro pressão e relação deslocamento-deformação.

As respostas para estas excitações estão caracterizadas por deslocamentos verticais, uma vez que a curva $x$ amplitude de frequência é conhecida. Aplicando os conceitos de engenharia inversa, foi possível caracterizar as propriedades mecânicas do solo, usando a metodologia do Algoritmo Genético como processo de otimização.

A utilização conjunta destas representações aplicadas ao MEC, e a integração entre a análise da otimização multiobjetivo via Algoritmo Genético NSGA-II, demonstrou ser ideal para a realização do processo, uma vez que permite a avaliação simultânea de todas as variáveis envolvidas.

O procedimento de otimização apresentado foi realizado, reescrevendo para a lingaguem do Fortran 90, onde o cálculo de solução otimizada foi elaborado. Posteriormente foi utilizado o MATLAB para obtenção das curvas das soluções.

Os resultados obtidos para todas as frequências no domínio dinâmico permitiram o desenvolvimento de uma nova curva (solução otimizada), a partir da qual, foi possível calcular a diferença entre a solução analítica, e aproximar então as propriedades mecânicas do solo, já que estas curvas carregam informações relativas as propriedades do solo. 
A análise inversa definiu um conjunto de constantes para avaliações, e o melhor conjunto da solução otimizada apresentou uma curva mais próxima da analítica, ou seja, apresentaram parâmetros de propriedades mecânicas do solo bem próximos.

As avaliações tendo como base as seis variáveis de projeto: $G, B, k, v, v_{u}$ e $\phi$ desempenharam funções diretamente associadas ao controle das propriedades do solo. Todas as variáveis apresentaram proximidades as características que definiam a curva da excitação da coluna.

O processo e análise dos resultados podem ser considerados satisfatórios, pois houve uma redução considerável do erro RMS, e os coeficientes de propriedades mecânicas otimizadas corresponderam como o esperado, para o Arenito de Berea, conforme solução analítica apresentada por Cheng (1991).

O coeficiente de permeabilidade $(k)$ foi uma das variáveis que mais influenciaram no processo, devido estar relacionada com a quantidade de poros e suas interligações, atuando diretamente na percolação do fluído. Este coeficiente é uma das principais características que define o tipo de solo trabalhado (arenito).

É importante ressaltar que, para problemas multiobjetivos, não há uma garantia de unicidade da solução por ser tratarem de problemas convexos. Neste sentido, com o uso de algoritmos heurísticos para uma segunda análise de otimização pode-se encontrar um valor melhor ou pior para a função objetivo.

Os ajustes dos operadores genéticos aumentam as possibilidades de encontrarem as soluções, porém elevando o custo computacional. Para uma aproximação dos valores referentes as propriedades mecânicas das soluções, sugere-se que aumente o número total de iterações e que as soluções de Bessel sejam analisadas.

A metodologia numérica desenvolvida neste trabalho aliada aos conceitos de engenharia inversa apresentou um comportamento robusto o suficiente para a partir dos deslocamentos sofridos por influência das frequências identificar as propriedades mecânicas do solo dentro de um intervalo de busca definido. Desta forma, torna-se possível a determinação das características do solo, estabelecendo quais características ou qual tipo de solo é trabalhado.

A metodologia aplicada nesta dissertação apresentou-se de maneira satisfatória, pois se determinou as propriedades mecânicas do solo, descartando a 
possibilidade de um estudo experimental, ou seja, através do desenvolvimento computacional fez-se o mesmo que experimental.

Em trabalhos futuros que utilizem a mesma linha de pesquisa, sugere-se:

- Expansão do presente estudos a problemas a 3D;

- Aplicação do processo de otimização para cálculos de pressão nos poros;

- Aplicação do processo de otimização para cálculos de tração nos poros;

- O domínio poroelástico apresenta comportamento semelhante ao termoelástico, podendo ser feitas análises para ambas as partes.

- Consideração do processo de otimização para meios porosos anisotrópicos. 


\section{REFERÊNCIAS BIBLIOGRÁFICAS}

ALBA, M. h. m. (2016). "Otimização paramétrica de chassi veicular tipo escada". Monografia, Universidade de Brasília. Faculdade do Gama - UnB, Brasília.

ALBRECHT, C. H. (2005). "Algoritmos Evolutivos Aplicados à Síntese e Otimização de Sistemas de Ancoragem". Tese de Doutorado, Universidade Federal do Rio de Janeiro/ COPPE, Rio de Janeiro.

ARAMAKI, G. e YASUHARA, W. (1981). "Applications of the boundary element method for axysimmetric Biot's consolidation”.Engineering Analysis, vol.2, pp. 184191.

ARENALES, M. N.; ARMENTANO, V. A.; MORABITO, R.; YANASSE, H. H. (2007). "Pesquisa operacional". Rio de Janeiro: Elsevier Editora Ltda.

ARROYO, J. E. C. (2002). "Heurísticas e metaheurísticas para otimização combinatória multiobjectivo".Tese de doutorado, Unicamp.

BANERJEE, P. K., BUTTERFIELD, R. (1981). "Boundary Element Methods in Engineering". London, McGraw Hill.

BARBOSA, H. J. C. (1998). "Algoritmos Genéticos para Otimização em Engenharia: Uma Introdução". IV Seminário sobre ElementosFinitos e Métodos Numéricos em Engenharia, Juiz de Fora - MG.

BAZARAA, M. S., SHETTY, C. M. (1979). "Nonlinear Programming - Theory and Algorithms". New York, John Wiley \& Sons.

BERRYMAN, J. G. e WANG, H. F. (1995). "The elastic coe \pm cients of double-porosity models for fluid transport in jointed rock”. J. Geo. Res., 100:24611-24627.

BIOT, M. A. (1935). "Le Problem de la Consolidation dês Matieres Argileuses sous une Charge". Annaies de la Societé Scientifique de Bruxelles, Series B, vol. 55, pp 110-113.

BIOT, M. A. (1941). "General theory ot three-dimensional consolidation". Jounal of Appied Physycs.Nr 12. pp. 155-164.

BIOT, M. A. (1955). "Theory of Elasticity and Consolidation for a Porous Anisotropic Media". Journal of Applied Physics, vol. 26 , pp 182 - 185.

BIOT, M. A. (1956). "Theory of Deformation of a Porous Viscoelastic Anisotropic Solid", Journal of Applied Physics, vol. 27 , pp 459 - 467.

BIOT, M. A. (1956a). "Theory of propagation of elastic waves in a fluid-satured porous solid. I. Low- frequency range". Journal of Applied Physycs. Nr 28. pp. 168178. 
BIOT, M. A. (1956b). "Theory of propagation of elastic waves in a fluid-satured porous solid. I. High- frequency range". Journal of Applied Physycs. Nr 28. pp. 179191.

BIOT, M. A. and Willis, D. G. (1956). "The elastic coefficients of the theory of consolidation". J. Appl. Mech., 24,594-601.

BISHOP, A. W. (1973). "The influence of an undrained change in stress on the pore pressure in porous media of low compressibility", Géotechnique, 23, 435-442.

BISHOP, A. W. and Henkel, D. J. (1962). "The Measurement of Soil Properties in the Triaxial Test”. 2nd ed., EdwardArnold, London, 1962.

BONNET, G.\& AURIAULT, J. L. (1985). "Dynamics of Saturated and Deformable Porous Media". In Physics of finely divided matter (pp. 306-316). Springer Berlin Heidelberg.

BOX, G. E. P., HUNTER, W. G., HUTER, J. S. (1978). "Statistics for experimenters". USA: John Wiley\& Sons.

BREBBIA, C.A.(1978). "The Boundary Element Method for engineers. London: Pentech Press". 188p.

CAPUTO, H. P. (1981). "Mecânica dos solos e suas aplicações". In Mecânica dos solos e suas aplicações. LTC.

CASTRO, R. E. (2001). "Otimização de Estruturas com Multi-objetivos Via Algoritmos Genéticos". Tese (Doutorado em Engenharia Civil) - COPPE/UFRJ. Universidade Federal do Rio de Janeiro, Rio de Janeiro.

CAVALCANTI, M. C. R. (2002). "Análise por Elementos de Contorno de Meios PoroElásticos Saturados pela Teoria de Biot". Tese (Doutorado em Engenharia Civil) - COPPE/UFRJ. Universidade Federal do Rio de Janeiro, Rio de Janeiro.

CAVALCANTI, M. C. \& TELLES, J. C. F. (2003). "Biot's consolidation theoryapplication of BEM with time independent fundamental solutions for poroelastic saturated media". Engineering Analysis with Boundary Elements, 27(2), 145-157.

CHENG, A. H. D., BADMUS, T., \& BESKOS, D. E. (1991). "Integral equation for dynamic poroelasticity in frequency domain with BEM solution". Journal of Engineering Mechanics, 117(5), 1136-1157.

CHENG, A. H. DETOURNAY, E. (1988). "A direct boundary element method for plane strain poroelasticity." International journal for Numerical and Analytical Methods in Geomechanics, v.12, p.551-72.

CHENG,A.H, DETOURNAY, E. (1998). "On singular integral equation and fundamental solutions of poroelasticity". International Journal of Solids and Structures, $n \cong 34 / 35$, pp 4521-4555. 
CHENG A. H. D.\& LIGGET, J. A. (1984). "Boundary Integral Equation Method for Linear Porous-Elasticity with Applications to soil Consolidation". International Journal of Numerical Methods in Engineering, vol. 20, pp. 255-278.

CHENG, A. H. D. \& PREDELEANU, M. (1987). "Transient boundary element formulation for linear poroelasticity". International Journal of AppliedMathematical Modeling, vol. 11, pp. 285-390.

CHIOU, Y. J. \& CHI, S. Y. (1994). "Boundary Element Analysis of Biot Consolidation in Layered Elastic Soils". International Journal for Numericaland Analytical Methods in Geomechanics, no 18, pp. 377-396.

CLEARY, M. P. (1977). "Fundamental Solutions for a Fluid-Saturated Porous Solid". International Journal of Solid Structures, vol.13, pp. 785-806.

CORNE, D.; KNOWLES, J.; OATES, M. (2000). "The pareto envelope-based selection algorithm for multiobjective optimization. In: DEB, K.; G. RUDOLPH, X. Y.; LUTTON, E.; MERELO, J. J.; SCHWEFEL, H. P., eds. Proceedings of the Parallel Problem Solving from Nature VI Conference,, Springer". Lecture Notes in Computer Science No. 1917, p. 839-848

COUSSY, O. (2004). "Poromechanics". Wiley, Chichester, 2004.

CRYER, C. W. (1963). "A Comparison of the Three-dimensional Consolidation Theories of Biot and Terzaghi". Quarterly Journal of Applied Mathematics, vol. XVI, Pt. 4, pp. 401-411.

DA CUNHA, R. D, (2005). "Introdução à Linguagem de Programação Fortran 90", Editora da UFRGS, Porto Alegre. ISBN 85-7025-829-1.

DARGUSH, G. F., BANERJEE, P. K. (1991). "A boundary element method foraxysimmetric soil consolidation", International Journal for Solid Structures, no 28, pp. 897-915.

DAVIS, L. (1991). "Handbook of genetic algorithms".

DEB, K. (2001). "Multi-objective optimization using evolutionary algorithms". WileyInterscienceSeries in Systems and Optimization. New York, NY: John Wiley \& Sons.

DEB, K.; AGRAWAL, S.; PRATAB, A.; MEYARIVAN, T. (2000). "A Fast Elitist NonDominated Sorting Genetic Algorithm for Multi-Objective Optimization: NSGAII". KanGAL report200001, Indian Institute of Technology, Kanpur, India.

DEB, K.\& SAHA, A. (2010). "Finding multiple solutions for multimodal optimization problems using a multi-objective evolutionary approach". In: Annual Conference onGenetic And Evolutionary Computation. New York. Proceedings. p. 447-454. 
DE JONG, J. (1957). "Application of Stress Functions to Consolidation Problems",FourthInternational Conference on Soil Mechanics and FoundationEngineering, vol. 1, pp-320-323.

DE JONG, K. A. (1975). "An Analysis of the Behavior of a class of Genetic Adaptive System". Ph.D. dissertation, University of Michigan, ANNArbor, MI.

DETOURNAY, E. \& CHENG, A.H.-D. (1993). "Fundamentals of poroelasticity," Chapter 5 in Comprehensive Rock Engineering: Principles, Practice and Projects, Vol. II, Analysis andDesign Method, ed. C. Fairhurst, Pergamon Press, pp. 113-171.

DOMINGUEZ, J. (1991). "An integral formulation for dynamic poroelasticity". Journal of Applied Mechanics, 58(2), 588-591.

DOMINGUEZ, J. (1992). "Boundary element approach for dynamic poroelastic problems". International Journal for Numerical Methods in Engineering, 35(2), 307-324.

DOMINGUEZ, J. (1993). "Boundary elements in dynamics". Wit Press.

EIBEN, A. E.; SMITH, J. E. (2003)."Introduction to evolutionary computing. Natural Computing Series". Berlin: Springer.

FATT, I. (1958). "The Biot-Willis elastic coefficients for a sandstone", J. Appl. Mech., ASME, 26, 296-297.

FERRO, M. A. C. (2002)."Poroelasticidade Dinâmica Acoplada usando o Método dos Elementos de Contorno". Tese (Doutorado em Engenharia Civil) COPPE/UFRJ. Universidade Federal do Rio de Janeiro, Rio de Janeiro.

FONSECA, C.; FLEMING, P. (1993). "Genetic Algorithms for Multiobjective Optimization: Formulation, Discussion and Generalization. In: FORREST, S., ed. Proceedings of the Fifth International Conference on Genetic Algorithms". University of Illinois at Urbana-Champaign, SanMateo, California: Morgan Kauffman Publishers, p. 416-423.

FOGEL, D. B. (1994). "An introduction to simulated evolution. IEEE Transaction on Neural Networks".v. 5, n. 1, p. 3-14.

FOGEL, L. J., OWENS, A. J., \& Walsh, M. J. (1966). "Intelligent decision making through a simulation of evolution". Behavioral science, 11(4), 253-272.

GASSMANN, F. (1951). "Elasticity of porous media". Vierteljahrsschrder Naturforschenden Gesselschaft, 96, 1-23.

GEERTSMA, J.(1966)."Problems of rock mechanics in petroleum production engineering." In Proc.1st Cong. Int. Soc. Rock Mech. Vol. 1. pp. 585-594. 
GEERTSMA, J. (1957). "A Remark on the Analogy Between Thermoelasticity and the Elasticity of Saturated Porous Media". Journal of the Mechanics and Physics of Solids, Vol 6, pp.13-16.

GOLDBERG, D. E. (1989). "Genetic algorithms in search, optimization, and machine learning”. NewYork: Addison-Wesley.

GREFENSTETTE, J. J. (1986). "Optimization of Control Parameters for Genetic Algorithms”. IEE Trans, Syst. Man. Cyber, pp. 122-128.

HAFTKA, R. T., KAMAT, M. P. (1985). "Elements of Structural Optimization".Dordrecht, Martinus Nijhoff Publishers.

HOLLAND, J. H. (1975). "Adaptation in Natural and Artificial Systems. University of Michigan Press". Ann Arbor.

HORN, J.; NAFPLIOTIS, N.; GOLDBERG, D. (1994). "A Niched Pareto Genetic Algorithm for Multiobjective Optimization. In: Proceedings of the First IEEE Conference on Evolutionary Computation, IEEE World Congress on Computational Intelligence". Piscataway, New Jersey: IEEE Service Center, p. 82-87.

KIRSCH, U. (1981). “Optimum Structural Design”. McGraw-Hill, 1981.

KOZA,J. R. (1992). "Genetic Programming: On the programing of computers by means of natural selection". MIT Pres.

KOZA, J. R. (1994). "Genetic Programming II: Automatic discovery of reusable programs". MIT Press.

KUROKI, T., ITO, T. \& ONISHI, K. (1982). "Boundary Element Method in Biot's Linear Consolidation", International Journal of Applied MathematicalModeling, vol. 6, pp 105.

LEMONGE, A. C. C. (1999). "Aplicação de Algoritmos Genéticos em Otimização Estrutural". Tese de D.Sc., Programa de Engenharia Civil,COPPE/UFRJ, Rio de Janeiro.

LUENBERGER, D. G. (1984). "Introduction to Nonlinear Programming". AddisonWesley Publishing Company, London.

MAHFOUD, S. W. (1995). "Niching methods for genetic algorithms". Urbana, 51 (95001), 62-94.

MANDEL, J. (1953). "Consolidation de Soils (Étude Mathématique)". Geotechnique, vol.3, $\mathrm{n} \cong 7$, pp. 287-299.

MICHELL, M. (1998). "An Introduction to Genetic Algorithms (Complex Adaptive Systems)". 
NEVES, F. A. (1997). "Programação com Multi-Objetivos Aplicada à Otimização do Projeto de Pontes Estaiadas". Tese de D.Sc., Programa de Engenharia Civil, COPPE/UFRJ, Rio de Janeiro, RJ, Brasil.

NISHIMURA, N. \& KOBAYASHI, S. (1989). "A Boundary Integral Equation Method for Consolidation Problems", International Journal of Solid Structures, vol 25, $\mathrm{n} \stackrel{\circ}{ }$ 1, pp. 1-21.

OLIVEIRA, T. S. L. DE. (2015). "Otimização evolucionária para problemas de transferência de calor em PCl usando MEC". Tese de D.Sc., Programa de Pós-graduação em Integridade de Materiais de Engenharia, Faculdade Gama, Universidade de Brasília, Brasília.

PARK, K. H., \& BANERJEE, P. K. (2006). "A simple BEM formulation for poroelasticity via particular integrals". International journal of solids and structures, 43(11), 3613-3625.

PINTO, C. (2006). "Curso Básico de Mecânica dos Solos em 16 aulas". $3^{a}$ edição, São Paulo. Oficina de textos.

PLONA, T. J. (1980). "Observation of a second bulk compresional wave in a porous medium at ultrasonic frequencies”. Appl. Phys. Lett., 36:259-261.

PREDELEANU, M. (1981)."Boundary Integral Method for Porous Media". ThirdInternational Conference on Boundary Element Methods, pp. 325-334.

PRESS, W. H., TEUKOLSKY, S. A., VETTERLING, W. T., FLANNERY,B. P. (1992). "Numerical Recipes in Fortran". University of Cambridge.

POLUBARINOVA-KOCHINA, P. YA. (1962). "Theory of Ground Water Movement". Translated from Russian by J.M. Roger de Wiest. Princeton, New Jersey: Princeton University Press.

RECHENBERG, E. (1973). “Optimierung technischer Systeme nach Prinzipien der biologischen Evolution”. Frommann-Holzboog Verlag, Stuttgart.

RECHENBERG, I. (1994). "Evolution strategy". Computational intelligence: Imitating life, 1.

RENDULIC, L. (1936). "Porenziffer und Porenwasserdruck in Tonen",Der Bauingenieur, Vol.17, $\mathrm{N} \cong 51 / 53$, pp 559-564.

RICE, J. R., CLEARY, M. P. (1976). "Some basic stress diffusion solutions for fluidsaturated elastic porous media with compressible constituents." Reviews of Geophysics and Space Physics, v.14, n.2, p.227-41.

RUDNICKI, J. W. (1986). "Fluid mass sources and point forces in linear elasticdiffusive solids", Mechanical Materials, vol. 5, pp. 383-393. 
SCHAFFER, J. (1985). "Multiple objective optimization with vector evaluated genetic algorithms. In: Genetic Algorithms and their Applications: Proceedings of the First International Conference on Genetic Algorithms", Lawrence Erlbaum, p. 93-100.

SCHIFFMAN, R. L., CHEN, A. T. F., JORDAN, J. C. (1969)."An analysis of Consolidation Theories", Journal of the Soil Mechanics and FoundationDivision, ASCE, vol. SM-1, pp. 285-312.

SELVADURAI, A.. P. S.(1996). Mechanics of poroelastic media. In ANTES, H., \& WIEBE, T. "Analyses of waves in 3-d poroelastic media". (pp. 371-387). Springer Netherlands.

SILVA, E. E. (2001). "Otimização de estruturas de concredo armado utilizando algoritmos genéticos". Dissertação de mestrado - Escola Politécnica da Universidade de São Paulo. Departamento de Engenharia de Estruturas e Fundações. São Paulo.

SRINIVAS, N., \& DEB, K. (1994). "Muiltiobjective optimization using nondominated sorting in genetic algorithms". Evolutionary computation, 2(3), 221-248.

SKEMPTON, A. W. (1954). "The pore pressure coefficients A and B". Géotechnique, $4,143-147$.

SKEMPTON,A. W. (1960). "Effective stress in soils, concrete and rocks, Pore Pressure and Suction in Soils".4-16, Butterworth, London.

SOMMER, R. C. (2010). "Otimização de estruturas por Algoritmos Genéticos submetidas a restrições de flexibilidade e flambagem". Dissertação de mestrado - Programa de Pós Graduação em Engenharia Mecânica da Universidade Federal do Rio Grande do Sul - UFRGS. Porto Alegre.

SUGUIO, K. (1980). "Rochas sedimentares: propriedades, gênese, importância econômica". São Paulo: Edgard Blücher. Ed da Universidade de São Paulo. (No. 552.5 SUG).

TAKAHAMA, T., \& SAKAI, S. (2004). "Constrained optimization by a constrained genetic algorithm (aGA)". Systems and Computers in Japan, 35(5), 11-22.

TANOMARU, J. (1995). "Motivation, fundamentals and applications of Genetic Algorithms". II Congresso Brasilero de Redes Neurais. University of Tokushima, Japan.

TERZAGHI, K. (1923). "Die Berechnung der Durchlässigkeitsziffer des Tones aus dem Verlauf der hydrodynamische Spannungserscheinungen".Sitzber. Akad. Wiss. Wien, Abt. Ila, 132, 125-138.

TERZAGHI, K. (1925). "Erdbaumechanik auf bodenphysykalischer Grundlage”.Deuticke, Leipzig. 
TERZAGHI, K. (1936). "The shearing resistance of satured soils and the angle between the planes of shear". Procedings of International Conference on Soil Mechanics and Foundation Engineering, pp. 54-56.

TICONA, W. G. C. (2003). "Algoritmos evolutivos multi-objetivo para a reconstrução de árvores filogenéticas". Tese de doutorado, ICMC, USP, São Carlos, S.P.

VERRUIJT, A. (2016). "Theory and problems of poroelasticity". Delft University of Technology, pp. 275.

WILSON, R. K. e AFANTIS, E. C. (1982). "On the theory of consolidation with double porosity". Int. J. Engng. Sci., 20:1009-1035.

WILSON, R. K. e AFANTIS, E. C. (1984). "A double porosity model for acoustic wave propagation in fractured-porous rock". Int. J. Engng Sci., 22:1209-1217.

YEW, C.H., JOGI, P.N. e GRAY, K.E. (1979). "Estimation of the mechanical properties of fluidsaturated rocks using the measured wave motions". J. Energy Res. Tech., 101, 112-116.

ZAMBRANO, F. H. C. (2009). "Os Mecanismos de Propagação e Atenuação de Ondas Sísmicas em Rochas Reservatórios Baseados na Poroelasticidade Dinâmica". Tese (Doutorado em Ciências Geofísicas) - UFBA. Universidade Federal da Bahia, Salvador.

ZITZLER, E.; DEB, K.; THIELE, L. (2000). "Comparison of Multiobjective Evolutionary Algorithms: Empirical Results". Evolutionary Computation, v. 8, n. 2, p. 173195.

ZITZLER, E.; THIELE, L. (1998). "An Evolutionary Algorithm for Multiobjective Optimization: The Strength Pareto Approach". Relatório Técnico 43, Computer Engineering and CommunicationNetworks Lab (TIK), Swiss Federal Institute of Technology (ETH), Zurich, Switzerland. 